NBER WORKING PAPER SERIES

\title{
LABOR MARKET IMPLICATIONS OF EDUCATION MISMATCH
}

\author{
Carla Varona Cervantes \\ Russell Cooper \\ Working Paper 28169 \\ http://www.nber.org/papers/w28169 \\ NATIONAL BUREAU OF ECONOMIC RESEARCH \\ 1050 Massachusetts Avenue \\ Cambridge, MA 02138 \\ December 2020, Revised May 2021
}

Comments and suggestions from Juan Dolado, Christian Dustmann, Pedro Gomes, Philipp Kircher, Huacong Liu, Alex Monge-Naranjo, Masao Ogaki and Marco Paccagnella are gratefully appreciated. The views expressed herein are those of the authors and do not necessarily reflect the views of the National Bureau of Economic Research.

NBER working papers are circulated for discussion and comment purposes. They have not been peer-reviewed or been subject to the review by the NBER Board of Directors that accompanies official NBER publications.

(C) 2020 by Carla Varona Cervantes and Russell Cooper. All rights reserved. Short sections of text, not to exceed two paragraphs, may be quoted without explicit permission provided that full credit, including (C) notice, is given to the source. 
Labor Market Implications of Education MisMatch

Carla Varona Cervantes and Russell Cooper

NBER Working Paper No. 28169

December 2020, Revised May 2021

JEL No. D15,I23,I26

\section{ABSTRACT}

This project studies the impact of education mismatch on labor outcomes. Across our sample of OECD countries, there is evidence of mismatch in educational attainment and labor markets. Labor market outcomes are not independent of education mismatch. Our framework for analysis is a dynamic choice model, focusing on education and training decisions. From the estimation of model parameters, the main factor explaining education mismatch is dispersion across individuals in the perceived value of education. From simulations of lifecycle dynamics and counterfactual experiments, among four key countries, education undermatch in Japan is sustained through labor market mechanisms while in Germany, Italy and the US, education undermatch is largely resolved in that these individuals are eventually employed in skilled jobs. Training plays a key role in these dynamics.

Carla Varona Cervantes

carla.varona@eui.eu

Russell Cooper

Department of Economics

European University Institute

Villa La Fonte

Via delle Fontanelle 18

I-50014 San Domenico di Fiesole (FI)

ITALY

russellcoop@gmail.com 


\title{
Labor Market Implications of Education MisMatch*
}

\author{
Carla Varona Cervantes ${ }^{\dagger}$ and Russell Cooper ${ }^{\ddagger}$
}

May 7, 2021

\begin{abstract}
This project studies the impact of education mismatch on labor outcomes. Across our sample of OECD countries, there is evidence of mismatch in educational attainment and labor markets. Labor market outcomes are not independent of education mismatch. Our framework for analysis is a dynamic choice model, focusing on education and training decisions. From the estimation of model parameters, the main factor explaining education mismatch is dispersion across individuals in the perceived value of education. From simulations of lifecycle dynamics and counterfactual experiments, among four key countries, education undermatch in Japan is sustained through labor market mechanisms while in Germany, Italy and the US, education undermatch is largely resolved in that these individuals are eventually employed in skilled jobs. Training plays a key role in these dynamics.
\end{abstract}

\section{Motivation}

Productive efficiency requires the matching of high ability individuals to appropriate education levels and eventually to jobs commensurate with their ability and training. Inefficiencies can arise in the form of education mismatch, job mismatch or both. The output loss from mismatch can be substantial. Mitigating mismatch has been a policy goal for individual countries and international organizations, such as the OECD and the International Labor Organization. ${ }^{1}$ Absent an understanding of the sources of mismatch and their interaction, designing policy remedies is quite difficult.

Mismatch refers to the lack of assortative matching between outcomes and ability. Applied to educational attainment, it occurs when high ability agents are not always the most educated while some low ability agents have high educational attainment. Imperfect capital markets, different tastes for education and information frictions about education opportunities and individuals' ability are possible sources of (measured) education mismatch. Job (labor market) mismatch arise from frictions in labor market reallocation like imperfect information, discrimination, training decisions and labor market regulations.

Earlier work, such as Pellizzari and Fichen (2013), McGowan and Andrews (2015), Dillon and Smith (2017) and Cooper and Liu (2019), study these forms of mismatch in isolation. However, it seems that education and labor mismatch might not be independent. To the extent that labor market allocations depend on the information conveyed about ability from education, factors that create education mismatch

\footnotetext{
*Comments and suggestions from Juan Dolado, Christian Dustmann, Pedro Gomes, Philipp Kircher, Huacong Liu, Alex Monge-Naranjo, Masao Ogaki and Marco Paccagnella are gratefully appreciated.

${ }^{\dagger}$ Department of Economics, the European University Institute, Carla.Varona@eui.eu

${ }^{\ddagger}$ Department of Economics, the European University Institute and NBER, russellcoop@gmail.com

${ }^{1}$ MisMatch was part of a hot issues discussion by the OECD in March 2016 and there is a dashboard dedicated to ongoing research and topics on skills development: http://www.oecd.org/skills/. For the International Labor Organization see https: //www.ilo.org/skills/Whatsnew/WCMS_740388/lang--en/index.htm.
} 
can generate labor market misallocation. ${ }^{2}$ Further, if borrowing constraints bind so that some high ability agents do not complete college, then their labor market outcomes can be impacted as well. In some cases, labor allocations may even appear efficient in that high productivity individuals, including the effects of college, are working in skills jobs and lower productivity individuals are not. Yet this masks mismatch in education in that some high ability individuals do not go to college and thus remain under placed in the labor market.

The contribution of this paper is to study the joint determination of education and labor market mismatch. In particular, what is the path, in terms of labor market outcomes, of high ability individuals who miss education opportunities? Are there mechanisms in the labor market, either through job assignment or training, to offset the lack of formal education for the undermatched?

Our main goal is to evaluate the extent that labor markets offset or perpetuate education mismatch. What are the labor market outcomes of those undermatched in education? Focusing on four leading OECD countries, we find that indeed labor market institutions do overcome this mismatch in Germany, Italy and the US. The mechanism for these labor market transitions, highlighted by the paper, is non-formal training. This is not the case in Japan, where education undermatch is perpetuated through job assignments and the lack of training for unskilled workers.

The first part of the paper, Section 2, provides evidence of both forms of mismatch using data from the OECD Program of International Assessment of Adult Competences (hereafter PIAAC). Individuals' jobs are divided into two categories: (i) skilled and (ii) unskilled occupations. For educational attainment, we define a dichotomous variable indicating two levels: (i) below college and (ii) college and above. PIAAC test scores are used as noisy measures of ability. Further, we divide the sample into two working phases: (i) early employment from 25-34 years old and (ii) late employment from 35-54 years old.

The distributions of PIAAC scores conditional on educational attainment overlap: there are individuals with a low level of education but a higher PIAAC score than those with high education. A similar pattern is observed for the distributions conditional on types of occupation: there are individuals in an unskilled occupation but with a higher PIAAC score than those with a skilled one. These overlapping distributions are the basis for the empirical measures of mismatch, both in educational attainment and in the labor market.

Our initial empirical analysis brings together evidence on the labor market implications of education outcomes. A first exercise adds empirical measures of education mismatch to standard Mincer wage regressions, building on Hanushek, Schwerdt, Wiederhold, and Woessmann (2015). At the individual country level, the mismatch measures are not statistically significant so that labor market corrections for education mismatch, through wage adjustments, do not seem to arise. This lack of correction in compensation implies that the effects of education mismatch are perpetuated through this dimension of labor market outcomes. The magnitude of these effects are studied more thoroughly through our dynamic simulations dependent on education mismatch.

A second exercise looks at job flows, drawing upon the PIAAC data, to analyze the effect of education mismatch on job assignment in early employment. In our pooled sample, around $39 \%$ (37\%) of the individuals that were overmatched (undermatched) in education, are also overmatched (undermatched) in the job. Similarly, around 39\% (33\%) of the individuals undermatched (overmatched) in the job, were also undermatched (overmatched) in education. This is part of the evidence that labor market outcomes are impacted by education mismatch.

\footnotetext{
${ }^{2}$ Most labor market frictions can impact the education rate as well as the opportunities available to those mismatched in education. It is less likely that these frictions are an independent source of education mismatch unless they are targeted differently at individuals based jointly on ability and education.
} 
The last section of the empirical analysis studies assignment to non-formal training for early workers. ${ }^{3}$ Offering training to high-ability individuals, initially undermatched in education, would allow them to acquire the necessary skills and then efficiently use them in the labor market. The key issue is selection into training. We find that the type of occupation in early employment is an important determinant in the assignment to non-formal training, with college and specially our proxy for ability, playing a minor role. Specifically, individuals with skilled jobs in our sample in early employment are more likely to receive non-formal training than individuals with unskilled jobs.

To understand the sources of education and job mismatch, their interaction and dynamic implications, we construct a model economy, presented in Section 3, combining heterogeneous individuals, differing in ability, and jobs with different skill requirements. ${ }^{4}$ Individuals make education and training decisions. Education choices are potentially influenced by tastes for education, capital market frictions and the labor market institutions that will ultimately determine the return to college. A strong negative taste for education may induce, for example, high ability agents to choose not to go to college. ${ }^{5}$ This case would indicate mismatch but the allocation may still be efficient, though not output maximizing. In a setting with imperfect capital markets, relatively high ability agents may choose a low level of education simply because of a binding borrowing constraint. So both variations in tastes and binding borrowing constraints can induce education mismatch. As in Cooper and Liu (2019), there is another source of education mismatch in the model associated with ability being measured instead of observed: individuals make education decisions based upon their true ability but PIAAC scores are imperfect signals of ability thus generating measured mismatch.

The allocation of workers to early jobs is based on the education choice: educated workers are more likely to be assigned to skilled jobs and workers with no education are more likely to be allocated to unskilled jobs. The model allows for training during the early work phase. As with education, training increases individuals' skills at the cost of devoting less time to productive activities. The training decision will depend on the individual's ability as well as early job assignment. Further, training and education will impact both productivity and individuals job assignment in the late work phase of life.

Country specific parameters of the model are estimated using simulated method of moments capturing mismatch in both education and labor allocation and their interconnection. A main outcome of the estimation, presented in Section 4, is a quantitative assessment of the sources of education mismatch and the consequences for labor market outcomes. The analysis addresses these points through the choice of appropriate moments and counterfactual exercises.

From the estimation, a main cause of educational mismatch are taste shocks. ${ }^{6}$ For Germany, this is supplemented with noise about ability at the time of the education decision, consistent with the discussion of early sorting into education. ${ }^{7}$ There is no evidence of credit market frictions as a source of education mismatch.

The estimated model is used in Section 6 to examine the output loss from mismatch and to generate dynamics that are not directly seen in the PIAAC data, as it is a single cross section. Together with the moments from the estimation, this allows us to determine, for example, the probability an agent is mismatched in early employment given education undermatch. Further, the simulations facilitate an understanding,

\footnotetext{
${ }^{3}$ We discuss our measure of training in some detail below.

${ }^{4}$ Specifically, Section 3 summarizes the model that is presented in complete detail in Appendix 10.

${ }^{5}$ As developed below, there are a number of interpretations for this taste shock, both in terms of its representation in the model and potential sources.

${ }^{6}$ This result differs from that of Cooper and Liu (2019) where mismatch reflected noise in test scores. A key difference in results is that the current study include labor market outcomes as well as education moments.

${ }^{7}$ For a discussion of this system and an emphasis on it flexibilities, see Dustmann, Puhani, and Schönberg (2017).
} 
through the model, of the selection into training and its role in overcoming undermatch. This is an important thought experiment as it makes clear the extent to which labor market flows compensate for education mismatch.

From the perspective of resolving education undermatch, there are marked differences across countries. At one extreme is Japan where undermatch in education is sustained through job assignments and training. Specifically, nearly $90 \%$ of individuals undermatched in education are assigned low skilled jobs and none of them choose to train. As a consequence they remain trapped in these jobs through their working lifetimes. In contrast, in Germany, Italy and the US, the undermatched in education fare better, in part because they are assigned a high skill job with higher probability than in Japan. Moreover, those assigned a low skill job are very likely to train and are subsequently placed in a high skill job. In the US, for example, about $70 \%$ of undermatched individuals are eventually placed in high skilled jobs. And, in these three countries, the compensation in the late employment period to the undermatched in education is considerably higher than the average paid to the well matched in education, with no college.

A final discussion, Section 7, provides a country perspective. That is, instead of looking at the model and its predictions from the viewpoint of sources and consequences of mismatch, the outcomes by country are discussed. This facilitates an understanding of how education and labor market institutions that differ across countries might impact mismatch.

\section{Related Literature}

This project is obviously related to the vast literature on the measurement, sources and consequences of education mismatch and labor market misallocations: including Dillon and Smith (2017), Abbott, Gallipoli, Meghir, and Violante (2019), McGowan and Andrews (2015), Pellizzari and Fichen (2013), Cooper and Liu (2019) and Garibaldi, Gomes, and Sopraseuth (2020).

We contribute to this literature in three important ways. First, our theoretical model allows both sources of mismatch allowing us to evaluate the effects of education mismatch on labor market allocations. Studies of education mismatch generally focus on its effects on production capacity and ignore the presence of other labor market frictions. At the same time, studies of labor market mismatch focus only on frictions in the labor market and do not take into account distortions to the education choice. Second, we add to the literature related to labor market inefficiencies from training decisions by evaluating the role of training in overcoming education undermatch. Third, the use of PIAAC data, allows us to conduct a cross-country comparison of the interconnection of both types of mismatch and discuss aspects of institutional structures that underlie the observed relationship.

Flinn and Mullins (2015) also look at the interaction of education choices and labor market outcomes. Their emphasis is on the role of labor market frictions and worker bargaining power on education choices. There is no education mismatch in their model. Our emphasis, in contrast, is on the effects of education frictions, leading to mismatch, on labor market outcomes without the presence of additional labor market frictions. From their analysis, it is clear how labor market frictions impact education rates without creating education mismatch.

Our paper also adds to the literature on the importance of pre-labor market conditions for lifetime earnings. Huggett, Ventura, and Yaron (2011) find that, as of age 23, differences in ability to learn, human capital, and wealth account for more of the variation in lifetime earnings, lifetime wealth, and lifetime utility than do differences in shocks received over the working lifetime. Our paper also assumes that difference in human capital are crucial in determining the lifecycle position in the labor market although the focus and 
methodology are very different.

There are numerous papers that focus on training, both selection into training and its effects on future earnings and job assignment. Our contribution highlights the role of training in overcoming education mismatch. The existing literature stresses the role of the hold-up problem as a disincentive for the accumulation of human capital, including training. In a setting with education and labor frictions, Flinn, Gemici, and Laufer (2017) study the determinants into training. But education is exogenous and there is no education mismatch. Thus the interaction between mismatch and training is not studied.

Given the interest in lifelong learning, it is not surprising that the PIAAC data has been used as a source of information on training and its consequences. A few of those studies relate directly to our goal of understanding the interaction between mismatch and training.

Martin (2018) provides a general assessment of the use of the PIAAC data, with some emphasis on both skill mismatch and lifelong learning. Martin (2018) notes that "In all countries, those workers with the most education and skills participate far more in learning opportunities than their peers with less education and skills."

Brunello and Rocco (2015) study Adult Education and Training (AET) in the PIAAC data. In terms of selection into training, they discuss evidence that training is more likely for individuals with higher educational attainment and more likely for younger individuals. As for the effects of training on labor market outcomes, they argue that training leads to both higher wages and present limited evidence that skills improve.

Cabrales, Dolado, and Mora (2017) study training in Spain and in other PIAAC countries. Their focus is on the interaction of job protection measures and training. They emphasize the interaction between training and the type of employment contract, temporary vs. permanent. Some of their findings for Spain are relevant for our model and its implications. They find a positive association between training and the accumulation of skills, measured by the PIAAC tests. On job assignment, they find that higher test scores are positively related to permanent jobs. And, perhaps most importantly, they argue that workers with temporary jobs are less likely to receive training.

The result that the type of contract is linked to training is most intriguing for us as it indicates another potential channel for the resolution of mismatch. However, using data for our 4 countries, there is no evidence that mismatch in education is related to the assignment of permanent versus temporary contracts. ${ }^{8}$

Another related study is Gauly and Lechner (2019) which focuses on selection bias and the evaluation of training outcomes. Like studies of the return to formal education, determining the effects of training requires some control for selection. Gauly and Lechner (2019) study this for Germany, supplementing the PIAAC data for Germany with a follow-up longitudinal study. Combining these data sets allows them to distinguish selection effects from the impact of training on skills. They conclude that the selection effects are quite strong and essentially accounts for the positive correlation of training and skills.

There is another related literature, such as Kawaguchi and Murao (2014) for OECD countries, that focuses on the effects of aggregate conditions at the time of an individual's first job on labor market outcomes later in life. ${ }^{9}$ The discussion there points to the effects of differences in labor market institutions on the persistent effects of initial conditions. While our study is not about aggregate conditions, the same persistent effect of initial conditions such as education mismatch may depend on labor market institutions. We return to this point below specifically in the case of Japan.

\footnotetext{
${ }^{8}$ This was also largely the case in Spain as well, the focus of Cabrales, Dolado, and Mora (2017), though overmatched individuals had a slightly higher rate of permanent attachment.

${ }^{9}$ Liu, Salvanes, and Sørensen (2016) provide a detailed account for Norway.
} 
Finally, to be clear on language relative to the literature, throughout we refer to education mismatch as reflecting the misallocation of individuals with respect to educational outcomes. And we refer to labor mismatch as denoting the misallocation of individuals with respect to job assignment. Some of the literature uses the terms education mismatch to denote the misallocation of workers, based upon their education, to jobs. And, some of the literature studies the co-existence of vacancies and unemployed workers as mismatch.

\section{Facts}

This section provides initial evidence on education and labor market mismatch and their interaction. It also includes evidence on the selection to training. These facts are used in part to motivate our analysis and also to provide a basis for the structural estimation that follows.

The main data source for this analysis is the Survey of Adult Skills from PIAAC. The use of PIAAC data is crucial to conduct a cross-country comparison of the relationship between ability, educational attainment and labor market allocations. The survey assesses the proficiency of adults aged 16-65 in three domains: literacy, numeracy and problem solving in technology-rich environments.

Before the skill assessment, all participants responded to a background questionnaire that provides information in four main areas: (i) basic demographic characteristics of respondents, (ii) education attainment and participation in learning activities, (iii) labor force status and employment and (iv) the use of skills at work and in daily life. Our analysis includes participants aged 25 to 54, excludes self-employed individuals and uses data from 21 participating countries from the first round of the survey: Austria, Belgium, Canada, Czech Republic, Denmark, England, Estonia, Finland, Germany, France, Ireland, Italy, Japan, Korea, Netherlands, Norway, Poland, Slovak Republic, Spain, Sweden and the United States (US). ${ }^{10}$ We report results for pooled sample and for 4 individual countries: Germany, Italy, Japan and the US. ${ }^{11}$

To study the relationship between ability and educational choices, we use the PIAAC numeracy score as a signal of cognitive ability. For the analysis relating skills and types of occupation, we include individuals' proficiency in literacy and problem solving. Thus, we use the average of the three dimensions as signal of individuals' skills in the labor market.

There are standard concerns with the use of PIAAC scores as measures of ability. First, as with all tests, scores signal ability with noise. Second, and more importantly for the education mismatch analysis, the exam is not taken prior to education but is given during working years, so that the test results might also reflect the effects of education, training and/or work experience. These concerns are dealt with in the quantitative analysis by adding noise to test scores, disciplined by model moments, and by a treatment allowing reverse causality.

For educational attainment we rely on the International Standard Classification of Education (ISCED). We define a dichotomous variable indicating two levels: (i) below college (ISCED 1 through 4) and (ii) college and beyond ( ISCED 5 and above). For individual's occupations we rely on the International Standard Classification of Occupations from 2008 (ISCO 08) and define two types of jobs: (i) unskilled (first to third ISCO skill levels) and (ii) skilled jobs (fourth ISCO skill level).

Figure 1 motivates, for Germany and Italy, the two notions of mismatch that we develop in this paper. The left panel shows the distribution of PIAAC numeracy scores by educational attainment for each country

\footnotetext{
${ }^{10}$ The data collection for the first round took place from August 2011 to November 2012. Individuals aged 25-54 are supposed to had made their education decisions before 2006, so the Great Recession cannot affect their educational choices.

${ }^{11}$ These countries were selected for the detailed study in part because of their differences in both education mismatch, training and labor market institutions. Some of these facts are established for the broader set of countries in Appendix subsection 9.1.
} 


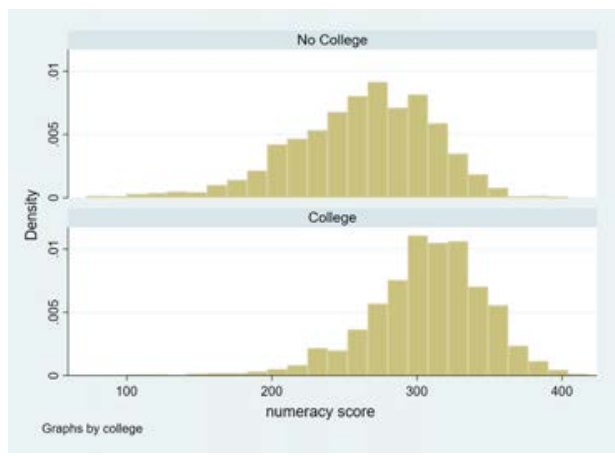

(a) Germany: Education Levels

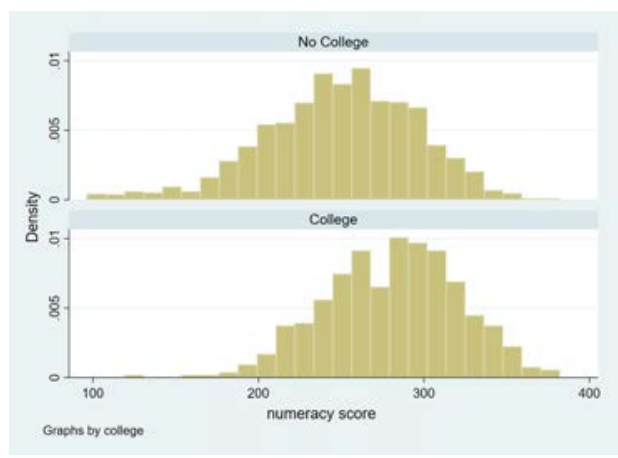

(c) Italy: Education Levels

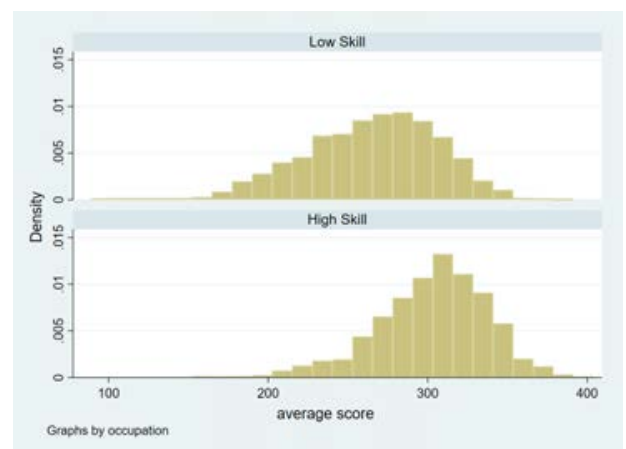

(b) Germany: Occupations

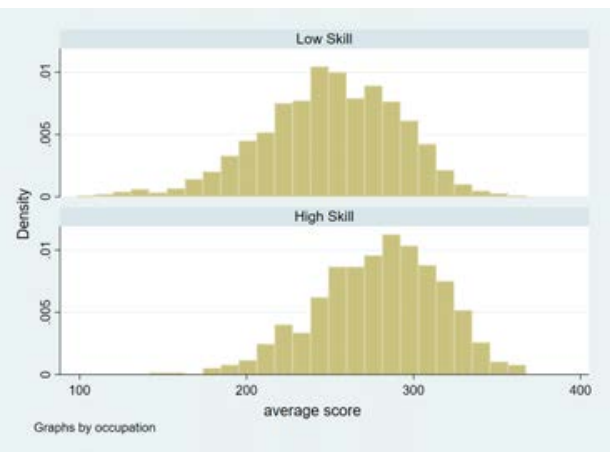

(d) Italy: Occupations

Figure 1: Ability, Education Levels and Occupations

Note: Figures in the left panels show the distribution of PIAAC numeracy scores by education by country. For each country, the top row is less than college and the bottom row is college and beyond. Figures in the right panel show the distribution of PIAAC average scores by occupations by country. For each country, the top row is low skilled jobs and the bottom row is skilled jobs.

while the right panel shows the distribution of PIAAC total average scores by types of occupations. Tables 1 and 2 report moments for those distributions. ${ }^{12}$

\begin{tabular}{lccccccc}
\hline & \multicolumn{3}{c}{ No College } & & \multicolumn{3}{c}{ College } \\
\cline { 2 - 4 } \cline { 6 - 8 } & Mean & Sd & N & & Mean & Sd & N \\
\hline Germany & 262.05 & 48.55 & 1939 & & 306.73 & 40.05 & 1117 \\
Italy & 249.45 & 46.03 & 2039 & & 280.91 & 40.62 & 460 \\
Japan & 279.62 & 37.56 & 1220 & & 308.71 & 33.79 & 1705 \\
United States & 231.80 & 51.39 & 1492 & & 289.25 & 42.37 & 1204 \\
Pooled & 256.13 & 49.21 & 38013 & & 297.99 & 41.06 & 26277 \\
\hline
\end{tabular}

Note: This table reports the moments of the distribution of the numeracy score by country and educational level. Data for all countries are reported in Table 28.

Table 1: PIAAC numeracy score

Some patterns are clear from Figure 1. First, for each of the countries, the distribution of PIAAC scores for those with college degrees (skilled occupations) is a rightward shift of the scores for the low education

\footnotetext{
${ }^{12}$ These tables condition on education but not age. There were no distinct patterns in the data relating scores to age.
} 
group (workers in low skilled occupations). These differences in means are clear from Tables 1 and 2 and are statistically significant. Second, for every country, we observe significant dispersion of PIAAC scores for each of the educational attainment levels and types of occupation. Third, and most importantly for the purposes of our study, there is considerable overlap in these distributions. This is indicative of mismatch: there are individuals that didn't go to college but whose scores are higher than those with a college degree and there are individuals in low-skilled jobs but whose scores are higher than those in high-skilled ones. These patterns are also apparent for the pooled sample of 21 countries.

\begin{tabular}{lccccccc}
\hline & \multicolumn{3}{c}{ Low-Skilled } & & \multicolumn{3}{c}{ High-Skilled } \\
\cline { 2 - 4 } \cline { 7 - 8 } & Mean & Sd & N & & Mean & Sd & N \\
\hline Germany & 264.09 & 43.08 & 1655 & & 302.60 & 34.75 & 1188 \\
Italy & 249.79 & 41.26 & 1388 & & 279.02 & 36.49 & 720 \\
Japan & 293.82 & 33.58 & 1534 & & 313.08 & 30.33 & 1008 \\
United States & 249.26 & 46.22 & 1248 & & 290.91 & 39.16 & 1237 \\
Pooled & 258.79 & 44.88 & 38013 & & 298.13 & 36.61 & 26277 \\
\hline
\end{tabular}

Note: This table reports the moments of the distribution of the average PIAAC score by country and type of occupation. Data for all countries are reported in Table 29.

Table 2: PIAAC average score

\subsection{Measuring Mismatch}

Figure 1 suggests the presence of important amounts of the two types of mismatch across OECD countries. We now conduct a more formal analysis to measure mismatch and to classify individuals into under, well and overmatched both in education and in the labor market. To do this, we estimate probabilities of (i) obtaining higher education and (ii) getting a skilled job conditional on PIAAC scores. Based on these estimates, an agent is undermatched (overmatched) in education if she didn't (did) complete college but the predicted probability of doing so is sufficiently high (low). Similarly, we say an agent is undermatched (overmatched) in her job if she doesn't (does) have a skilled job but the predicted probability of doing so is sufficiently high (low). The residuals are termed well matched. ${ }^{13}$

These measures of mismatch play two roles. First, they are useful summary statistics of the overlap in distributions of ability by education and job assignment. Second, they are used as moments in the estimation. That said, these measures are not directly related to the structure of the model. The mapping from the model to these measures of mismatch is determined after the estimation as we explore the origins of mismatch.

\subsubsection{Education Mismatch}

In this section we generate empirical measures of education mismatch. Specifically, consider the following logistic model of educational choice:

$$
\operatorname{Pr}\left(e_{i}=1 \mid a_{i}\right)=\frac{\exp ^{\alpha_{0}+\alpha_{1} a_{i}}}{1+\exp ^{\alpha_{0}+\alpha_{1} a_{i}}}
$$

where $a_{i}$ is the PIAAC numeracy score, considered as a proxy for individual $i$ 's ability. ${ }^{14}$ Here $e_{i}=0$ signifies that individual $i$ has no college degree and $e_{i}=1$ signifies college attainment and beyond. The regressions

\footnotetext{
${ }^{13}$ This builds upon the methodology used by Smith, Pender, and Howell (2013).

${ }^{14}$ The PIAAC data report 10 plausible values for the numeracy score for each individual. We use the mean of these plausible values as a proxy for ability.
} 
are run at the individual level by country. In order to better compare the results, we normalize the test score within each country to have a mean zero and a standard deviation of unity.

Predicted values from these logistic regressions are used to classify individuals into under- and overmatched. An individual is overmatched in education if $e_{i}=1$ but the model's predicted probability of $e_{i}=1$ is lower than the 20th percentile of all predicted values. Similarly, an individual is undermatched in education if $e_{i}=0$ but the model's predicted probability of $e_{i}=1$ is higher than the 80th percentile of all predicted values $^{15}$

\begin{tabular}{|c|c|c|c|c|c|c|c|}
\hline & College Rate & Undermatch & Overmatch & $\alpha_{0}$ & $\alpha_{1}$ & Marg. Effect & $\mathbf{N}$ \\
\hline Germany & 0.366 & 0.092 & 0.061 & $\begin{array}{c}-0.883 \\
(0.05)\end{array}$ & $\begin{array}{l}1.274 \\
(0.07)\end{array}$ & 0.222 & 3,056 \\
\hline Italy & 0.184 & 0.157 & 0.065 & $\begin{array}{r}-1.972 \\
(0.07)\end{array}$ & $\begin{array}{l}1.015 \\
(0.07)\end{array}$ & 0.113 & 2,499 \\
\hline Japan & 0.583 & 0.071 & 0.116 & $\begin{array}{l}0.137 \\
(0.04)\end{array}$ & $\begin{array}{l}0.919 \\
(0.05)\end{array}$ & 0.194 & 2,925 \\
\hline United States & 0.447 & 0.065 & 0.040 & $\begin{array}{c}-0.465 \\
(0.05)\end{array}$ & $\begin{array}{l}1.437 \\
(0.07)\end{array}$ & 0.253 & 2,696 \\
\hline Pooled & 0.409 & 0.083 & 0.054 & $\begin{array}{l}-1.561 \\
(0.047)\end{array}$ & $\begin{array}{c}1.192 \\
(0.013)\end{array}$ & 0.224 & 64,290 \\
\hline
\end{tabular}

Note: This table reports data moments including $\alpha_{0}$ and $\alpha_{1}$ from equation 1. Standard errors are provided in parenthesis for the logistic coefficient estimates. The column labeled "Marg. Effects" is the average marginal effect of the normalized numeracy score on college attainment. $\mathrm{N}$ is the size for the 25-54 age groups in each sample.

Table 3: Education Mismatch

Results for this exercise are presented in Table 3 for Germany, Italy, Japan, the US and the pooled sample. The estimated coefficients from columns 1-5 are used as moments in the structural estimation. ${ }^{16}$

College attainment, under- and overmatch rates for every country are reported in the first three columns. Here, the undermatch (overmatch) rate represents the proportion of individuals that didn't (did) choose college and are mismatched. The fourth and fifth columns show the estimates of the coefficients from the logistic model while column six represents the average marginal effect of the numeracy score on the probability of college attendance.

From the pooled sample, there is evidence of both forms of mismatch. For this large sample, the average marginal effect of the numeracy score on education is about 0.22 .

There is important variation across countries. Although college attainment rates are relatively high for these four advanced economies, they are considerably lower in Germany and in Italy compared to Japan. Mismatch rates are lowest in the US. The undermatch rate is highest in Italy, where the college attainment is lowest. The overmatch rate is highest is Japan, where the college attainment is higher. In general, this pattern is observed for the whole sample of 21 countries: countries with higher education rates tend to have lower undermatch rates and higher overmatch rates.

There are clearly problems with this direct measure of education mismatch. The choice of cut-offs values is arbitrary and PIAAC scores are imperfect measures of ability, reflecting possibly some effect of education itself. In addition, coefficient estimates from (1) might suffer from omitted variable bias coming from the

\footnotetext{
${ }^{15}$ Appendix sub-section 9.2.3 considers an alternative measure in which these percentiles are calculated within the appropriate reference group by education rather than the entire population.

${ }^{16}$ The sample and thus estimates are a bit different than those reported in Cooper and Liu (2019) since the age group here is 25-54 year old, and we excluded self-employed. In particular, the average college rate is a bit lower.
} 
omission of demographic characteristics, family background variables, labor market experience and other controls. While section 5 considers a number of alternative specifications to (1) to deal with these potential problems and to study the robustness of our results to those specifications, it is important to keep in mind that one virtue of the structural estimation exercise is that inference about the sources of mismatch are not coming directly from these regressions results. The estimates of the underlying parameters are coming rather indirectly from matching the coefficients in (1) and the implied mismatch rates in the structural estimation. Moreover, as the same regressions are run on both the simulated and PIAAC data sets, some of the omitted variable bias is also included the structure. Finally, it is worth noting that once we estimate the model parameters, we use the simulated data to detect under- and overmatched individuals based on their true ability and education decisions. Our main findings regarding implications of mismatch are drawn from those measures of actual mismatch, rather than from the methodology used with the data.

\subsubsection{Labor Mismatch}

We follow the same methodology to generate empirical measures of labor market mismatch. ${ }^{17}$ In particular, we now consider the following logistic model:

$$
\operatorname{Pr}\left(o_{i}=1 \mid \hat{a}_{i}\right)=\frac{\exp ^{\delta_{0}+\delta_{1} \hat{a}_{i}}}{1+\exp ^{\delta_{0}+\delta_{1} \hat{a}_{i}}}
$$

where $\hat{a}_{i}$ is the PIAAC average score of the three dimensions, considered as a proxy for individual $i$ 's skills, $o_{i}=0$ signifies that individual $i$ has an unskilled occupation and $o_{i}=1$ signifies skilled occupation. As in (1), ability is measured as the average of all reported plausible values of the three dimensions. This allows for education and previous job experience to impact, say, the problem solving component of the test score and thus measured ability. ${ }^{18}$

McGowan and Andrews (2015) identify individuals, by occupation, who are well-matched in terms of their self-assessment of their own skills relative to those required to perform their job. From this group, they obtain critical test scores for, say, the 5th and 95th percentiles. All workers in the occupation are evaluated relative to these cutoffs. As with our measure, mismatch is identified as being outside of these values.

For this analysis, we defined two phases of the working life. Individuals aged 25-34 are classified as early workers while individuals aged 35-54 are considered late workers. Regressions are run at the individual level by country and employment phase. As with education mismatch, the average score is normalized within each country and employment group to have a mean zero and a standard deviation of unity.

Predicted values from these logistic regressions are used to classify individuals into under- and overmatched in the labor market. An individual is overmatched in the labor market if $o_{i}=1$ but the model's predicted probability of $o_{i}=1$ is lower than the 20th percentile of all predicted values. Similarly, we say an individual is undermatched in the labor market if $o_{i}=0$ but the model's predicted probability of $o_{i}=1$ is higher than the 80 th percentile of all predicted values.

Table 4 shows the labor market mismatch rates by employment phase for Germany, Italy, Japan, the US and the pooled sample. These rates are calculated as the ratio of the number of agents in a type of job that are mismatched divided by the number of agents in that type of job.

The pooled sample exhibits a number of important characteristics. There is substantial job mismatch

\footnotetext{
${ }^{17}$ Other empirical approaches use job satisfaction to measure mismatch as discussed in McGowan and Andrews (2015).

${ }^{18}$ As suggested to us by Huacong Liu, this timing and choice of test might also allow for the current job to impact the score since we do not know how long the individual was in the current job. We return to this below in a robustness exercise, sub-section 9.2.4.
} 
in the early work phase, with the undermatch rate exceeding the overmatch rate. Further, these mismatch rates are slightly lower for older compared to younger workers.

Measures of labor market mismatch also vary significantly across countries. Undermatch rates are higher than overmatch rates for all of them. Similarly, important differences in terms of mismatch rates are observed between the two age groups. In every country, the labor market undermatch rate is significantly higher for the subsample of individuals in early employment, except for Japan in which there is almost no difference. Overmatch rates are higher for late workers in Japan, Germany and the pooled sample, and lower in the US and Italy.

Lower mismatch rates for late workers might be indicative of the presence of labor market mechanisms like training that help in the reallocation of under-matched workers into jobs. Higher mismatch rates, on the other hand, might reflect some failure for the labor market to correct the initial misallocation of workers. However, there is a word of caution in interpreting these differences. The PIAAC data is cross-sectional, not panel. Thus, we cannot distinguish between the cohort effect and the age effect when analyzing the two groups. The differences in overmatch rates, for example, might be indicative of different labor market agreements for that cohort that make it more difficult to separate overmatch individuals from their skilled jobs. In order to avoid any misinterpretation of those differences in mismatch rates in late employment, we use only early employment labor mismatch rates as moments in our structural estimation.

As with the education mismatch rates, measured labor market mismatch might suffer suffer from omitted variable bias. However, these estimates are only used in the structural estimation since they are informative about our parameters. We return to study labor mismatch through simulations of the estimated model.

\begin{tabular}{lcccc}
\hline & under job early & under job late & over job early & over job late \\
\hline Germany & 0.101 & 0.091 & 0.038 & 0.055 \\
Italy & 0.165 & 0.144 & 0.086 & 0.070 \\
Japan & 0.134 & 0.133 & 0.085 & 0.101 \\
United States & 0.091 & 0.078 & 0.075 & 0.055 \\
Pooled & 0.102 & 0.091 & 0.060 & 0.057 \\
\hline
\end{tabular}

Table 4: Labor Market Mismatch by Employment Age

\subsection{Empirical Effects of Education Mismatch on Labor Market Outcomes}

The evidence indicates both education and job mismatch. A key motivation of this paper is understanding their interaction. Leaving aside the issue of causality, is there evidence that education and labor market outcomes, in terms of mismatch, are correlated? Further, how do these patterns evolve? One intriguing hypothesis is that education undermatch initially leads to labor market undermatch but over time, through training and/or reallocation across jobs, the effects of the initial education undermatch disappear.

A simple correlation analysis, in Table 27, shows positive and significant correlations for all countries between (i) being mismatched (either under or over) in education and in the job, (2) being overmatched in education and overmatched in the job and (3) being overmatched in education and overmatched in the job. The next steps go beyond those correlations by analyzing the impact of education mismatch on compensation and job assignment and studying selection into training. 


\subsubsection{Mincer Regressions: The Wage Effects of Education Mismatch}

This section analyzes the wage effects of education mismatch. To do so, we add the obtained measures of education mismatch for each individual by country to a standard Mincer wage regressions. Hanushek, Schwerdt, Wiederhold, and Woessmann (2015) use also the PIAAC scores as a measure of cognitive skills in these type of regressions. It is clear from their analysis that both the PIAAC numeracy score as well as education are positively correlated with labor market earnings.

We use the gross hourly earnings of wage and salary workers as the labor income measure. ${ }^{19}$ We follow Hanushek, Schwerdt, Wiederhold, and Woessmann (2015) for some sample selection criteria that further restrict our sample. First, in each country, we trim the bottom and top one percent of the wage distribution to limit the influence of outliers. Second, to avoid other influences such as family demands or health limitations that might affect labor-force attachment, we limit the estimation sample to full-time workers, defined as those working at least 30 hours per week.

\begin{tabular}{lccccc}
\hline & Pooled & Germany & Italy & Japan & US \\
\hline numeracy score & $0.095^{* *}$ & $0.149^{* *}$ & $0.092^{* *}$ & $0.137^{* *}$ & $0.159^{* *}$ \\
& $(0.001)$ & $(0.01)$ & $(0.02)$ & $(0.01)$ & $(0.01)$ \\
college & $0.243^{* *}$ & $0.237^{* *}$ & $0.276^{* *}$ & $0.120^{* *}$ & $0.243^{* *}$ \\
& $(0.001)$ & $(0.02)$ & $(0.03)$ & $(0.03)$ & $(0.03)$ \\
late_emp & $0.143^{* *}$ & $0.173^{* *}$ & $0.226^{* *}$ & $0.268^{* *}$ & $0.179^{* *}$ \\
& $(0.001)$ & $(0.02)$ & $(0.02)$ & $(0.02)$ & $(0.02)$ \\
gender & $-0.161^{* *}$ & $-0.116^{* *}$ & $-0.136^{* *}$ & $-0.298^{* *}$ & $-0.117^{* *}$ \\
& $(0.001)$ & $(0.02)$ & $(0.02)$ & $(0.02)$ & $(0.02)$ \\
under_educ & $0.043^{* *}$ & -0.001 & 0.018 & -0.070 & 0.099 \\
& $(0.01)$ & $(0.04)$ & $(0.04)$ & $(0.05)$ & $(0.06)$ \\
over_educ & $-0.066^{* *}$ & -0.034 & -0.053 & -0.005 & -0.022 \\
& $(0.01)$ & $(0.07)$ & $(0.15)$ & $(0.05)$ & $(0.09)$ \\
\hline$R^{2}$ & 0.578 & 0.302 & 0.225 & 0.302 & 0.310 \\
\hline
\end{tabular}

Note: This table reports the results from Mincer type regressions for our small sample of 4 countries and the pooled sample. The depend variables for all of them is log hourly earnings. Standard errors are reported in parenthesis. The numeracy score is normalized within each country to have zero mean and standard deviation of unity. The variable gender takes the value 1 if the individual is female, and 0 otherwise. The variable late_emp takes the value 0 if the individual is an early employee $(25-34$ years old) and 1 otherwise. A*/** next to the coefficient indicates significance at the 10/5\% level. Table 30 includes Mincer regressions for all countries among the moments.

Table 5: Mincer Regressions by Country.

Some interesting relations are clear from Table 5, both for the individual country and pooled regressions. First, earnings depend positively on PIAAC numeracy scores indicating they are not just noise. Second, all regressions show an obvious college premium. Third, the positive coefficient on late employment signals a seniority effect. These results are in line with findings in Hanushek, Schwerdt, Wiederhold, and Woessmann (2015).

Fourth, education mismatch appears to have a statistically significant effect on predicting wages for the pooled sample. In particular, the positive coefficient on education undermatch means that those who were undermatched in education get compensated compared to the well-matched without college. In a

\footnotetext{
${ }^{19}$ In the Public Use File, earnings data for Austria, Canada, Germany, Sweden, and the United States are reported only in deciles. We thank Marco Paccagnella for running these regressions for us.
} 
similar manner, the negative coefficient for education overmatch implies that those who were overmatched in education get a pay cut relative to the well-matched college graduates. This could represent a way in which education mismatch impacts labor market outcomes.

However, at the individual country level, these effects are absent. This is also true for majority of the 21 countries in our sample. ${ }^{20}$ This does not mean that mismatch has no implications for labor market compensation. In fact, the opposite is the case: the absence of a significant effect of mismatch on wages means that this dimension of the labor market perpetuates the effects of education mismatch. We return to this point in the counterfactual discussion, in sub-section 6.2.2.

\subsubsection{Education Mismatch and Skill Assignment}

\begin{tabular}{lccc}
\hline & Ed-Job (general) & Ed-Job (undermatch) & Ed-Job (overmatch) \\
\hline Germany & $0.330^{*}$ & $0.386^{*}$ & $0.179^{*}$ \\
Italy & $0.420^{*}$ & $0.460^{*}$ & $0.394^{*}$ \\
Japan & $0.256^{*}$ & $0.330^{*}$ & $0.346^{*}$ \\
United States & $0.311^{*}$ & $0.412^{*}$ & $0.197^{*}$ \\
Pooled & $0.339^{*}$ & $0.339^{*}$ & $0.345^{*}$ \\
\hline
\end{tabular}

Note: This table reports correlations between different estimates of education and job mismatch. The star indicates significance at the $1 \%$ level. Table 27 reports correlations for all countries.

Table 6: Correlations between education and job mismatch.

Beyond compensation, another dimension of labor market outcomes is the assignment to jobs. In particular, does the labor market assignment overcome or reinforce mismatch in education?

Table 6 looks at the correlations of education and job mismatch for the four countries. ${ }^{21}$ The first column reports the correlation between being mismatched in education and in the job. The second column reports correlations between being undermatched in education and undermatched in the job. The third column shows the correlation between being overmatched in education and overmatched in the job. Clearly mismatch in education is positively correlated with mismatch in jobs.

This positive correlation does not imply though that education mismatch translates mechanically into labor market mismatch. While the correlation is high, not all individuals undermatched in education are undermatched in their job. It is entirely possible that some individuals, undermatched in education, might either be placed in skilled jobs in early employment, or through training, be employed in skilled jobs in late employment. Understanding the dynamic flows that underlie these correlations is a main point of the paper.

Building on this, Table 7 goes further and displays the cross sectional distribution of education and job mismatch, by country, for early employment. The first three columns show the distribution across (early) labor market outcomes, in terms of job mismatch, conditional on education mismatch for the pooled sample, Germany, Italy, Japan and the US. In the pooled sample, almost 40\% (37\%) of the individuals that were overmatched (undermatched) in education are also overmatched (undermatched) in the job. Similarly, the last three columns tell us that around 39\% (33\%) of the individuals undermatched (overmatched) in the job were also undermatched (overmatched) in education. These proportions vary across countries. Notice that there are no individuals in our sample undermatched (overmatched) in education but overmatch

\footnotetext{
${ }^{20}$ Coefficients from these regressions for all countries are shown in Table 30 in the appendix. Only a few countries show statistically significant coefficients for our measures of education mismatch.

${ }^{21}$ Table 27 in the appendix reports the same correlations for all countries.
} 


\begin{tabular}{|c|c|c|c|c|c|c|}
\hline \multirow{3}{*}{ Education Outcome } & \multicolumn{6}{|c|}{ Early Job Outcome } \\
\hline & Undermatch & Well-match & Overmatch & Undermatch & Well-match & Overmatch \\
\hline & \multicolumn{3}{|c|}{ Conditional on Educ } & \multicolumn{3}{|c|}{ Conditional on Job } \\
\hline GERMANY & & & & & & \\
\hline Undermatch & $37.70 \%$ & $62.30 \%$ & $0.00 \%$ & $47.92 \%$ & $4.86 \%$ & $0.00 \%$ \\
\hline Well-match & $3.23 \%$ & $95.23 \%$ & $1.55 \%$ & $52.08 \%$ & $94.37 \%$ & $85.71 \%$ \\
\hline Overmatch & $0.00 \%$ & $75.00 \%$ & $25.00 \%$ & $0.00 \%$ & $0.77 \%$ & $14.29 \%$ \\
\hline \multicolumn{7}{|l|}{ ITALY } \\
\hline Undermatch & $44.57 \%$ & $55.43 \%$ & $0.00 \%$ & $64.06 \%$ & $10.78 \%$ & $0.00 \%$ \\
\hline Well-match & $5.09 \%$ & $92.70 \%$ & $2.21 \%$ & $35.94 \%$ & $88.58 \%$ & $71.43 \%$ \\
\hline Overmatch & $0.00 \%$ & $42.86 \%$ & $57.14 \%$ & $0.00 \%$ & $0.63 \%$ & $28.57 \%$ \\
\hline \multicolumn{7}{|l|}{ JAPAN } \\
\hline Undermatch & $60.87 \%$ & $39.13 \%$ & $0.00 \%$ & $21.54 \%$ & $1.36 \%$ & $0.00 \%$ \\
\hline Well-match & $7.49 \%$ & $91.04 \%$ & $1.47 \%$ & $78.46 \%$ & $93.37 \%$ & $45.45 \%$ \\
\hline Overmatch & $0.00 \%$ & $74.47 \%$ & $25.53 \%$ & $0.00 \%$ & $5.27 \%$ & $54.55 \%$ \\
\hline \multicolumn{7}{|l|}{ US } \\
\hline Undermatch & $47.22 \%$ & $52.78 \%$ & $0.00 \%$ & $40.48 \%$ & $2.33 \%$ & $0.00 \%$ \\
\hline Well-match & $2.97 \%$ & $93.70 \%$ & $3.33 \%$ & $59.52 \%$ & $96.81 \%$ & $87.50 \%$ \\
\hline Overmatch & $0.00 \%$ & $63.64 \%$ & $36.36 \%$ & $0.00 \%$ & $0.86 \%$ & $12.50 \%$ \\
\hline \multicolumn{7}{|l|}{ Pooled } \\
\hline Undermatch & $37.03 \%$ & $62.97 \%$ & $0.00 \%$ & $39.36 \%$ & $4.60 \%$ & $0.00 \%$ \\
\hline Well-match & $4.16 \%$ & $93.73 \%$ & $2.10 \%$ & $60.64 \%$ & $93.80 \%$ & $66.79 \%$ \\
\hline Overmatch & $0.00 \%$ & $60.51 \%$ & $39.49 \%$ & $0.00 \%$ & $1.60 \%$ & $33.21 \%$ \\
\hline
\end{tabular}

Note: This table shows the distribution between different labor market and education outcomes in terms of mismatch. The first three columns represent the distribution across labor market outcomes conditional on the education one (row interpretation). The last three columns condition the distribution on the labor market match (column interpretation.)

Table 7: Distribution of Education and Early Labor Market Outcomes

(undermatch) in the labor market. The moments indicating job outcome conditional on education will be used in the estimation. As the PIAAC is not a panel, the dynamic of job assignment is not well captured. Hence our focus on early assignment in Table 7 and in the estimation.

Another dimension of labor market outcomes is job assignment by skill conditional on educational attainment. Table 8 indicates these flows for early and late workers, where $\delta_{c s}\left(\delta_{n s}\right)$ is the probability a college educated (no college educated) individual obtains a skilled job in the designated employment phase. From the top panel, for all countries, $0<\delta_{c s}<1$ for the subsample of individuals in early employment so that having a college education does not guarantee the attainment of a skilled job. Likewise, $0<\delta_{n s}<1$ in all countries as well so that some individuals can obtain a skilled job even without a college degree. The latter effect thus provides a path for undermatched individuals to be selected into a skilled job.

The late workers flows have a similar pattern where a college degree increases the chances of a skilled job but does not guarantee one. Again, as this is not a panel we cannot separate the age and cohort effects in the observed differences in job assignment probabilities between the two groups of workers. Therefore, the dynamics from early to late employment can not be taken directly from the data and we are unable to determine the fraction, for example, of college educated individuals assigned to skilled jobs in early that retain those jobs in the late employment period. Thus for much of the estimation we rely on $\left(\delta_{c s}, \delta_{n s}\right)$ for early employment as calculated from the data. But we estimate and/or otherwise set the flows for late employment, conditional on training and education outcomes, as explained below. 


\begin{tabular}{c|ccccc} 
& Germany & Italy & Japan & US & Pooled \\
\hline \hline \multicolumn{5}{c}{ Early emp. } \\
$\delta_{c s}$ & 0.773 & 0.681 & 0.471 & 0.743 & 0.693 \\
$\delta_{n s}$ & 0.233 & 0.168 & 0.120 & 0.228 & 0.205 \\
\multicolumn{5}{c}{ Late emp. } \\
$\delta_{c s}$ & 0.759 & 0.833 & 0.578 & 0.798 & 0.754 \\
$\delta_{n s}$ & 0.199 & 0.246 & 0.201 & 0.270 & 0.240 \\
\hline \hline
\end{tabular}

Note: This table reports flows from education. Here $\left(\delta_{c s}, \delta_{n s}\right)$ are the probabilities that a college educated (no college educated) individual obtains a skilled job in the designated employment phase.

Table 8: Job Flows

\subsubsection{Training}

The goal of our analysis is to understand not only the interaction between education and labor market mismatch but also how this interaction evolves over time. If education mismatch matters for labor market allocations, does its effect last over time? What are the mechanism at play? In principle, training allows high-ability individuals initially undermatched in education to acquire skills and then efficiently use them in the labor market. In this way, we consider training as a possible mechanism for overcoming education undermatch.

The PIAAC data report different measures related to training. Specifically, it provides information on whether individuals participated in formal and/or non-formal adult education/training (AET) for job related reasons, in the last 12 months prior to the interview. The background questionnaire defines formal education as the one "provided in schools, colleges, universities or other educational institutions and leads to a certification that is taken up in the national educational classification". However, because of two main data limitations, it is difficult to separate the education variable from the one related to formal training. First, PIAAC data do not report the level/type of formal AET followed by the respondent. Second, our education variable refers to the highest educational attainment at the time of the interview. The lack of a dynamic component does not allow us to distinguish between educational attainment before and after formal AET. ${ }^{22}$

In contrast, non-formal AET refers to participation in one of the following four activities: (i) courses conducted through open or distance education, (ii) organized sessions for on-the-job training or training by supervisors or co-workers, (iii) seminars or workshop and (iv) courses or private lessons. While different from formal education, these activities can impact labor market skills and therefore job allocation. Thus, the main measure used in our analysis corresponds to non-formal training, although formal training is also considered as an alternative.

Our main interest is selection into training. Table 9 reports the results from a logistic regression of the probability of receiving non-formal training in early employment, conditional on individual and some firm characteristics. Since training is received in less than 12 months prior to the interview we assume that the type of occupation, at the moment of the interview, is not a consequence of training but rather the type of job they held while being trained.

It is clear from the table that the type of occupation appears to be a strong determinant in participation into non-formal training with educational attainment and our proxy of ability playing a less important role. In particular, early workers with skilled jobs have a higher probability of receiving non-formal training than

\footnotetext{
${ }^{22}$ AET might coincide with the highest educational attainment for those individuals that completed their highest education level in the 12 months before the interview, or to an ongoing or unfinished degree.
} 


\begin{tabular}{lccccc}
\hline & Pooled & Germany & Italy & Japan & USA \\
\hline non-formal training & & & & & \\
numeracy & $0.213^{* *}$ & $0.313^{* *}$ & $0.248^{*}$ & 0.053 & 0.196 \\
skilled job & $0.617^{* *}$ & $0.854^{* *}$ & $0.579^{* *}$ & $0.965^{* *}$ & $0.585^{*}$ \\
college & $0.326^{* *}$ & 0.038 & $0.757^{* *}$ & $0.600^{* *}$ & -0.100 \\
gender & $-0.372^{* *}$ & $-0.517^{* *}$ & -0.147 & $-0.516^{* *}$ & $-0.691^{* *}$ \\
private & $-0.449^{* *}$ & $-0.614^{* *}$ & 0.311 & -0.361 & $-0.812^{* *}$ \\
permanent & $0.403^{* *}$ & $0.506^{* *}$ & 0.389 & $0.451^{* *}$ & 0.267 \\
size & $0.307^{* *}$ & 0.122 & 0.051 & $0.368^{*}$ & 0.217 \\
\hline
\end{tabular}

Note: This table reports for each country, the probability of receiving training, conditional on individual and firm characteristics.

Table 9: Training assignment

the ones with unskilled jobs. Note too that college is significant in only Italy and Japan: for these countries education is positively correlated with training. In all countries, there is a positive correlation with numeracy, though this is not statistically significant in Japan and the US. ${ }^{23}$ The weak dependence of training on the score for those two countries is consistent with the dynamics generated by our model estimation explained in section 6.2.

These results are suggestive that training does not substitute for education but instead propagates education and labor market mismatch. But, it is difficult to interpret these estimates directly since both education attainment and job assignment are endogenous. We return to disentangling these effects after the estimation of the model.

The estimation focuses on training means by type of occupation as shown in Table 10. These means are used as moments in the structural estimation. The training rates are about one-third for unskilled and two-thirds for workers in skilled jobs. The rates are relatively low in Italy.

\begin{tabular}{lccccc}
\hline rate & Germany & Italy & Japan & US & Pooled \\
\hline \multicolumn{5}{c}{ non-formal } \\
unskilled & 0.386 & 0.195 & 0.380 & 0.436 & 0.372 \\
skilled & 0.643 & 0.364 & 0.685 & 0.682 & 0.626 \\
\multicolumn{5}{c}{ Formal } \\
unskilled & 0.126 & 0.032 & 0.029 & 0.141 & 0.109 \\
skilled & 0.183 & 0.128 & 0.054 & 0.207 & 0.162 \\
\hline
\end{tabular}

Note: This table reports training rates by early workers conditional on the type of occupation and type of training.

Table 10: Training Rates

\section{Model Overview}

This section provides an overview of the model, highlighting the critical choices regarding education and training. The complete model that is taken to the data is presented and analyzed in Appendix 10. Subsection 4.1 describes the quantitative analysis of the complete model, including functional form assumptions.

There are three phases of the life cycle emphasized in the model that accord with the structure of the data analysis. The first stage allows the individual to obtain formal education. The second and third stages are

\footnotetext{
${ }^{23}$ Choi (2019) focuses on the impact of permanent vs temporary work status on training. Our model lacks this distinction.
} 
employment periods. They differ, in part, because of the opportunity for training in the middle period that impacts productivity, earnings and job assignment in the final period. Figure 2 shows these three periods.

\begin{tabular}{rrrr}
\multicolumn{2}{c}{ education } & early work & \multicolumn{2}{c}{ late work } \\
\hline$T^{s}$ & Training & $T^{s}+T^{e}$ & $T^{s}+T^{e}+T^{l}$
\end{tabular}

Figure 2: Phases of Household Life Cycle

Associated with these phases are two choices: (i) education and (ii) training. The identification in the estimated model comes from the dependence of these decisions on underlying parameters. The discussion that follows is intended to provide the basic outline of the model and the factors that influence these choices.

\subsection{Technology}

Table 11 summarizes the underlying technology in this economy. We assume a competitive labor market so that worker compensation equals productivity.

As in the data analysis, there are two types of jobs, skilled and unskilled, two education levels and two training outcomes. The entries in the table indicate output for each combination of these variables where $\theta$ is ability. Educational attainment is indicated by $e \in\{0,1\}$, with $e=1$ indicating college educated.

\begin{tabular}{clc}
\hline education & unskilled & skilled \\
\hline \multicolumn{3}{c}{ No Training } \\
no college & 1 & $\theta h(0)$ \\
college & 1 & $\theta h(1)$ \\
& Training & \\
no college & 1 & $\theta h(0) \zeta(0)$ \\
college & 1 & $\theta h(1) \zeta(1)$ \\
\hline
\end{tabular}

Table 11: Productivity

In the model, human capital is accumulated through education and training. The function $h(e)$ captures the effects of formal education and $\zeta(e)$ captures the expected returns to training. Here, "expected" refers to the fact that the training decision will reflect the joint human capital accumulation from training as well as placement into a skilled job, with the compound effect captured by $\zeta(e)$.

From the timing, the training occurs in early employment. Thus the productivity in the early employment phase is summarized by the top panel, "No Training", as is the productivity in late employment for those who choose not to train. The bottom panel states the productivity in late employment of those who train.

There are a couple of key features of the technology. First, there is an underlying complementarity between education and ability that generates the sorting into education attainment by ability. Because of this, even if $h(1)<h(0)$, there may be a return to education since, conditional on being assigned a skilled job, the wage premium, $\theta h(1)-h(0)$, is increasing in ability.

Second, ability and human capital, either accumulated by formal education or training, matter only in skilled jobs. In this model, this defines a skilled job so that the productivity in an unskilled job is set at unity. From this, individuals deciding on these two forms of investment will take into account the probability of being assigned a skilled job. These assumptions are used here to facilitate the presentation of the key trade-offs and, as discussed later, are used for identification in the quantitative analysis. 
Though the return to education accrues through a skilled job, the model allows for a random assignment of individuals to jobs. In this way, some educated individuals will be assigned to unskilled jobs in early employment and may choose to train to obtain a skilled job in late employment. The randomness in job assignment impacts both the gains to education and training. The estimation ensures that the lotteries over job assignment are data consistent.

\section{$3.2 \quad$ Job Assignment}

Associated with the two job phases are assignments to skilled and unskilled jobs. The early job assignment follows the data, using the flows reported in Table 8 . As in that table, $\delta_{c s}$ is the probability a college educated worker obtains a skilled job, while $\delta_{n s}$ is the probability of a skilled job for an individual without education.

The late job assignment is made difficult by the lack of data on the dynamics of job transitions. Thus, we estimate these transitions as part of our simulated method of moments routine.

The model uses these flows but does not explain them. ${ }^{24}$ They may naturally reflect frictions in the labor market that lead to the misallocation of workers. Sub-section 5.4 assesses the role of these flows for our findings regarding the sources and implications of education mismatch.

\subsection{Training Decision}

The training decision is made in the early employment phase, as a vehicle for supplementing the formal education received in the education phase. At this point, a worker, given education, is either employed in a skilled or unskilled job.

From Table 11, the gains to training depend on the level of education and the agents ability. This is true regardless of the job type in early employment.

The model includes a cost of training in the form of an opportunity cost of time. This cost will depend on the job assignment. If $\theta h(e)>1$, then all else the same, training is more expensive for someone in a skilled job.

To be clear, in the model the returns to training has two components, captured through $\zeta(e)$. The first, is the accumulation of human capital. The second is job assignment in late employment: the returns to training only materialize in a skilled job.

\subsection{Education Decision}

The education is made in the first phase, anticipating the random job assignments that follow as well as the training decision. In the analysis, the education decision is discrete, consistent with our measurement.

There are a couple of potential gains to education. First, there is the direct human capital accumulation through $h(e)$. Second, if $\zeta(1)>\zeta(0)$, then training is more productive for educated individuals. Third, job assignment, in both the early and late phases are dependent on education, allowing for education to increase the chances of placement in a skilled job. Again, the return through $h(1)$ is realized through assignment to a skilled job.

There are two costs of education. First, there is a direct tuition payment. Second, there is an opportunity cost of time. An individual not attending college, earns labor income in the education phase while someone attending college is only able to work part-time.

\footnotetext{
${ }^{24} \mathrm{~A}$ full articulated search and matching model of the labor market would be a natural source of labor market frictions independent of the forces creating mismatch that are the focus of our anlaysis.
} 
The model has an element of assortative choice into education. As ability and education are, by assumption, complements in productivity in skilled jobs, individuals, all else the same, will sort into education based on ability. That is, all agents above a critical ability will choose college.

But there are other factors at play. Agents may differ in their perceived valuation of college, either the experience itself, or the prestige of a degree, or even the type of job they might obtain upon graduation, etc. These factors, taken together, are captured by a shock to "tastes". The estimation uncovers these variations as a major factor explaining educational attainment.

\subsection{Understanding MisMatch}

It is useful to relate the education choice directly to the measures of mismatch. In the model, education mismatch will arise either from the presence of taste shocks or binding borrowing constraints. In both cases undermatch may occur, high ability individuals may not choose the college option, either because they do not directly value the experience or because of the cost due to limited borrowing possibilities. Further, overmatch can arise from taste shocks that induce a relatively low individual to choose the college path.

Finally, another possibility is that no education mismatch occurs despite its measurement in the data. This would reflect noisy test scores. While individuals sort efficiently based on ability, the test results are noisy enough to produce the levels of mismatch found in the data. This result is not trivial since there is discipline in the estimation on the informativeness of the test score in wage regressions.

Importantly, the assignment of agents to jobs in the early work phase will have an independent impact on the education choice. For example, if either low education agents can be assigned high skilled jobs or high education agents are assigned to low skilled job, then the return to education falls relative to no education. While this impacts the education rate, it does not create education mismatch.

To be clear, measured education mismatch need not be a signal of inefficiency. In the optimal allocation, there can indeed be relatively low individuals who obtain a college degree due to a large taste shock.

But this allocation will not be the one that maximizes total output. And if the taste shocks are viewed as transitory whims or the outcome of inappropriate role models, then perhaps they should be ignored in the planners solution. To given an extreme example, if some very high ability individual is brought up in an environment where the leading role model is a criminal, then that individual might indeed bypass education in favor of an alternative occupation. This might not be viewed as an efficient allocation even though the choice did reflect individual tastes.

\section{Quantitative Analysis}

This section of the paper brings the model to the data through a simulated method of moments approach. The moments include those that summarize: (i) education choices, (ii) education mismatch, (iii) wages, (iv) job assignment and (v) training. These moments are topical in that they motivate our analysis and are informative about our parameters.

\subsection{Approach and Functional Forms}

The estimation finds the parameter vector $\Theta$ that solves:

$$
£ \equiv \min _{\Theta}\left(M^{d}-M^{s}(\Theta)\right) W\left(M^{d}-M^{s}(\Theta)\right)^{\prime} .
$$


In this expression, the data moments are given by $M^{d}$, the simulated moments, that depend on the parameters are given by $M^{s}(\Theta)$. W is the conforming identity matrix.

The model plays a prominent role in the analysis since it provides the mapping from the parameters $\Theta$ to the moments. This mapping comes from: (i) the policy functions at the individual level characterizing education and training decisions given $\Theta$, (ii) creating a panel by drawing shocks from the estimated processes and simulating the resulting choices and (iii) calculating moments from the simulated data.

For the estimation, the parameter vector is defined by

$$
\Theta \equiv\left(\phi, \bar{\varepsilon}, \sigma_{e}, h(1), w_{2}, \sigma_{j}, \zeta(0), \zeta(1), \bar{e}^{t}, \delta_{c s s}, \delta_{n s u}, n b p, b b a r\right)
$$

All parameters from the model are summarized in Table 12.

There are some functional form assumptions, as in Cooper and Liu (2019), that underlie $\Theta$. First, ability has a Pareto distribution, with a shape parameter denoted $\phi$. So the CDF of ability, $\theta$, is given by $1-\theta^{-\phi}$ with a mean of $\frac{\phi}{\phi-1}$, decreasing in $\phi .^{25}$

The model assumes that agents know their ability and use this for education, employment and training decisions. As researchers, we do not observe ability directly. Instead, through the PIAAC data set, we have test scores. These scores have already been used to create moments such as the regression coefficients in (1), which used the numeracy score as an input, and the regression coefficients in (2), which used an average of scores, in order to measure labor market mismatch.

For the estimation, it is necessary to create versions of the test scores in the model. There are two noisy test scores, one for education and the other for the job. The score in test $k$ for agent $i$, denoted $t s^{i k}$, is a noisy signal of worker ability:

$$
t s^{i k}=\theta_{i}+\sigma_{k} \zeta^{i k}
$$

Here $\sigma_{k}$ for $k \in\{e, j\}$ parameterizes the noise in test $k$, denoted $\zeta^{i k}$, and these are elements of $\Theta$, where $e$ denotes the education test score and $j$ is the job test score. The shocks in these test scores are assumed to be uncorrelated.

Taste shocks are assumed to be uniformly distributed in the interval $[-\bar{\varepsilon}, \bar{\varepsilon}]$ and independent of ability in the baseline model. In the parameter vector, $h(1)$ is the human capital accumulated from college and $w_{2}$ is the wage in the late period of employment. ${ }^{26}$

The parameters $\left(\zeta(0), \zeta(1), \bar{e}^{t}\right)$ relate directly to training: $(\zeta(0), \zeta(1))$ are the (expected) human capital accumulation parameters if training occurs, distinguished by education level, $e .^{27}$ The opportunity cost of training is $\bar{e}^{t}$. Under this specification, there is a component of the training choice that is education dependent, $\zeta(e)$, and a component that depends on the job assignment in early employment through the opportunity cost $\bar{e}^{t}$.

The model allows a rich specification of flows between skilled and unskilled jobs over time. The estimation places restrictions on those flows to highlight the effects of training on job flows. With that in mind, the parameters $\left(\delta_{c s s}, \delta_{n s u}\right)$ control the flows from skilled jobs in early employment to job assignment in the late

\footnotetext{
${ }^{25}$ The minimum of ability is set to unity to reduce the number of parameters estimated. From inspection of the estimation results, distinguishing this lower bound from the return on education is very difficult. Thus we do not attempt to estimate this parameter.

${ }^{26}$ For the implementation, there is a single taste shock to influences the difference in values between college and no college. The level of human capital without education, $h(0)$ was set to one, allowing the estimation to focus on the difference between the college and no college outcomes.

${ }^{27} \mathrm{As}$ in the theory model presented in Appendix 10, the expectation arises from the fact that training does not guarantee a skilled job.
} 
working phase if training is not chosen, dependent on the education outcome. ${ }^{28}$ Further, the likelihood a worker who does not train is promoted from an early unskilled job to a late skilled job is equal to zero. In this way, we focus on the role of training to obtain a promotion to a skilled position.

Flows into early employment in skilled jobs, with and without college, denoted $\left(\delta_{c s}, \delta_{n s}\right)$ respectively, are taken directly from the data, as in the top panel of Table 8. We conduct experiments to determine the role of these probabilities for the outcomes of education mismatch.

In the cases with capital market imperfections, $n b p$ is the fraction of agents unable to borrow and $b b a r$ is a borrowing limit. Our adoption of this formulation of a borrowing constraint is explained below.

Throughout the estimation, the fraction of time at school is fixed at $\bar{e}=0.75$, for all countries. But the out of pocket cost is country specific. Relative to the US, the cost in Germany is 0, is $26.06 \%$ in Italy and $92.91 \%$ in Japan. ${ }^{29}$ Finally, $\omega_{1}=1$ is a normalization of the education phase wage.

\begin{tabular}{c|c} 
Parameters & Description \\
\hline \hline Set & fraction of time at school \\
$\bar{e}$ & Tuition for college \\
$p$ & Wage in education and early work phases \\
$\omega_{1}$ & Human capital accumulation in case of no college in skilled jobs \\
$h(0)$ & Flows from college to skilled job in early employment \\
$\delta_{c s}$ & Flows from no college to skilled job in early employment \\
$\delta_{n s}$ & Shape parameter for the Pareto distribution of ability \\
\hline Estimated & Taste shocks \\
$\phi$ & Noise in the education test \\
$\bar{\varepsilon}$ & Human capital accumulation from college \\
$\sigma_{e}$ & Wage in the late period of employment \\
$h(1)$ & Noise in the job test \\
$\omega_{2}$ & Gain from training of individuals with no college \\
$\sigma_{j}$ & Gain from training for individuals with college \\
$\zeta(0)$ & Direct cost for formal training \\
$\zeta(1)$ & Time cost of training \\
$p^{t}$ & Fraction of agents unable to borrow \\
$\bar{e}^{t}$ & Borrowing Limit \\
$\delta_{c s s}$ & Flow from early skilled job to late skilled job if college and no training \\
$\delta_{n s u}$ & Flow from early skilled job to late unskilled job if no college and no training \\
$n b p$ & Frong \\
$b b a r$ & The
\end{tabular}

Table 12: Parameters: Description

\subsection{Moments}

For the estimation, there are three types of moments. They are chosen with a couple of criteria in mind. First and foremost, they are informative about underlying structural parameters in $\Theta$. Second, since the PIAAC is a single cross section, the moments do not reflect any dynamics between individuals of different ages. All moments are summarized in Table $13 .{ }^{30}$

\footnotetext{
${ }^{28}$ Relative to the more general notation in the complete model of the Appendix,$\delta_{c s s}=\delta_{2}^{s}(\bar{e}, \theta, 0)$ and $\delta_{n s u}=\left(1-\delta_{2}^{s}(0, \theta, 0)\right)$ for all $\theta$.

${ }^{29}$ These expenses and the time cost of education are taken from Cooper and Liu (2019).

${ }^{30}$ Moments for all countries are in Table 30.
} 


\begin{tabular}{c|c} 
Moments & Description \\
\hline \hline Education & $\begin{array}{c}\text { Education rate } \\
\text { ed }\end{array}$ \\
un & Education Undermatch rate \\
$\alpha_{0}$ & Education Overmatch rate \\
$\alpha_{1}$ & Constant in logistic regression 1 \\
Labor market & Coefficient for education test in logistic regression 1 \\
test & Coefficient for education test in mincer regression by country \\
ed & Coefficient for education level in mincer regression by country \\
late & Coefficient for employment age indicator in mincer regression by country \\
ed un & Coefficient for education undermatch indicator in mincer regression by country \\
ed ov & Coefficient for education overmatch indicator in mincer regression by country \\
uu & Flow from education to job undermatch in early employment \\
uo & Flow from education undermatch to job overmatch in early employment \\
ou & Flow from education overmatch to job undermatch in early employment \\
oo & Flow from education to job overmatch in early employment \\
ue & Labor market undermatch rate for early workers \\
oe & Labor market overmatch rate for early workers \\
\hline Training & Fraction of early workers with unskilled jobs receiving training \\
unsk & Fraction of early workers with skilled jobs receiving training \\
sk & a
\end{tabular}

Table 13: Moments: Description

The first five moments in Table 14 summarize educational outcomes. These include, in order, the college rate, the undermatch rate and the overmatch rate. The coefficients $\left(\alpha_{0}, \alpha_{1}\right)$ are from the logistic regression in (1) that relates the educational decision to a constant and the education test score. For the data, this regression uses the PIAAC numeracy score. In creating the simulated data, this test score comes from (5) for $k=e$, parameterized by $\sigma_{e}$. This is used as a regressor in (1) and the mismatch rates are calculated as in the data.

The labor market outcomes include wage patterns and the assignment of workers to job types. The coefficients for the wage regressions are taken from Table 5. The moments are the estimated coefficients on the test score (numeracy), education attainment, period of employment (early,late) and dummy variables indicating either undermatch or overmatch in education. Here the inclusion of the period of employment helps to pin down the second period wage, $w_{2}$.

As for job assignment, the moments are the distribution across labor market outcomes, in terms of underand overmatch, conditional on education outcomes, again in terms of under- and overmatch. These flows are displayed in Table 7 . In addition, the early work phase mismatch rates, from Table 4, are included as well. ${ }^{31}$ For the simulated data, the test score for the job mismatch rates comes from (5), for $k=j$, thus parameterized by $\sigma_{j}$, and used as an input into (2) to calculate job mismatch rates.

The training outcomes are captured by the frequency of non-formal training by early workers. These moments reflect our emphasis on training as a source of upward mobility. The robustness section includes estimates with formal training.

\footnotetext{
${ }^{31}$ Mismatch in late employment is not included, consistent with the view of minimizing moments that enforce a steady state on the data.
} 


\subsection{Estimation Results}

This section presents the baseline estimation results. The economic interpretation and implications are brought out in section 6.2. A main finding is that education mismatch is largely due to taste shocks.

The moments are reported in Table 14 and parameter estimates in Table 15. For the baseline model, there are 18 moments and 11 parameters, so the model is overidentified.

From Table 14, the baseline model matches quite well the education moments, including the differences across countries in education rates. The model captures the low education and high undermatch rate in Italy as well as the relatively high education and high overmatch rates in Japan. The logistic coefficients, including the positive sign for $\alpha_{0}$ only in Japan, are picked up as well.

In terms of the Mincer regressions, the model generates positive wage responses to the test score as well as to education and seniority. ${ }^{32}$ But the responses to both the score and education are muted compared to the data. These results reflect, in part, the inclusion of under and overmatch in education as regressors. ${ }^{33}$

Looking at the moments summarizing labor flows, the estimated model matches very well the interactions between education and job mismatch, with the exception of Italy. So, for example, the "uu" rate of 0.393 of Germany in the simulated data comes from the $9.5 \%$ of individuals who are undermatched in education who are assigned unskilled jobs. These individuals test well in those jobs and are thus viewed as undermatched in employment. This predicted rate is quite close to that of 0.377 found in the actual data.

The model does not capture the frequency of early labor overmatch, denoted oe, which is considerably higher in the model than in the data. This is not because the model creates an excessive amount of overmatch in education. Rather this is produced through the labor markets, i.e. $\left(\delta_{c s}, \delta_{n s}\right)$, and the relatively large amount of noise in the job test score.

The moments that summarize the training rates are well matched. The estimated model captures the differences in training rates across countries as well as the fact that training is more likely for those in high skilled jobs. As discussed later, this is a key element in the contribution of training to offsetting education mismatch.

There are a couple of noteworthy features of the parameter estimates in Table 15. First, the returns to education and seniority are present with estimates of $h(1)$ and $\omega_{2}$ above unity. Second, the noise in the education test, $\sigma_{e}$, is much smaller than the job test noise, $\sigma_{j}$. Third, there appears to be substantial variation in taste through a large estimate of $\bar{\varepsilon}$, made clear below by the restricted re-estimation.

As for the training process, for Germany and Italy the expected human capital accumulation is lower for college educated than for the non-college group. The opposite is the case in Japan and the US. Also, for each of the countries either $\zeta(0)$ or $\zeta(1)$ lie below one. Recall that these are the expected productivity gains to training, incorporating the likelihood training succeeds as well as job assignment to take advantage of the increased human capital. ${ }^{34}$ This does not imply though that workers will not train: the return to training is not only through human capital but it also impacts job assignment. These forces are reflected in training decisions conditional on education and thus the simulated average training rates.

As for the flows associated with job transitions conditional on not training, $\left(\delta_{c s s}, \delta_{n s u}\right)$ vary considerably across the countries. These probabilities have direct effects on the training decision by job assignment, thus distinct from $\zeta(e)$, since they apply if the agent chooses not to train. Indirectly they also impact the

\footnotetext{
${ }^{32}$ In both actual and simulated data, the test here is the education not the job score.

${ }^{33}$ The estimated model in Cooper and Liu (2019) included the coefficient on the test score in a Mincer regression with and without education and did not include education under and overmatch. For that estimation, the coefficients on the test score were well matched.

${ }^{34}$ If we re-estimate the model imposing $\zeta(e) \geq 1$, the fit worsens a bit in all countries.
} 
education decision. The estimate of $\delta_{c s s}$ is low in Germany and Italy. The estimate of $\delta_{n s u}$ is very high in Germany and relatively low in Italy. Thus individuals without college degrees who initially are assigned a skilled job are unlikely to retain that job, particularly in Germany.

For Japan and the US, $\left(\delta_{c s s}, \delta_{n s u}\right)$ were not identified by the variation in the PIAAC data. That is, at the baseline parameter estimates, variations in these parameters did not impact the moments. ${ }^{35}$ For the baseline moments and parameter estimates, as well as the analysis that follows, the lack of identification is remedied in two distinct ways.

In Japan, we set $\left(\delta_{c s s}=1, \delta_{n s u}=0\right)$ so that workers who do not train do not lose their position in a skilled job. This can be viewed as extreme job protection of workers in skilled jobs, a characteristic of labor markets in Japan. In this way, there is no additional randomization in job assignment. To be clear, the setting of these two parameters is inconsequential for the analysis of Japan except for the dynamics of employment flows studied in section 6.2.4.

For the US, we turned to the NLSY97, a panel data set, to study the skill assignment over time of workers conditional on training. Following the procedures presented in Appendix sub-section 9.3, these flows were calculated as $\delta_{c s s}=0.423, \delta_{n s u}=0.576$. The model was re-estimated given these flows.

The next experiments study the sources of education mismatch. By eliminating one shock at a time, the results provide some intuition on identification. Here we find one of our main results: the taste shock is critical for generating education mismatch and thus matching data moments.

The panel labeled "No Taste Shock" shows the re-estimated model with the restriction that $\bar{\varepsilon}==0$, thus eliminating taste shocks. Clearly the fit of the model deteriorates for all countries, most noticeably in Italy. Note that in this case, the model produces mismatch as a consequence of noisy test scores: the $\sigma_{e}$. This is seen in the parameter estimates, Table 15, where the noise in the education test score is much higher than the baseline for all the countries, particularly Japan and the US. Further the estimated noise in the job test increases as well, particularly for Italy. From this experiment, there is a tradeoff between noise in the tests and taste shocks. The baseline results indicate that the presence of the taste shocks is more effective in matching moments.

The fit worsens largely because of the model's inability to match the flows between education and job mismatch. For example, in Japan, the undermatch rate in education is $7.5 \%$ but none of these individuals are undermatched in the job. This occurs because the education and job mismatch are largely driven by uncorrelated noise in the test scores. Eliminating the taste shock improves the fit of the Mincer regression, particularly the education regressor since, in the absence of taste shocks, education is more closely correlated with ability. The coefficient on the test score is relatively low reflecting the added noise in the education test.

The importance of the taste shock is further reinforced by the case which eliminates noise in the education score, denoted "No Noise in Ed Test". The fit of the model does deteriorate without the noise, but not by very much. Interestingly, the job mismatch flows do not collapse to zero without noise in the education score indicating that the job mismatch is driven by both the education mismatch and the assignment of workers to jobs by skill. From Table 15, eliminating the noise in the education test has a small positive effect on the estimated variability of taste shocks.

\footnotetext{
${ }^{35}$ At the baseline estimates, individuals without a college degree in Japan and in unskilled jobs do not train, regardless of the size of $\delta_{n s u}$.
} 


\begin{tabular}{|c|c|c|c|c|c|c|c|c|c|c|c|c|c|c|c|c|c|c|c|}
\hline & \multicolumn{5}{|c|}{ Education } & \multicolumn{5}{|c|}{ Mincer Reg. } & \multicolumn{4}{|c|}{ Ed $\rightarrow$ Early Job } & \multirow{2}{*}{$\begin{array}{c}\text { Emp. } \\
\text { ue }\end{array}$} & \multirow{2}{*}{$\begin{array}{c}\text { Mismatch } \\
\text { oe }\end{array}$} & \multicolumn{2}{|c|}{ Training } & \multirow[b]{2}{*}{ fit } \\
\hline & ed & un & ov & $\alpha_{0}$ & $\alpha_{1}$ & test & ed & late & ed un & ed ov & uu & uo & ou & oo & & & unsk & sk & \\
\hline & \multicolumn{19}{|c|}{ Data } \\
\hline Germ. & 0.366 & 0.092 & 0.061 & -0.883 & 1.274 & 0.149 & 0.237 & 0.173 & -0.001 & -0.034 & 0.377 & 0.000 & 0.000 & 0.250 & 0.101 & 0.038 & 0.386 & 0.643 & na \\
\hline It. & 0.184 & 0.157 & 0.065 & -1.972 & 1.015 & 0.092 & 0.276 & 0.226 & 0.018 & -0.053 & 0.446 & 0.000 & 0.000 & 0.571 & 0.165 & 0.086 & 0.195 & 0.364 & na \\
\hline Jap. & 0.583 & 0.071 & 0.116 & 0.137 & 0.915 & 0.137 & 0.120 & 0.270 & -0.070 & -0.005 & 0.609 & 0.000 & 0.000 & 0.255 & 0.134 & 0.085 & 0.380 & 0.685 & na \\
\hline \multirow[t]{2}{*}{ US. } & 0.447 & 0.065 & 0.040 & -0.465 & 1.437 & 0.159 & 0.243 & 0.179 & 0.099 & -0.022 & 0.472 & 0.000 & 0.000 & 0.364 & 0.091 & 0.075 & 0.436 & 0.682 & na \\
\hline & & \multicolumn{18}{|c|}{ Baseline } \\
\hline Ger. & 0.313 & 0.095 & 0.069 & -0.871 & 1.280 & 0.097 & 0.176 & 0.173 & -0.067 & 0.001 & 0.393 & 0.004 & 0.008 & 0.200 & 0.138 & 0.150 & 0.408 & 0.645 & 0.032 \\
\hline It. & 0.150 & 0.141 & 0.040 & -1.940 & 1.024 & 0.118 & 0.120 & 0.167 & -0.039 & -0.047 & 0.549 & 0.000 & 0.000 & 0.303 & 0.171 & 0.161 & 0.267 & 0.284 & 0.135 \\
\hline Jap. & 0.512 & 0.080 & 0.141 & 0.115 & 0.928 & 0.070 & 0.234 & 0.321 & -0.089 & 0.000 & 0.611 & 0.000 & 0.000 & 0.232 & 0.168 & 0.155 & 0.387 & 0.807 & 0.048 \\
\hline \multirow[t]{2}{*}{ US } & 0.379 & 0.080 & 0.055 & -0.458 & 1.439 & 0.071 & 0.276 & 0.187 & -0.037 & -0.023 & 0.494 & 0.000 & 0.000 & 0.330 & 0.140 & 0.155 & 0.443 & 0.707 & 0.044 \\
\hline & \multicolumn{19}{|c|}{ No Taste Shock } \\
\hline Ger. & 0.329 & 0.089 & 0.060 & -0.873 & 1.273 & 0.055 & 0.291 & 0.206 & -0.089 & 0.013 & 0.131 & 0.048 & 0.047 & 0.138 & 0.175 & 0.168 & 0.340 & 0.680 & 0.128 \\
\hline It. & 0.154 & 0.149 & 0.052 & -2.010 & 1.009 & 0.021 & 0.346 & 0.252 & -0.032 & -0.027 & 0.133 & 0.036 & 0.132 & 0.000 & 0.161 & 0.137 & 0.066 & 0.426 & 0.482 \\
\hline Jap. & 0.524 & 0.075 & 0.107 & 0.130 & 0.931 & 0.023 & 0.280 & 0.344 & -0.039 & 0.012 & 0.000 & 0.044 & 0.051 & 0.000 & 0.151 & 0.078 & 0.399 & 0.813 & 0.507 \\
\hline US & 0.405 & 0.060 & 0.060 & -0.451 & 1.441 & 0.036 & 0.316 & 0.241 & -0.054 & 0.015 & 0.044 & 0.061 & 0.059 & 0.063 & 0.110 & 0.121 & 0.185 & 0.690 & 0.398 \\
\hline \multicolumn{20}{|c|}{ No Noise In Ed Test } \\
\hline Ger. & 0.305 & 0.102 & 0.038 & -0.875 & 1.281 & 0.096 & 0.151 & 0.160 & -0.058 & -0.026 & 0.387 & 0.000 & 0.001 & 0.255 & 0.156 & 0.163 & 0.413 & 0.645 & 0.038 \\
\hline It. & 0.149 & 0.140 & 0.039 & -1.944 & 1.029 & 0.117 & 0.119 & 0.171 & -0.038 & -0.049 & 0.570 & 0.000 & 0.000 & 0.301 & 0.170 & 0.161 & 0.268 & 0.290 & 0.139 \\
\hline Jap. & 0.510 & 0.088 & 0.138 & 0.115 & 0.928 & 0.065 & 0.232 & 0.321 & -0.084 & -0.019 & 0.619 & 0.000 & 0.000 & 0.234 & 0.173 & 0.172 & 0.385 & 0.805 & 0.052 \\
\hline US & 0.377 & 0.078 & 0.056 & -0.465 & 1.443 & 0.072 & 0.275 & 0.187 & -0.037 & -0.023 & 0.501 & 0.000 & 0.000 & 0.329 & 0.139 & 0.154 & 0.447 & 0.677 & 0.043 \\
\hline \multicolumn{20}{|c|}{ Capital Market Imperfections } \\
\hline Ger. & 0.313 & 0.094 & 0.069 & -0.874 & 1.281 & 0.097 & 0.178 & 0.172 & -0.069 & 0.001 & 0.385 & 0.005 & 0.009 & 0.198 & 0.137 & 0.150 & 0.403 & 0.645 & 0.032 \\
\hline It. & 0.150 & 0.141 & 0.040 & -1.940 & 1.024 & 0.118 & 0.120 & 0.167 & -0.039 & -0.047 & 0.549 & 0.000 & 0.000 & 0.303 & 0.171 & 0.161 & 0.267 & 0.284 & 0.135 \\
\hline Jap. & 0.512 & 0.080 & 0.141 & 0.114 & 0.925 & 0.070 & 0.234 & 0.322 & -0.089 & -0.000 & 0.616 & 0.000 & 0.000 & 0.234 & 0.168 & 0.155 & 0.386 & 0.807 & 0.048 \\
\hline US & 0.378 & 0.079 & 0.055 & -0.463 & 1.443 & 0.072 & 0.276 & 0.187 & -0.038 & -0.023 & 0.499 & 0.000 & 0.000 & 0.333 & 0.140 & 0.154 & 0.445 & 0.701 & 0.043 \\
\hline \multicolumn{20}{|c|}{ Formal Training } \\
\hline Ger. & 0.313 & 0.093 & 0.073 & -0.871 & 1.279 & 0.086 & 0.153 & 0.161 & -0.090 & 0.014 & 0.384 & 0.006 & 0.009 & 0.212 & 0.138 & 0.151 & 0.158 & 0.181 & 0.041 \\
\hline It. & 0.148 & 0.142 & 0.046 & -1.952 & 0.996 & 0.117 & 0.114 & 0.150 & -0.052 & -0.043 & 0.570 & 0.000 & 0.000 & 0.323 & 0.171 & 0.164 & 0.165 & 0.219 & 0.150 \\
\hline Jap. & 0.503 & 0.082 & 0.140 & 0.080 & 0.934 & 0.065 & 0.192 & 0.301 & -0.071 & -0.004 & 0.627 & 0.000 & 0.000 & 0.232 & 0.168 & 0.157 & 0.379 & 0.046 & 0.152 \\
\hline US & 0.367 & 0.073 & 0.067 & -0.529 & 1.453 & 0.053 & 0.257 & 0.209 & -0.054 & -0.016 & 0.495 & 0.000 & 0.000 & 0.334 & 0.137 & 0.155 & 0.178 & 0.655 & 0.259 \\
\hline
\end{tabular}

Note: This table reports data and simulated moments for the estimated models. See Table 13 for a full list of variables.

Table 14: Moments

\section{$5 \quad$ Extensions and Robustness}

This section explores the robustness of our results. Throughout the focus is on the sensitivity of our main findings regarding the role of taste shocks rather than noisy test scores as the source of education mismatch. Some of these extensions are continued in our study of the implications of the estimated models for explaining education mismatch and subsequent labor market outcomes.

There are three main findings. First, there is no evidence of capital market frictions. Second, the extension of the model to include imperfect information about ability leads to a better fit for Germany, though not for other countries. This is of interest since among the countries Germany is known for its early tracking system, consistent with the findings reported below. Third, while parental education contributes to mismatch, it does not seem to operate through the taste for education.

There are additional robustness exercises presented in Appendix 9.2. These relate to alternative measures of mismatch and the use of formal rather than non-formal training.

\subsection{Imperfect Capital Markets}

The estimation was extended to include two models with borrowing constraints. In the first case, all agents are subject to an upper bound, bbar, on the amount they can borrow during the education phase. If this constraint binds, then, due to the assumed concavity of utility, the cost of education is increased and undermatch can occur. The economic significance of this constraint depends on the outside resources of young agents. For this case, the estimation includes a parameter for the maximal level of borrowing during the education phase.

In the second case, a fraction of agents, $n b p$, are unable to borrow at all, while the remainder face no 


\begin{tabular}{|c|c|c|c|c|c|c|c|c|c|c|c|c|}
\hline & $\phi$ & $\bar{\varepsilon}$ & $\sigma_{e}$ & $h(1)$ & $\omega_{2}$ & $\sigma_{j}$ & $\zeta(0)$ & $\zeta(1)$ & $p^{t}$ & $\bar{e}^{t}$ & $\delta_{c s s}$ & $\delta_{n s u}$ \\
\hline & \multicolumn{12}{|c|}{ Baseline } \\
\hline Ger. & 6.392 & 2.517 & 0.101 & 1.246 & 1.000 & 0.496 & 1.031 & 0.937 & na & 0.219 & 0.156 & 0.994 \\
\hline It. & 4.511 & 4.951 & 0.017 & 1.127 & 1.110 & 0.825 & 0.834 & 0.772 & na & 0.137 & 0.001 & 0.315 \\
\hline Jap. & 8.968 & 5.793 & 0.050 & 1.352 & 1.004 & 0.003 & $0.693^{*}$ & 1.165 & na & 0.210 & 0.993 & 0.992 \\
\hline \multirow[t]{2}{*}{ US } & 10.682 & 2.457 & 0.004 & 1.132 & 1.000 & 0.236 & 0.974 & 1.351 & na & 0.059 & 0.423 & 0.576 \\
\hline & \multicolumn{12}{|c|}{ No Taste Shock } \\
\hline Ger. & 6.056 & na & 0.288 & 1.236 & 1.030 & 2.990 & 1.034 & 0.975 & na & 0.232 & 0.143 & 1.000 \\
\hline It. & 6.135 & na & 0.498 & 1.151 & 1.274 & 1.092 & 0.767 & 0.832 & na & 0.071 & 0.044 & 0.238 \\
\hline Jap. & 14.313 & na & 0.113 & 1.441 & 1.015 & 0.000 & 0.794 & 1.147 & na & 0.210 & 0.986 & 0.686 \\
\hline \multirow[t]{2}{*}{ US } & 11.630 & na & 0.106 & 1.147 & 1.028 & 0.317 & 0.940 & 1.387 & na & 0.121 & 0.423 & 0.576 \\
\hline & \multicolumn{12}{|c|}{ No Noise in Ed Test } \\
\hline Ger. & 7.235 & 2.665 & na & 1.248 & 1.004 & 0.694 & 1.029 & 0.932 & na & 0.199 & 0.149 & 0.999 \\
\hline It. & 4.590 & 4.935 & na & 1.126 & 1.118 & 0.727 & 0.834 & 0.773 & na & 0.129 & 0.000 & 0.323 \\
\hline Jap. & 10.130 & 5.995 & na & 1.374 & 1.000 & 0.189 & 0.817 & 1.164 & na & 0.220 & 0.950 & 0.991 \\
\hline \multirow[t]{2}{*}{ US } & 10.632 & 2.459 & na & 1.132 & 1.001 & 0.229 & 0.975 & 1.351 & na & 0.059 & 0.423 & 0.576 \\
\hline & \multicolumn{12}{|c|}{ Capital Market Imperfections } \\
\hline Ger. & 6.371 & 2.498 & 0.105 & 1.246 & 1.000 & 0.499 & 1.030 & 0.937 & na & 0.220 & 0.156 & 0.996 \\
\hline It. & 4.511 & 4.951 & 0.017 & 1.127 & 1.110 & 0.825 & 0.834 & 0.772 & na & 0.137 & 0.001 & 0.315 \\
\hline Jap. & 9.037 & 5.787 & 0.049 & 1.357 & 1.004 & 0.003 & 0.692 & 1.162 & na & 0.212 & 0.992 & 0.993 \\
\hline \multirow[t]{2}{*}{ US } & 10.657 & 2.454 & 0.004 & 1.132 & 1.000 & 0.231 & 0.975 & 1.351 & na & 0.059 & 0.423 & 0.576 \\
\hline & \multicolumn{12}{|c|}{ Formal Training } \\
\hline Ger. & 6.184 & 2.552 & 0.110 & 1.207 & 1.147 & 0.555 & 0.967 & 0.914 & 1.960 & 0.276 & 0.269 & 0.994 \\
\hline It. & 4.572 & 4.969 & 0.010 & 1.128 & 1.119 & 0.725 & 0.824 & 0.772 & 1.823 & 0.147 & 0.003 & 0.338 \\
\hline Jap. & 8.293 & 5.673 & 0.052 & 1.535 & 1.000 & 0.027 & 0.899 & 1.102 & 0.448 & 0.446 & 0.606 & 0.017 \\
\hline US & 14.275 & 2.494 & 0.003 & 1.144 & 1.024 & 0.162 & 0.934 & 1.380 & 0.426 & 0.107 & 0.423 & 0.576 \\
\hline
\end{tabular}

Note: This table reports parameter estimates for the baseline models.

Table 15: Parameter Estimates

constraint. In a more general setting, the probability of borrowing might depend on a range of individual characteristics, including parental education, income and wealth. But those covariates are not available in the PIAAC data.

The identification of capital market imperfects comes largely from its asymmetric effects on mismatch. In particular, a binding borrowing constraint can produce undermatch in education but not overmatch. This differs from the symmetric, by assumption, effects of tastes shocks.

Tables 14 and 15 show the estimation and moments for the case with $n b p$ allowed to be larger than zero. There was no evidence of either form of borrowing constraint. Though out of pocket tuition is thought to be relatively low in these countries, there remains an opportunity cost of college through foregone income during the education phase. Thus, in principle, borrowing constraints might have mattered. They did not.

\subsection{Imperfect Information}

This section explores a variant of the model which introduces imperfect information at the stage of the education choice. ${ }^{36}$ In the baseline model, individuals make education choices based on observed ability. In this extension, individuals choose college having only a signal of their ability: $s_{i}=\theta_{i}+\sigma_{e d} \eta_{i} .{ }^{37}$ In this

\footnotetext{
${ }^{36}$ This extension as well as the reverse causality case builds on Cooper and Liu (2019).

${ }^{37}$ Here $\eta^{i}$ is a mean zero, uniform random variable in the $[-0.5,0.5]$ interval.
} 


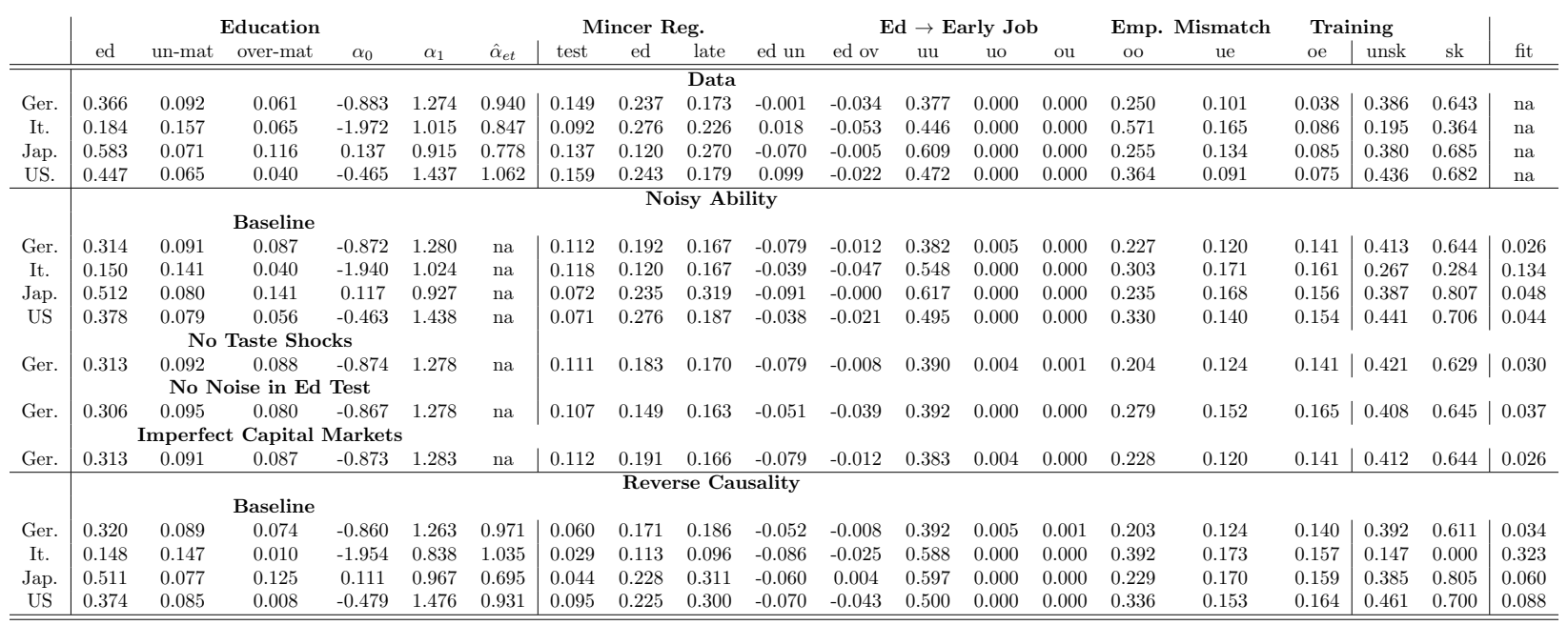

Note: This table reports data and simulated moments for the estimated models. See Table 13 for a full list of variables.

Table 16: Moments: Imperfect Information and Reverse Causality

specification, the parameter $\sigma_{e d}$ controls the impact of the noise, $\eta_{i}$ on the agent's perceived ability, $s_{i}$.

To be clear, the signal is only used for the education choice: compensation and training decisions are made using actual ability. So this specification introduces an information friction at the time of the education decision to produce mismatch but then removes the friction at the time of training. Depending on selection, training may overcome the education mismatch.

The panel labeled "Noisy Ability" in Tables 16 and 17 report the parameter estimates and moments for this case. The moments to be matched are the same as in the baseline with $\sigma_{e d}$ as an additional parameter.

Comparing Table 16 with Table 14, the fit of the model with imperfect information is better for Germany, but not for the other countries. From Table 17, the estimated noise in Germany is 0.506 which means that individuals are very uncertain about their ability, much more than the noise created from the education test score alone. Further, compared to the baseline, the variability in the taste shock, a competing source of mismatch, is lower. There is also a large reduction in the estimate of $\sigma_{j}$ relative to the baseline. This uncertainty in ability is either zero or close to zero in the other countries.

Further, from Table 16 this good fit remains after eliminating the taste shocks and/or the noise in the test score. As before, there is no evidence of the effects of imperfect capital markets. Evidently, imperfect information about ability is key to understanding mismatch and its labor market implications in Germany.

It is interesting that the imperfect information matters in Germany. As discussed in Dustmann, Puhani, and Schönberg (2017) and Brunello and Checchi (2007), among other studies, Germany has more earlier tracking compared to other countries such as the US and Italy. Early tracking is a natural sources of imperfect information about ability.

\subsection{Reverse Causality: Dependence of Test Score on Education}

The test score has been assumed to reflect the ability of the individual agent but not education. This assumption is easy to question in the PIAAC data as the test is taken after educational achievement. To the extent that the test score reflects some of the effects of schooling, there is the potential for reverse causality.

Our choice of the numeracy score as indicative of ability was made with this concern in mind. This 


\begin{tabular}{|c|c|c|c|c|c|c|c|c|c|c|c|c|c|}
\hline \multirow[t]{3}{*}{ c } & $\phi$ & $\bar{\varepsilon}$ & $\sigma_{e}$ & $h(1)$ & $\omega_{2}$ & $\sigma_{j}$ & $\zeta(0)$ & $\zeta(1)$ & $\bar{e}^{t}$ & $\delta_{c s s}$ & $\delta_{n s u}$ & $\sigma_{e d}$ & $\alpha_{e d}$ \\
\hline & \multicolumn{13}{|c|}{ Noisy Ability } \\
\hline & \multicolumn{13}{|c|}{ Baseline } \\
\hline Ger. & 5.485 & 1.923 & 0.147 & 1.242 & 1.050 & 0.002 & 0.978 & 0.871 & 0.174 & 0.030 & 0.995 & 0.506 & na \\
\hline It. & 4.512 & 4.951 & 0.017 & 1.127 & 1.110 & 0.826 & 0.834 & 0.772 & 0.137 & 0.002 & 0.314 & 0.000 & na \\
\hline Jap. & 8.819 & 5.944 & 0.050 & 1.353 & 1.000 & 0.000 & 0.688 & 1.165 & 0.211 & 0.884 & 1.000 & 0.013 & na \\
\hline \multirow[t]{2}{*}{ US. } & 10.708 & 2.449 & 0.007 & 1.131 & 1.000 & 0.235 & 0.975 & 1.352 & 0.060 & 0.432 & 0.576 & 0.001 & na \\
\hline & \multicolumn{13}{|c|}{ No Taste Shocks } \\
\hline Ger. & $\begin{array}{c}5.548 \\
\text { No I }\end{array}$ & $\begin{array}{c}\text { na } \\
\text { oise ir }\end{array}$ & $\begin{array}{l}0.143 \\
\text { t Score }\end{array}$ & 1.241 & 1.041 & 0.086 & 0.991 & 0.875 & 0.188 & 0.042 & 1.000 & 0.821 & na \\
\hline \multirow[t]{2}{*}{ Ger. } & 6.659 & 2.351 & na & 1.216 & 1.071 & 0.706 & 0.968 & 0.895 & 0.139 & 0.052 & 0.923 & 0.468 & na \\
\hline & \multicolumn{13}{|c|}{ Imperfect Capital Markets } \\
\hline \multirow[t]{3}{*}{ Ger. } & 5.492 & 1.927 & 0.146 & 1.242 & 1.049 & 0.002 & 0.978 & 0.871 & 0.174 & 0.028 & 1.000 & 0.503 & na \\
\hline & \multicolumn{13}{|c|}{ Reverse Causality } \\
\hline & \multicolumn{13}{|c|}{ Baseline } \\
\hline Ger. & 10.186 & 1.434 & 0.069 & 1.223 & 1.031 & 0.118 & 1.043 & 1.021 & 0.180 & 0.343 & 0.120 & 0.137 & 0.003 \\
\hline It. & 15.758 & 3.309 & 0.003 & 1.171 & 1.007 & 0.166 & 1.127 & 1.091 & 0.397 & 0.893 & 0.265 & 0.001 & 0.000 \\
\hline Jap. & 14.108 & 0.516 & 0.036 & 1.553 & 1.001 & 0.002 & 0.617 & 1.038 & 0.253 & 0.028 & 2.998 & 0.389 & 0.008 \\
\hline US & 7.957 & 3.890 & 0.001 & 1.201 & 1.000 & 0.437 & 1.053 & 1.287 & 0.213 & 0.432 & 0.576 & 0.012 & 0.030 \\
\hline
\end{tabular}

Table 17: Parameter Estimates: Imperfect Information and Reverse Causality

extension of the model goes further and allows the test score to depend on education. In particular, for the model assume the education test score is given by,

$$
t s_{i}=\theta_{i}+\alpha_{e d} e_{i}+\sigma_{e d} \zeta^{i e}
$$

Here $\alpha_{e d}$ parameterizes the dependence of the test score on education. As in the baseline model, the test score does not impact the education decision. But, building on the previous section, the education decision is made using a noisy signal of ability. Among other things, this guarantees that education and ability are not perfectly correlated. ${ }^{38}$ The parameter $\alpha_{e d}$ is included in the set of structural parameters for this case.

It is not possible to create a data counterpart to (6) since ability is not observed. Thus to obtain some measure of the correlation between the test score and education, (7) is run on the PIAAC data and the coefficient $\hat{\alpha}_{e t}$, estimated by OLS, is used as an additional moment.

$$
t s_{i}=\hat{\alpha}_{e t} e_{i}+\zeta^{i e} \text {. }
$$

To be clear, there is no reason to believe that $\alpha_{e d}=\hat{\alpha}_{e t}$, as the latter is obtained from a regression without ability as a regressor, so that there is omitted variable bias by construction. The argument here is that by including $\hat{\alpha}_{e t}$ as a moment, it will be informative about the structural parameter $\alpha_{e d}$.

The panel labeled "Reverse Causality" in Tables 16 and 17 report the parameter estimates and moments for this case. Note that here $\alpha_{e d}$ is in the set of parameters and $\hat{\alpha}_{e t}$ is an additional moment.

Looking first at the moments, the estimates of $\hat{\alpha}_{e t}$ range from around 0.78 to 1.06 , indicating the positive correlation between education and test score. Of course this is not causal since education depends on ability which is not observed. For the "Reverse Causality" block, this moment is obtained by an OLS regression on the simulated data to obtain the model produced counterpart of $\hat{\alpha}_{e t}$. In this manner, the omitted variable bias is present in the regression from simulated data as well.

The structural estimate, $\alpha_{e d}$ indicates the estimated impact of education on the test score. As indicated

\footnotetext{
${ }^{38}$ This could otherwise occur, for example, if there are no taste shocks.
} 
in Table 17, these estimates are near zero for all of the countries.

As in the baseline results, the mismatch seems to be driven largely by taste shocks: eliminating them reduces the fit considerably. And, once again, borrowing constraints have negligible impact. ${ }^{39}$

\subsection{Job Flows}

\begin{tabular}{|c|c|c|c|c|c|c|c|c|c|c|c|c|c|c|c|c|c|c|c|}
\hline & \multicolumn{5}{|c|}{ Education } & \multicolumn{5}{|c|}{ Mincer Reg. } & \multicolumn{4}{|c|}{ Ed $\rightarrow$ Early Job } & \multirow{2}{*}{$\begin{array}{c}\text { Emp. } \\
\text { ue }\end{array}$} & \multirow{2}{*}{$\begin{array}{c}\text { Mismatch } \\
\text { oe }\end{array}$} & \multicolumn{2}{|c|}{ Training } & \multirow[b]{2}{*}{ fit } \\
\hline & ed & un-mat & over-mat & $\alpha_{0}$ & $\alpha_{1}$ & test & ed & late & ed un & ed ov & uu & uo & ou & oo & & & unsk & sk & \\
\hline & & & & & & & & & Data & & & & & & & & & & \\
\hline Germ. & 0.366 & 0.092 & 0.061 & -0.883 & 1.274 & 0.149 & 0.237 & 0.173 & -0.001 & -0.034 & 0.377 & 0.000 & 0.000 & 0.250 & 0.101 & 0.038 & 0.386 & 0.643 & na \\
\hline It. & 0.184 & 0.157 & 0.065 & -1.972 & 1.015 & 0.092 & 0.276 & 0.226 & 0.018 & -0.053 & 0.446 & 0.000 & 0.000 & 0.571 & 0.165 & 0.086 & 0.195 & 0.364 & na \\
\hline Jap. & 0.583 & 0.071 & 0.116 & 0.137 & 0.915 & 0.137 & 0.120 & 0.270 & -0.070 & -0.005 & 0.609 & 0.000 & 0.000 & 0.255 & 0.134 & 0.085 & 0.380 & 0.685 & na \\
\hline US. & 0.447 & 0.065 & 0.040 & -0.465 & 1.437 & 0.159 & 0.243 & 0.179 & 0.099 & -0.022 & 0.472 & 0.000 & 0.000 & 0.364 & 0.091 & 0.075 & 0.436 & 0.682 & na \\
\hline \multicolumn{20}{|c|}{ Baseline } \\
\hline Ger. & 0.313 & 0.095 & 0.069 & -0.871 & 1.280 & 0.097 & 0.176 & 0.173 & -0.067 & 0.001 & 0.393 & 0.004 & 0.008 & 0.200 & 0.138 & 0.150 & 0.408 & 0.645 & 0.032 \\
\hline It. & 0.150 & 0.141 & 0.040 & -1.940 & 1.024 & 0.118 & 0.120 & 0.167 & -0.039 & -0.047 & 0.549 & 0.000 & 0.000 & 0.303 & 0.171 & 0.161 & 0.267 & 0.284 & 0.135 \\
\hline Jap. & 0.512 & 0.080 & 0.141 & 0.115 & 0.928 & 0.070 & 0.234 & 0.321 & -0.089 & 0.000 & 0.611 & 0.000 & 0.000 & 0.232 & 0.168 & 0.155 & 0.387 & 0.807 & 0.048 \\
\hline \multicolumn{19}{|c|}{$\delta_{c s}=1, \delta_{n s}=0$} & 0.044 \\
\hline Ger. & .314 & 0.090 & 0.082 & -0.880 & 1.277 & 0.098 & 0.232 & 0.164 & -0.107 & 0.012 & 0.380 & 0.000 & 0.000 & 0.241 & 0.090 & 0.084 & 0.399 & 0.651 & 0.022 \\
\hline It. & 0.149 & 0.150 & 0.015 & -1.942 & 0.982 & 0.113 & 0.140 & 0.151 & -0.088 & -0.043 & 0.587 & 0.000 & 0.000 & 0.356 & 0.157 & 0.081 & 0.261 & 0.417 & 0.116 \\
\hline Jap. & 0.509 & 0.081 & 0.142 & 0.088 & 0.872 & 0.074 & 0.287 & 0.168 & -0.106 & 0.032 & 0.566 & 0.000 & 0.000 & 0.391 & 0.073 & 0.137 & 0.000 & 0.727 & 0.228 \\
\hline US. & \multicolumn{19}{|c|}{$\delta_{c s s}=1, \delta_{n u s}=0$} \\
\hline Ger. & 0.312 & 0.096 & 0.072 & -0.874 & 1.286 & 0.115 & 0.204 & 0.150 & -0.064 & -0.000 & 0.395 & 0.006 & 0.008 & 0.188 & 0.135 & 0.148 & 0.405 & 0.000 & 0.442 \\
\hline It. & 0.150 & 0.143 & 0.001 & -1.948 & 1.011 & 0.096 & 0.147 & 0.187 & -0.063 & -0.073 & 0.584 & 0.000 & 0.000 & 0.421 & 0.169 & 0.151 & 0.254 & 0.000 & 0.213 \\
\hline Jap. & 0.511 & 0.080 & 0.142 & 0.114 & 0.926 & 0.074 & 0.235 & 0.322 & -0.085 & 0.000 & 0.618 & 0.000 & 0.000 & 0.235 & 0.168 & 0.156 & 0.386 & 0.806 & 0.048 \\
\hline US. & 0.378 & 0.079 & 0.057 & -0.462 & 1.435 & 0.074 & 0.275 & 0.192 & -0.033 & -0.021 & 0.495 & 0.000 & 0.000 & 0.329 & 0.140 & 0.155 & 0.438 & 0.666 & 0.042 \\
\hline
\end{tabular}

Note: This table reports data and simulated moments for the estimated models with alternative job flows.

Table 18: Moments: Alternative Flows

The baseline model put some restrictions on job flows. First, from Table 8, the estimation imposed the flows from education into skilled and unskilled early jobs in a data consistent manner. Second, the estimated parameters $\delta_{c s s}$ and $\delta_{n s u}$ determine the probability of flows to job types in late employment by education if there was no training.

In this sub-section we study two cases, re-estimating the model with alternatives restrictions. For the first, we set $\delta_{c s}=1$ and $\delta_{n s}=0$ so that an individual is assigned to a skilled job iff they went to college. Thus there is no initial job randomization. In the second case, we impose $\delta_{c s s}=1$ and $\delta_{n s u}=0$ so that the only gain from training is through human capital accumulation, not job retention.

From Table 18, imposing $\delta_{c s}=1$ and $\delta_{n s}=0$ leads to an improvement in fit for Germany and Italy but a deterioration for Japan and the US. This is perhaps not so surprising for Japan since in the data $\delta_{c s}=0.471$, much lower than the other countries. This stochastic job assignment was creating some early job mismatch that is removed when $\delta_{c s}=1$. From the parameter estimates in Table 19, for Japan, this restriction leads to a large increase in the noise of the job test score. For the US, the training rate for skilled workers climbs to $100 \%$, far over the data moment. As with Germany and Italy, the "ue,oe" flows are much closer to the data than the baseline. This is not an improvement over the baseline estimates since the estimation takes $\delta_{c s}$ and $\delta_{n s}$ from the data.

For the second case of $\delta_{c s s}=1$ and $\delta_{n s u}=0$, the fit deteriorated in Germany and Italy. In Germany and Italy, once the incentive to train brought about by job loss is removed, the training rates of skilled workers go to zero. Interestingly, the return to training by low education workers is higher compared to the baseline, particularly in Italy, in order to maintain incentives. But this supports training by unskilled workers.

\footnotetext{
${ }^{39}$ As this alternative model does not dominate the baseline, these other experiments are not reported in the table.
} 
For the US, the fit did not change. For Japan, the baseline estimation already set $\delta_{c s s}=1$ and $\delta_{n s u}=0$. This is again indicative of the lack of identification of these two parameters for these countries.

\begin{tabular}{|c|c|c|c|c|c|c|c|c|c|c|c|}
\hline & $\phi$ & $\bar{\varepsilon}$ & $\sigma_{e}$ & $h(1)$ & $\omega_{2}$ & $\sigma_{j}$ & $\zeta(0)$ & $\zeta(1)$ & $\bar{e}^{t}$ & $\delta_{c s s}$ & $\delta_{n s u}$ \\
\hline & \multicolumn{11}{|c|}{ Baseline } \\
\hline Ger. & 6.392 & 2.517 & 0.101 & 1.246 & 1.000 & 0.496 & 1.031 & 0.937 & 0.219 & 0.156 & 0.994 \\
\hline It. & 4.511 & 4.951 & 0.017 & 1.127 & 1.110 & 0.825 & 0.834 & 0.772 & 0.137 & 0.001 & 0.315 \\
\hline Jap. & 8.968 & 5.793 & 0.050 & 1.352 & 1.004 & 0.003 & 0.693 & 1.165 & 0.210 & 0.993 & 0.992 \\
\hline US. & 10.682 & 2.457 & 0.004 & 1.132 & $\begin{array}{r}1.000 \\
\delta_{c s}\end{array}$ & $\begin{array}{l}0.236 \\
1, \delta_{n s}\end{array}$ & $\begin{aligned} & 0.974 \\
= & 0\end{aligned}$ & 1.351 & 0.059 & 0.432 & 0.576 \\
\hline Ger. & 6.199 & 2.025 & 0.134 & 1.243 & 1.004 & 0.488 & 1.070 & 0.898 & 0.257 & 0.118 & 0.995 \\
\hline It. & 4.972 & 4.720 & 0.030 & 1.068 & 1.085 & 0.919 & 0.884 & 0.755 & 0.168 & 0.001 & 0.328 \\
\hline Jap. & 10.109 & 5.898 & 0.056 & 1.299 & 1.000 & 0.112 & 0.691 & 1.177 & 0.254 & 0.978 & 0.998 \\
\hline US. & 10.704 & 2.669 & 0.029 & 1.116 & $\begin{array}{r}1.000 \\
\delta_{c s s}\end{array}$ & $\begin{array}{l}0.334 \\
=1, \delta_{n s \imath}\end{array}$ & $\begin{array}{l}0.985 \\
=0\end{array}$ & 1.331 & 0.047 & 0.725 & 0.010 \\
\hline Ger. & 5.407 & 2.661 & 0.135 & 1.107 & 1.000 & 0.519 & 1.040 & 0.949 & 0.257 & 1 & 0 \\
\hline It. & 5.282 & 4.271 & 0.020 & 1.038 & 1.052 & 0.578 & 0.969 & 0.804 & 0.300 & 1 & 0 \\
\hline Jap. & 8.556 & 5.737 & 0.052 & 1.353 & 1.000 & 0.000 & 0.680 & 1.167 & 0.208 & 1 & 0 \\
\hline US. & 10.345 & 2.402 & 0.008 & 1.135 & 1.001 & 0.240 & 0.973 & 1.352 & 0.062 & 1 & 0 \\
\hline
\end{tabular}

Table 19: Parameter Estimates: Alternative Flows

\subsection{Taste Shocks: the Role of Parental Influence}

\begin{tabular}{|c|c|c|c|c|c|c|}
\hline & \multicolumn{3}{|c|}{ Education Outcome (all) } & \multicolumn{3}{|c|}{ Job Outcome (early) } \\
\hline & Undermatch & Well-match & Overmatch & Undermatch & Well-match & Overmatch \\
\hline \multicolumn{7}{|l|}{ GERMANY } \\
\hline No parents with tertiary & $6.11 \%$ & $91.78 \%$ & $2.11 \%$ & $3.49 \%$ & $94.34 \%$ & $2.18 \%$ \\
\hline \multicolumn{6}{|l|}{ ITALY } & $0.31 \%$ \\
\hline No parents with tertiary & $12.97 \%$ & $86.04 \%$ & $0.98 \%$ & $11.16 \%$ & $86.06 \%$ & $2.79 \%$ \\
\hline \multicolumn{6}{|l|}{ JAPAN } & $0.00 \%$ \\
\hline No parents with tertiary & $3.18 \%$ & $90.84 \%$ & $5.98 \%$ & $6.06 \%$ & $90.36 \%$ & $3.58 \%$ \\
\hline $\begin{array}{l}\text { At least one with tertiary } \\
\text { US }\end{array}$ & $2.32 \%$ & $89.01 \%$ & $8.67 \%$ & $11.02 \%$ & $86.72 \%$ & $2.26 \%$ \\
\hline No parents with tertiary & $3.39 \%$ & $94.85 \%$ & $1.76 \%$ & $3.20 \%$ & $91.99 \%$ & $4.81 \%$ \\
\hline At least one with tertiary & $4.04 \%$ & $94.04 \%$ & $1.92 \%$ & $6.18 \%$ & $91.45 \%$ & $2.38 \%$ \\
\hline \multicolumn{7}{|l|}{ Pooled } \\
\hline No parents with tertiary & $5.77 \%$ & $91.71 \%$ & $2.52 \%$ & $5.90 \%$ & $91.17 \%$ & $2.93 \%$ \\
\hline At least one with tertiary & $5.49 \%$ & $91.11 \%$ & $3.40 \%$ & $7.24 \%$ & $90.18 \%$ & $2.58 \%$ \\
\hline
\end{tabular}

Table 20: Distribution of Education and Labor Market Outcomes, conditional on Parents' Education

Given the significance of taste variations as a source of mismatch, it is worth exploring further potential sources of these differences in the valuation of a college degree. Table 20 provides some initial evidence on the relationship between parents education and both education and job mismatch. By country, the rows indicate the educational attainment of parents. The blocks report the education and early labor outcomes. 
For the pooled sample, parent's educational attainment does not have a large impact on education undermatch. For Italy and to a lesser extent in Japan, the undermatch rate is higher for those with low parental education. Overmatch in education is higher in both Italy and Japan for those whose parents have higher educational attainment. Interestingly, the job outcome effects are much larger. In all four countries, parental educational attainment is positively associated with higher levels of early job undermatch. Whether these are direct effects or arising through education choices will be clearer from the estimated model.

Building upon the evidence in Table 20, this section reports the estimated model extended to include the influence of parental education. To do so, we introduce parental education into the analysis in two ways. First, the regression used to predict the education outcome, (1), is supplemented to include parental education, $p e_{i}$ :

$$
\operatorname{Pr}\left(e_{i}=1 \mid a_{i}, p e_{i}\right)=\frac{\exp ^{\alpha_{0}+\alpha_{1} a_{i}+\alpha_{2} p e_{i}}}{1+\exp ^{\alpha_{0}+\alpha_{1} a_{i}+\alpha_{2} p e_{i}}} .
$$

The regression coefficient on this additional variable, denoted $\alpha_{2}$, appears in the moments given in Table $21{ }^{40}$ Note that this parameter is positive for all the countries and about the same magnitude as the effects of the test score, $\alpha_{1} \cdot{ }^{41}$ Compared to the baseline model, the estimated $\alpha_{1}$ is a bit lower due to the inclusion of parental education.

Second, the effects of parental education must be included in the model. To do so, the individual taste shock is assumed to be a proxy for parental education. In this way, we are allowing parental education to have a maximal impact on the education choice but not to directly impact mismatch in the labor market.

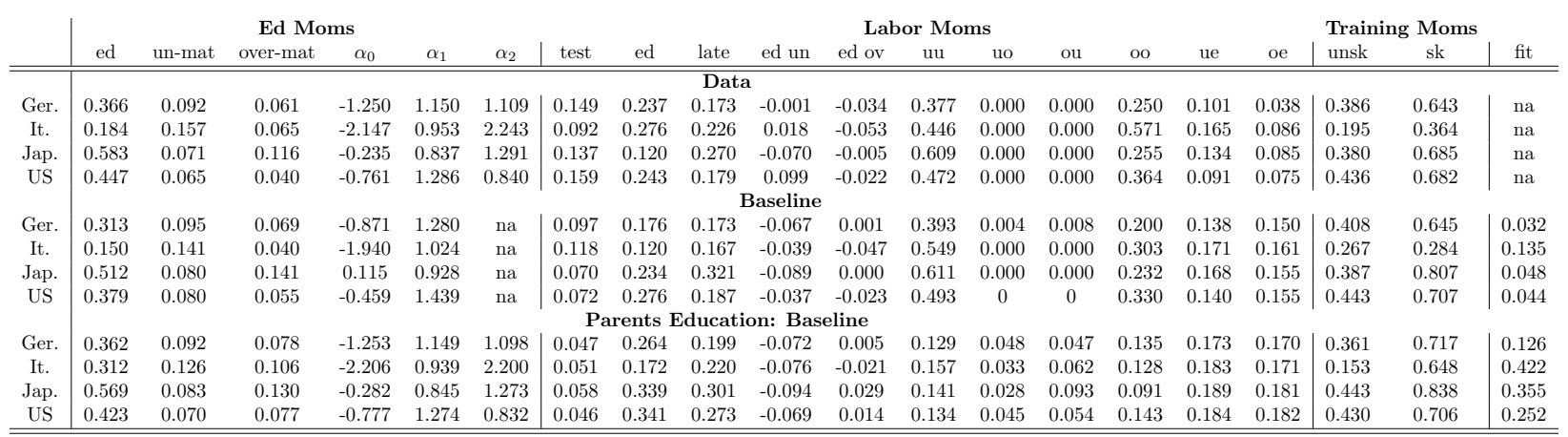

Note: This table reports data and simulated moments for the estimated models with parents education influencing the test score.

Table 21: Moments: Parents Education

The model is re-estimated with this added moment, captured by $\alpha_{2}$. As indicated by the moments in Table 21 , the fit is significantly worse than the baseline (shown as well), reflecting, of course, the added moment. The estimated model continues to match well all of the education moments, including the dependence of the education choice on parents education through the associated taste shock. The estimated model does not match very well the moments summarizing the flow between education mismatch and job mismatch. For all countries, the flows from undermatch in education to undermatch in early employment are much lower than in the data and in the baseline model.

This deterioration in the fit is linked to the parameter estimates. Using the taste shock to proxy for parental influence leads to a large reduction in the variability of the taste shock, $\bar{\varepsilon}$, relative to the baseline

\footnotetext{
${ }^{40}$ Other moments are left untouched, and thus we match the baseline moments.

${ }^{41}$ This points to a positive correlation between parents' education and test scores.
} 
estimate. While this reduction in noise helps to match the $\alpha_{2}$ parameter in the education choice regression, it is coupled with a large increase, relative to the baseline, in noise in the test score, $\sigma_{e}$. The large amount of noise in the test score reduces the link between education and job mismatch, as evidenced by the deterioration in those moments.

\begin{tabular}{c|cccccccccccc} 
& $\phi$ & $\bar{\varepsilon}$ & $\sigma_{e}$ & $h(1)$ & $\omega_{2}$ & $\sigma_{j}$ & $\zeta(0)$ & $\zeta(1)$ & $\bar{e}^{t}$ & $\delta_{c s s}$ & $\delta_{n s u}$ \\
\hline \hline & & & \multicolumn{1}{c}{ Baseline } \\
Ger. & 6.392 & 2.517 & 0.101 & 1.246 & 1.000 & 0.496 & 1.031 & 0.937 & 0.219 & 0.156 & 0.994 \\
It. & 4.511 & 4.951 & 0.017 & 1.127 & 1.110 & 0.825 & 0.834 & 0.772 & 0.137 & 0.001 & 0.315 \\
Jap. & 8.968 & 5.793 & 0.050 & 1.352 & 1.004 & 0.003 & 0.693 & 1.165 & 0.210 & 0.993 & 0.992 \\
US & 10.682 & 2.457 & 0.004 & 1.132 & 1.000 & 0.236 & 0.974 & 1.351 & 0.059 & 0.432 & 0.576 \\
& & \multicolumn{8}{c}{ Parents Education: Baseline } \\
Ger. & 7.680 & 0.565 & 0.221 & 1.212 & 1.141 & 2.069 & 0.970 & 0.938 & 0.089 & 0.104 & 0.908 \\
It. & 6.571 & 3.842 & 0.318 & 0.999 & 1.010 & 2.735 & 0.819 & 1.318 & 0.267 & 0.034 & 0.355 \\
Jap. & 6.523 & 1.519 & 0.294 & 1.352 & 1.000 & 2.999 & 0.507 & 1.130 & 0.118 & 0.256 & 0.514 \\
US & 9.162 & 0.466 & 0.152 & 1.086 & 1.001 & 2.979 & 1.013 & 1.500 & 0.101 & 0.432 & 0.576 \\
\hline \hline
\end{tabular}

Table 22: Parameter Estimates: Parents Education

From this exercise, it is clear that parental education matters for mismatch, both in education and in labor market outcomes. The model studied here can incorporate the effects of parental education on education alone but this does not carry over to labor market outcomes.

Clearly, from Table 20, the effects of parental education could also impact job outcomes directly. That is outside of the scope of this analysis as it pertains to labor market mismatch that is not a consequence of education mismatch.

\section{Implications of Education Mismatch}

This section uses the estimated models to study the implications of mismatch. ${ }^{42}$ There are two exercises. The first quantifies the output loss from mismatch. The second returns to one of the central themes of the paper: the effects of education mismatch on labor market outcomes.

\subsection{Earnings Loss from MisMatch}

Using the baseline estimates, Table 23 computes earnings over the three phases of the lifecycle. ${ }^{43}$ These calculations are for the baseline model and another treatment, called "Maximal Output". ${ }^{44}$ Given baseline parameters, this latter allocation was obtained by removing two key sources of mismatch:(i) taste shocks and (ii) the randomness in the allocation to early jobs, i.e. $\left(\delta_{c s}=1, \delta_{n s}=0\right)$. This is the allocation that generates the most earnings, and hence output, in the early and late work phases.

Importantly, the "Maximal Output" allocation removes both education and labor market mismatch. Removing labor market mismatch alone can have much smaller effects. For example, using model estimates,

\footnotetext{
${ }^{42}$ It uses the baseline parameter estimates for Italy, Japan and the US from Table 15 and the parameter estimated from the model with imperfect information about ability for Germany from Table 17.

${ }^{43}$ Garibaldi, Gomes, and Sopraseuth (2020) also calculates output loss from labor market mismatch. Their formulation allows an interaction between over and undermatched workers, through the production function, that is absent in our model.

${ }^{44}$ For purposes of comparison, this is the baseline taken from Table 15 for all countries.
} 
in Japan, there are no individuals in unskilled jobs with higher productivity than those in skilled jobs, even though many of the unskilled workers were undermatched in education.

The first three entries are mean earnings over each of the three phases. Note that these earnings are net of lost income and tuition due to schooling and training. Hence, for example, as the education rate changes across treatments, so do mean earnings in the education phase. Thus low earnings in the education phase indicate high college rates. The last entry is total income from the three phases. All of these measures are discounted to the start of the education phase.

Compared to the maximal output allocation, the earning in the education phase are higher in the baseline model. This reflects the lower returns to education when there is randomness in the early job assignment. These low returns translate into a lower college rate than in the maximal output calculation. This is particularly true for Japan: in the maximal output allocation the education rate is over $70 \%$.

The output cost of education mismatch is seen by comparing the baseline and the maximal output allocation, for each country, the mean earnings in early and late work. For Japan, this difference is substantial, over $12 \%$, indicating the loss associated with undermatch in both education and jobs. This loss is most pronounced in the early work period. For the other countries, these differences in earnings are present but are smaller. In fact, for Italy, the mean earnings in late work are higher than in the maximal output allocation and the total is only slight lower. For Italy, the education mismatch rate is high, as is the value of $\delta_{n s}$ in late employment.

\begin{tabular}{c|cccc} 
& Ed Phase & Early Work & Late Work & Total \\
\hline \hline & \multicolumn{4}{|c}{ Maximal Output } \\
Ger. & 0.457 & 8.708 & 13.535 & 22.700 \\
It. & 0.572 & 8.691 & 13.520 & 22.783 \\
Jap. & 0.024 & 9.100 & 17.220 & 26.344 \\
US. & 0.239 & 8.654 & 14.776 & 23.670 \\
& \multicolumn{4}{|c}{ Estimated Model } \\
Ger. & 0.516 & 8.004 & 13.306 & 21.825 \\
It. & 0.580 & 8.285 & 13.604 & 22.469 \\
Jap. & 0.211 & 7.803 & 15.441 & 23.454 \\
US & 0.311 & 8.213 & 14.217 & 22.741 \\
\hline
\end{tabular}

This table shows discounted present value of earnings over the education and work phases using baseline parameters.

Table 23: Earnings Net of Education and Training Costs

\subsection{Dynamics of Mismatch}

A key contribution is using the model to generate dynamics. As mentioned numerous times, the data has no dynamic component. But once the model is estimated, we are able to simulate and study the dynamics of mismatch. Thus this section relies entirely on simulation of these dynamics using the estimated model to trace the effects of mismatch on: (i) wages, (ii) training and (iii) job assignment.

For this exercise, we construct a direct measure of education mismatch. The estimated model included moments from measured mismatch. As discussed, while informative the measures of mismatch are somewhat arbitrary. Their main role was in providing informative moments for the estimation. Accordingly, the education mismatch that is studied in this section does not rely on the logistic regression to predict likelihoods of education attainment. Instead, it uses a direct measure of ability. That is, the simulated data is used to 
detect individuals who: (i) did not go to college and (ii) were above the 80 th percentile in ability. These individuals are classified as undermatched in education for the analysis that follows. There is an analogous definition for overmatched in education: (i) did go to college and (ii) were below the 20th percentile in ability.

Figure 3 illustrates the path of an individual, undermatched in education. The focus in this figure is how that individual evolves through the labor market, starting with an unskilled job and then into training and finally to late employment. This path is a main focus of the discussion as it highlights the conditions under which an individual undermatched in education remains undermatched in the labor market.

With probability $\left(1-\delta_{n s}\right)$ that individual is employed in an unskilled job in the early employment period, where this probability is taken from the data. If the agent does not choose to train, then the individual remains in an unskilled job with probability 1. If instead the agent trains, then with some probability, detailed below, the agent moves to a skilled job.

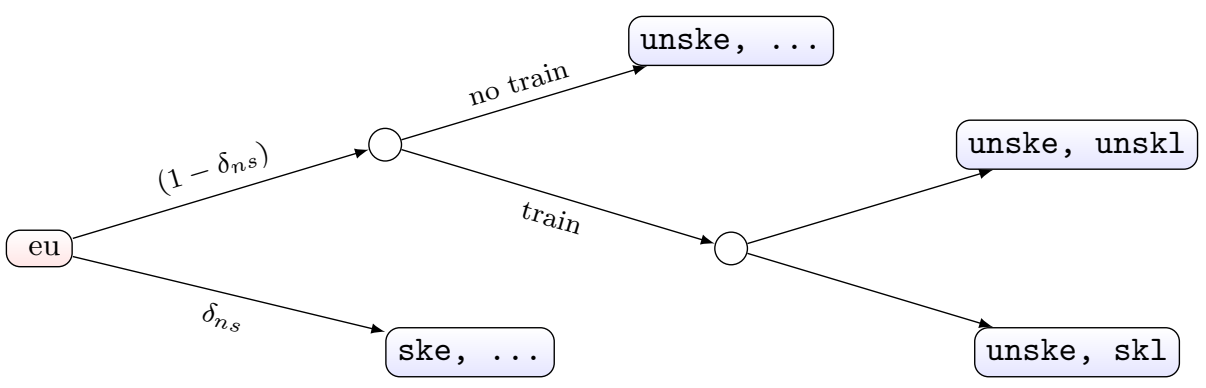

Figure 3: Dynamics of Education Mismatch

Note: The figure shows the dynamic of an individual undermatched in education through an unskilled early job and then training. The nodes indicate the job outcomes, in both the early and late periods, as well as the training choice. Here eu=education undermatch, ske(l) means skilled job early (late) and unske(l) means unskilled job early (late).

Tables 24 provides a summary of results. It highlights the wage, job assignment and training experiences of both under- and overmatched in education individuals by country. It is explained in detail in the subsections that follow.

For the undermatched, it follows the path of Figure 3. For the overmatched, there is a parallel construction, following them through their early employment, training and ultimately late employment. The nodes are essentially the same but the probabilities differ based upon the early employment assignment for college educated and the subsequent assignment into training and late employment.

\subsubsection{Sources of Education Mismatch}

The starting point of the analysis is the determination of the source of education mismatch. The first column of Table 24 shows the education mismatch rates constructed from the simulated data based on true ability. They follow the same patterns as those used in the baseline estimation, reported in Table 14, constructed using the predictions of the logistic regressions. Note the asymmetry in Italy where undermatch dominates as well as the opposite for Japan where overmatch in education is larger than undermatch.

The fact that these two measures of mismatch are so close is indicative of two features of the estimated model. First, there is little noise in the test score. Second, this is consistent with the finding that education mismatch is largely due to taste shocks.

As argued, education mismatch, joint with other moments, is best explained through taste shocks for Italy, Japan and the US. The fit of the baseline model is essentially maintained when there is no noise in the 


\begin{tabular}{|c|c|c|c|c|c|c|c|c|}
\hline & MM Rate & wre & $w r l$ & $\operatorname{pr}(s k e)$ & $\operatorname{pr}(\operatorname{tr} \mid s k e)$ & $\operatorname{pr}($ tr|unske $)$ & $\operatorname{pr}(s k l \mid s k e)$ & $\operatorname{pr}($ skel|unske) \\
\hline $\begin{array}{l}\text { Germany (n.a) } \\
\text { undermatch ed }\end{array}$ & 0.072 & 0.937 & 1.351 & 0.229 & & & & \\
\hline overmatch ed & 0.061 & 0.891 & 0.647 & 0.778 & $\begin{array}{l}1.000 \\
0.000\end{array}$ & $\begin{array}{l}1.000 \\
0.142\end{array}$ & $\begin{array}{l}0.020 \\
0.032\end{array}$ & $\begin{array}{l}0.010 \\
0.109\end{array}$ \\
\hline Italy & & & & & & & & \\
\hline undermatch ed & 0.140 & 0.999 & 1.405 & 0.169 & 0.000 & 1.000 & 0.679 & 0.674 \\
\hline $\begin{array}{l}\text { overmatch ed } \\
\text { Japan }\end{array}$ & 0.039 & 0.779 & 0.689 & 0.709 & 0.000 & 0.000 & 0.002 & 0.000 \\
\hline undermatch ed & 0.073 & 1.023 & 1.000 & 0.118 & 0.000 & 0.000 & 1.000 & 0.000 \\
\hline overmatch ed & 0.129 & 0.908 & 0.845 & 0.467 & 1.000 & 1.000 & 0.580 & 0.575 \\
\hline $\begin{array}{l}\text { United States } \\
\text { undermatch ed }\end{array}$ & 0.079 & 0.989 & 1.163 & 0.221 & 1.000 & 1.000 & 0.705 & 0.693 \\
\hline overmatch ed & 0.054 & 0.887 & 0.858 & 0.744 & 1.000 & 1.000 & 0.811 & 0.799 \\
\hline
\end{tabular}

Note: This table shows the life cycle path for under- and overmatched in education individuals by country .

Table 24: Simulated LifeCycle

education test score and allowing capital market imperfections does not improve the fit either. For Germany, the introduction of noisy ability at the time of the education decision improved the model fit relative to the baseline.

\subsubsection{Wages}

From the Mincer regressions reported in Table 5, the coefficients on both under- and overmatch in education were not significantly different from zero and their point estimates were all small. Thus, there was no direct offset in wages for education mismatch. Put differently, if an individual was undermatched in education, that was not offset by higher compensation reflecting their higher than average ability within the no college group.

These effects are brought out further in Table 24 which shows the compensation patterns based upon education mismatch. These are simulated patterns based upon the estimated model which itself used as moments the coefficients on mismatch in the Mincer regressions, reported in Table 14. The columns labeled wre and wrl report the average wage of an individual mismatched in education relative to a well matched individual with the same education in early and late employment. The idea is to summarize the effects of education mismatch on wages conditional on education. So, for example, in the early work period, an undermatched individual in Germany receives about 6.4\% less than an average well-matched individual who also did not go to college. But in late employment, the under-matched individuals obtain a $35.1 \%$ bonus.

This seems to be a general pattern. The wage ratio for undermatched individuals is either below or very close to 1 in the early period. The ratio exceeds one in the late period, except for Japan. And the wage ratio is considerably below one for overmatched in education individuals. Thus the model does predict some wage correction, but mostly in the late period. These corrections are much smaller in Japan and the US compared to Italy.

Note that the wages income in both periods also reflects training. In the early period, the time cost of training reduces labor income while the benefits of training appear in the late employment income.

Overall, education mismatch matters for subsequent labor compensation. This is made clear by these wage ratios. The next task is to uncover the contribution of training and job assignment for this connection. 


\subsubsection{Training Selection}

What is the role of training in resolving education mismatch? In particular, do individuals undermatched in education receive training and thus advance to skilled jobs?

Table 24 shows the training rates, conditional on early job assignment, for the under- and overmatched in education group. The training rates for this mismatched group are extreme: either all agents in a group train or none train. ${ }^{45}$

But there are differences across countries that are relevant for understanding labor market outcomes for the mismatched individuals. The stark difference is in Japan where individuals undermatched in education do not train, regardless of their early job placement. In Italy, the undermatched train iff they were placed in an unskilled job. In this way, individuals undermatched in education and placed in unskilled jobs do have an opportunity to advance to skilled jobs through training.

To study the selection into training in more detail, Table 25 adds to the training rates from Table 24 individuals well-matched in education. Recall that, by definition, individuals undermatched in education do not have a college education while the overmatched do. Some of the well-matched have a college degree and others do not. Comparison against the well-matched is a way to distinguish individuals in the tails of the ability distribution conditional on education and job.

Overall, the selection into training depends, in part, on the return which itself has two components. First, there is human capital accumulation captured by $\zeta(e)$. By construction, this part of the return depends on education. This return surely provides a way for undermatched individuals to climb the job ladder. Second, there is job assignment which depends on the likelihood an individual who does not train can remain in a skilled job. This is controlled by the estimated parameters $\left(\delta_{c s s}, \delta_{n s u}\right)$.

Based on this, the model has some clear predictions about selection into training. First, all else the same, higher education individuals have a bigger return to training and thus are more likely to train. Second, all else the same, the return to training also increases in ability and thus in the test score.

Selection into training varies across the four countries. In Japan, for example, it depends solely on the level of education: all individuals with college train, while none of the individuals without college do. This can be explained by differences in the estimated return to training $\zeta(\cdot)$ for the two groups, reported in Table 15. ${ }^{46}$ It is consistent with the evidence in Table 9 that the likelihood of training in Japan did not depend on the numeracy score, given education and job assignment.

In Germany, Italy and the US, education mismatch, operating through the interaction of ability and educational attainment, impacts the training outcome as well. For Germany, the undermatched have a higher probability of training, regardless of early job assignment compared to the well-matched. This highlights the influence of ability since the undermatched, by definition, have higher ability than the well-matched without college. In Italy, the undermatched again have a higher probability of training if they are initially assigned to unskilled jobs. But the overmatched in education, do not receive training. The US looks like Germany in that those undermatched in education train. But in the US, in contrast to Germany, the overmatch all train as well.

Finally, conditional on the education outcome, training is more frequent across the group assigned to unskilled jobs. This is true in all countries.

\footnotetext{
${ }^{45}$ This highlights the incentives to train but also indicates that the model does not include a choice specific shock associated with the training choices.

${ }^{46}$ This points to another issue of identification for Japan since any lower level of $\zeta(0)$ will generate the same moments given that no one without a college degree trains. This has no bearing on any of our findings.
} 


\begin{tabular}{lcc}
\hline & $p r(t r \mid s k)$ & $p r(t r \mid$ unsk $)$ \\
\hline Germany & & \\
undermatch ed & 1.000 & 1.000 \\
well-matched no college & 0.234 & 0.290 \\
overmatch ed & 0.000 & 0.142 \\
well-matched college & 0.932 & 1.000 \\
Italy & & \\
undermatch ed & 0.000 & 1.000 \\
well-matched no college & 0.000 & 0.110 \\
overmatch ed & 0.000 & 0.000 \\
well-matched college & 0.712 & 0.765 \\
Japan & & \\
undermatch ed & 0.000 & 0.000 \\
well-matched no college & 0.000 & 0.000 \\
overmatch ed & 1.000 & 1.000 \\
well-matched college & 1.000 & 1.000 \\
United States & & \\
undermatch ed & 1.000 & 1.000 \\
well-matched no college & 0.049 & 0.273 \\
overmatch ed & 1.000 & 1.000 \\
well-matched college & 1.000 & 1.000 \\
\hline
\end{tabular}

Note: This table shows the probabilities of receiving training in early employment, conditional on the type of job and the education match.

Table 25: Selection into training

\subsubsection{Labor Market Mismatch}

The selection into training provides an opportunity for advancement to a skilled job, but that assignment is not guaranteed. Job assignment, both in early and late employment, matters as well. Here we follow individuals both under and overmatched in education, through the two work phases.

For early employment, the estimated model was able to match fairly well the flows from education to job mismatch, as shown in Table 14. In both the data and in the model a large fraction, about $38 \%$ in Germany and nearly $61 \%$ in Japan, of undermatched individuals in education were also undermatched in early employment. The overmatched in education in Germany and Japan were not nearly as frequently overmatched in employment. In all countries other than Japan, the overmatched in education were very likely to be placed in a skilled job in early employment.

From Table 24, a relatively small fraction of those undermatched in education are placed in early skilled jobs, ranging from $11.8 \%$ in Japan to almost $23 \%$ in the Germany. Recall that in the baseline model, the likelihood of an early skilled job depended on education but not test score. Allowing this latter dependence does provide a way for the undermatched to advance at a higher rate, but not much more than reported for the baseline. ${ }^{47}$

For late employment, the model does not directly generate transitions across jobs. Recall that the return to training, summarized by $\zeta(\cdot)$, incorporates both the human capital associated with training as well as the likelihood of assignment to a skilled job. For the estimation and the theory model it is based upon, decomposing this compound lottery was not needed.

\footnotetext{
${ }^{47}$ Specifically, we estimated the dependence of flows to skilled jobs on education and the test score and then simulated the paths for the undermatched. Indeed $\operatorname{pr}(s k e)$ was higher for the undermatched compared to Table 24 but the rates remained under $35 \%$.
} 
But to determine the likelihood an individual transits, say, from an unskilled to a skilled job does require this information. The bottom panel of Table 8 provides data moments summarizing late job assignment by education attainment. Taking these as given along with the training probabilities from the model and the estimates of $\left(\delta_{c s s}, \delta_{n s u}\right)$, it is possible to calculate the probability an individual is assigned a skilled job conditional on training. ${ }^{48}$

Using these flows, the last two columns of Table 24 shows the transitions in terms of job assignment by education mismatch. So, for example, an undermatched individual in Germany is assigned a skilled job with probability 0.229 . That individual trains with probability 1 and remains in a skilled job with probability 0.623. This latter probability reflects not just the training decision but also the likelihood of being assigned a skilled job conditional on training which is about 0.60 for those without college in Germany.

For all countries, those undermatched in education are less likely to obtain a skilled job in the early work phase compared to those who are overmatched. But in all the countries except Japan, there are forces to overcome this by late employment. In particular, for Germany, Italy and the US, the undermatched assigned to unskilled jobs early choose to train (the rate is $100 \%$ in Germany, Italy and the US). These individuals are likely to obtain late skilled jobs. For the undermatched initially assigned skilled jobs, in Italy, they choose not to train and thus risk their skilled job assignment as training is most costly for them. This reduces the fraction of undermatched in education individuals who ultimately have skilled jobs.

\section{Cross-Country Perspective}

Countries differ in both educational and labor market institutions. As discussed already, Germany is known for its early sorting into education. As discussed in evaluating labor market outcomes in the PIAAC data, Hanushek, Schwerdt, Wiederhold, and Woessmann (2015) point to various differences in labor market institutions across countries.

Here we interpret our results from a country perspective, rather than emphasizing the channels linking education to job mismatch. This perspective allows us to consider institutional features that differ across countries. That said, the focus is not on labor market frictions per se. For the most part, those frictions, such as firing costs, will not directly determine education mismatch. Rather, they influence outcomes from the job flows captured in the model through the parameters governing job assignment.

\subsection{Germany}

There are a couple of features of the German education and labor markets that stand out. First, as noted earlier, higher education decisions in Germany are made earlier and thus with limited information about individual ability. This was confirmed in our estimation. Second, there are the effects on education and labor market outcomes of parents education noted by Dustmann (2004) and others. This in part motivated our analysis linking parental education to tastes. These features underlie our account of education and labor market outcomes in Germany.

In Germany, there is considerable education mismatch, partly due to noise about ability at the time of the education decision. Undermatched in education individuals receive training and about $60 \%$ succeed in being placed in skilled jobs. Part of the overmatch in education is solved by other labor market reallocation mechanisms.

\footnotetext{
${ }^{48}$ These calculations are used in Table 24. Derivations are shown in Appendix sub-section 9.4.
} 
In particular, all of the individuals undermatched in education in Germany decide to train and many are placed at skilled jobs in late employment. This is true for undermatched individuals in both types of jobs in early employment. As a results, flows from education to job undermatch decreases in late employment. In this sense, training helps overcome education undermatch.

\section{$7.2 \quad$ Italy}

In Italy, the college education rate is relatively low. There is considerable education undermatch which largely reflects taste shocks. There is no evidence of capital market imperfections. Labor market mechanisms in Italy create a path for the undermatched in education and reallocate overmatched to unskilled jobs in late employment.

The transition from school to work in Italy is close to the pooled average, with about $68 \%$ of individuals with a college degree obtaining a skilled job and only about $17 \%$ of those without college are in a comparable job. Those who are overmatched in education are paid less than average in both early and late employment, while the undermatched are paid considerably more.

Looking specifically at the path of the undermatched, about $83 \%$ of them are initially placed in unskilled jobs. All of them decide to train. As a result, around $68 \%$ are reassigned to skilled jobs in late employment. In this sense, training helps solving the initial misallocation of undermatched individuals. In contrast, none of those allocated to skilled jobs in early employment choose to train. However the estimated value of $\delta_{n s u}$ implies that almost $70 \%$ of them keep anyways their skill jobs.

As Table 24 shows, none of the individuals overmatched in education receive training. In addition, $\delta_{c s s}$ is almost zero. Thus, overmatched individuals assigned to skilled jobs in early are reallocated to unskilled jobs in late employment. In this way, the labor market solves the education overmatch. As a result, flows from education to job mismatch decrease substantially in late employment for both types of mismatch. As with Germany, differences in training decisions between over- and undermatched individuals come from differences in the estimated return to training $(\zeta(1)<\zeta(0))$ and the relatively low ability of overmatch individuals.

In a comparison of OECD countries, Kawaguchi and Murao (2014) study how a cohort specific scarring effect, which itself depends on labor market conditions at the time of labor market entry, influences unemployment rates in later years. From that study, Italy stands out as one of the OECD countries, along with Portugal and Spain, with the highest employment protection index. In contrast, the US is the lowest. The argument in Kawaguchi and Murao (2014) is that high employment protection is positively associated with larger scarring effects.

The results for Italy reported in Table 24 are, in some ways, in conflict with this view. Individuals undermatched in education are not likely to get skilled jobs. But those assigned to unskilled jobs, train and over $67 \%$ of them do indeed end up with skilled jobs. In this way, despite the apparent rigidities in Italian labor markets, a large fraction of the undermatched find a way to succeed. So, for Italy, unlike Japan, the undermatched are not trapped in unskilled jobs.

\subsection{Japan}

In Japan, the education rate is very high and there is more education overmatch than undermatch. As with the other countries, education mismatch reflects taste shocks. Labor market mechanisms in Japan perpetuate the effects of education undermatch throughout the lifetime employment. 
Specifically, and in stark contrast to Italy, none of the undermatched in education individuals train, regardless of their job assignment in early employment. The point estimate of $\zeta(0)=0.693$ for Japan makes clear that those without education do not have an incentive to train. ${ }^{49}$ Thus these agents are trapped. From Table 4, the fraction of late workers undermatched in employment is high in Japan, compared to the pooled sample, reflecting the limited incentives to train.

The opposite is true for the education overmatched. They train, regardless of initial job assignment. This is driven mainly by the estimated return to training of $\zeta(1)=1.165$.

Recall that these estimates of the return to training incorporates the human capital accumulated through training as well as job assignment to take advantage of the increased human capital. Thus, the estimates for Japan implies that those likelihoods are much higher for college graduates than for the non-educated individuals.

This persistence of initial effects is perhaps not surprising given the nature of labor market institutions in Japan. ${ }^{50}$ Kondo (2007) uses micro data to study the effects of first jobs on future labor market outcomes, including training. The paper concludes that the probability of regular full time employment is adversely impacted by initial job placement. ${ }^{51}$ Given the estimated value of $\delta_{n s}=0.12$, those who are undermatched in education in our model are unlikely to obtain a skilled job and thus find the path to training and a future skilled job difficult at best.

Genda, Kondo, and Ohta (2010) specifically compares US and Japan and find that the conditions at graduation have a more persistent effect in Japan than in the US. They highlight two key features in the Japanese system. The first is the role played by high schools in the process of matching graduates with jobs. Evidently, colleges pay a role as well but to a lesser degree. The second are job protection measures that severely limit flexibility in terms of firing full time regular workers. They argue that these features are central to the persistent effects of unemployment rate when the individual entered the labor market on subsequent earnings. These effects of the initial unemployment rate are more pronounced in Japan and larger for less-educated individuals.

\subsection{US}

In the US, like Italy and Japan, education mismatch is attributed to taste shocks. The training serves as a device so that agents undermatched in education are unlikely to be trapped in a low skilled job. Overmatched individuals also train and by doing so protect their job status.

Specifically, for the US, there is no evidence of imperfect capital markets creating undermatch in education. The undermatch reflects taste shocks.

Training rates are high for all mismatched individuals in the US. The training pays off. The undermatched individuals placed at unskilled jobs in early employment all train, and almost $70 \%$ of them are reassigned to skilled jobs in late employment. The undermatched allocated to skilled jobs in early employment also choose to train and about $70 \%$ retain skilled jobs.

As for the overmatched, because of the particularly high estimated value of the expected return to training, $\zeta(1)$, all of them decide to train regardless of their job assignment in early employment. As a result, a large fraction of overmatched individuals are placed at skilled jobs in late employment. Thus, flows from education to job overmatched persist during late employment.

\footnotetext{
${ }^{49}$ Though lower values of $\zeta(0)$ in Japan do not change these moments, if $\zeta(0)$ is high enough, then individuals without education will train and the fit will worsen.

${ }^{50}$ We are grateful to Masao Ogaki for suggesting this link to the literature on persistent effects of labor market conditions.

${ }^{51}$ In Kondo (2007), a distinction is made between permanent and temporary attachments.
} 
Returning to Kawaguchi and Murao (2014), the US is often viewed as a country with a minimal level of employment protection. The three measures of labor market rigidity reported by the authors - EPL, Union Coverage and benefit duration of Unemployment Insurance- are considerably low in the US. The high training rates coupled with mobility into skilled jobs for undermatched is consistent with the overall flexibility in labor markets.

\section{Conclusions}

The goal of the paper was to determine the impact of education mismatch on labor market outcomes. The paper provides evidence of under- and over-match both in education and in the labor market among OECD countries. In fact, these types of mismatch interact with a correlation of about 0.40 between education and job mismatch, pooling across countries.

A key step in the analysis was to determine the causes of educational mismatch, taking into account labor market outcomes. Education mismatch largely reflects taste shocks and not noise in the test score. For Germany, mismatch is also attributed to education choices based upon imperfect information about ability.

The analysis was structured to highlight the impacts of education mismatch rather than autonomous labor market mismatch. From this perspective, we find evidence that education mismatch does indeed have labor market effects through wages, job assignment and training.

From Table 24, relative wages in late employment offset the lost education of undermatched individuals in Germany, Italy and the US. This effect is particularly strong in Italy. In a similar way, the relative wage of overmatched in education individuals is suppressed by late employment.

The selection into training is very much country specific and education dependent. In Germany and the US, being undermatched in education leads to high training rates, regardless of initial job assignment. In Italy, these high training rates for education undermatched are high only for those assigned to unskilled job in early employment. In Japan, the undermatched in education do not have training opportunities.

Finally, looking the job assignment, in all countries even a college degree does not guarantee a skilled job. Workers without a college degree, including undermatched individuals, are usually assigned to unskilled jobs. In Germany, Italy and the US between 60 and $70 \%$ of the education undermatched are placed in skilled jobs, in part due to training. For Japan, in contrast, education undermatch persists.

As structured, the analysis excludes independent sources of labor market mismatch. Through this focus, the analysis omits additional frictions, associated with search and matching as well as non-formal frictions, government regulations and so forth, that certainly impede the job assignment process and thus impact education decisions. These factors are surely important in understanding education rates alone. What remains to be better understood is how these frictions create education mismatch.

The paper began with a broad statement about the economic effects of mismatch from the policy perspective. At this point, the paper does not address explicitly the sources of inefficiency and potential policy actions to remedy them. This is of intense interest as well.

\section{References}

Aвbott, B., G. Gallipoli, C. Meghir, and G. L. Violante (2019): "Education policy and intergenerational transfers in equilibrium," Journal of Political Economy, 127(6), 2569-2624. 
Brunello, G., And D. CHecchi (2007): "Does school tracking affect equality of opportunity? New international evidence," Economic Policy, 22(52), 782-861.

Brunello, G., And L. Rocco (2015): "The effects of vocational education on adult skills and wages: What can we learn from PIAAC?," OECD Social, Employment and Migration Working Papers, No. 168.

Cabrales, A., J. J. Dolado, and R. Mora (2017): "Dual Labour Markets and (Lack of) On-the-Job Training: Evidence for Spain Using PIAAC Data," SERIEs, Journal of the Spanish Economic Association, $8,345-371$.

Choi, I. (2019): “Training and Persistence in Temporary Employment," Penn. State University, Department of Economics.

Cooper, R., And H. Liu (2019): "MisMatch in Human Capital Accumulation," International Economic Review, 60(3), 1291-1328.

Dillon, E. W., And J. A. Smith (2017): "Determinants of the match between student ability and college quality," Journal of Labor Economics, 35(1), 45-66.

Dustmann, C. (2004): "Parental background, secondary school track choice, and wages," Oxford Economic Papers, 56(2), 209-230.

Dustmann, C., P. A. Puhani, And U. Schönberg (2017): "The long-term effects of early track choice," The Economic Journal, 127(603), 1348-1380.

Flinn, C., A. Gemici, and S. Laufer (2017): "Search, matching and training," Review of Economic Dynamics, 25, 260-297.

Flinn, C., AND J. Mullins (2015): "Labor market search and schooling investment," International Economic Review, 56(2), 359-398.

Garibaldi, P., P. Gomes, and T. Sopraseuth (2020): "Output Costs of Education and Skill Mismatch," IZA Discussion Paper.

Gauly, B., And C. M. Lechner (2019): "Self-perfection or self-selection? Unraveling the relationship between job-related training and adults? literacy skills," PloS one, 14(5), e0215971.

Genda, Y., A. Kondo, And S. OHta (2010): "Long-term effects of a recession at labor market entry in Japan and the United States," Journal of Human Resources, 45(1), 157-196.

Hanushek, E. A., G. Schwerdt, S. Wiederhold, and L. Woessmann (2015): "Returns to Skills around the World: Evidence from PIAAC," European Economic Review, 73, 103-130.

Huggett, M., G. Ventura, and A. Yaron (2011): "Sources of lifetime inequality," American Economic Review, 101(7), 2923-54.

Kawaguchi, D., And T. Murao (2014): "Labor-Market Institutions and Long-Term Effects of Youth Unemployment," Journal of Money, Credit and Banking, 46(S2), 95-116.

Kondo, A. (2007): "Does the first job really matter? State dependency in employment status in Japan," Journal of the Japanese and International Economies, 21(3), 379-402. 
Liu, K., K. G. Salvanes, And E. Ø. Sørensen (2016): "Good skills in bad times: Cyclical skill mismatch and the long-term effects of graduating in a recession," European Economic Review, 84, 3-17.

Martin, J. P. (2018): "Skills for the 21st century: Findings and policy lessons from the OECD survey of adult skills," OECD.

McGowan, M., And D. Andrews (2015): "Skill mismatch and Public Policy in OECD Countries," Discussion paper, OECD, ECO/WKP(2015)28.

Pellizzari, M., And A. Fichen (2013): "A new measure of skills mismatch: Theory and evidence from the survey of adult skills (PIAAC)," OECD.

Smith, J., M. Pender, And J. Howell (2013): "The full extent of student-college academic undermatch," Economics of Education Review, 32, 247-261.

\section{Appendix: Data}

This data appendix provides supplemental facts and estimation.

\subsection{Facts for All Countries}

Here we present some of the calculations and moments for all countries, not just the four major ones of our analysis.

\subsubsection{Mincer Regressions}




\begin{tabular}{|c|c|c|c|c|c|c|}
\hline & \multicolumn{2}{|c|}{ numeracy } & \multicolumn{2}{|c|}{ literacy } & \multicolumn{2}{|c|}{ average } \\
\hline & (1) & $(2)$ & $(3)$ & (4) & $(5)$ & (6) \\
\hline \multirow[t]{2}{*}{ score } & $0.095^{* *}$ & $0.095^{* *}$ & $0.082^{* *}$ & $0.082^{* *}$ & $0.107^{* *}$ & $0.107^{* *}$ \\
\hline & $(0.002)$ & $(0.002)$ & $(0.002)$ & $(0.002)$ & $(0.002)$ & $(0.002)$ \\
\hline \multirow[t]{2}{*}{ college } & $0.243^{* *}$ & $0.243^{* *}$ & $0.260^{* *}$ & $0.260 * *$ & $0.225^{* *}$ & $0.225^{* *}$ \\
\hline & $(0.004)$ & $(0.004)$ & $(0.004)$ & $(0.004)$ & $(0.004)$ & $(0.004)$ \\
\hline \multirow[t]{2}{*}{ late_emp } & $0.143^{* *}$ & $0.143^{* *}$ & $0.148^{* *}$ & $0.147^{* *}$ & $0.155^{* *}$ & $0.155^{* *}$ \\
\hline & $(0.004)$ & $(0.004)$ & $(0.004)$ & $(0.004)$ & $(0.004)$ & $(0.004)$ \\
\hline \multirow[t]{2}{*}{ gender } & $-0.161^{* *}$ & $-0.161^{* *}$ & $-0.178^{* *}$ & $-0.178^{* *}$ & $-0.168^{* *}$ & $-0.168^{* *}$ \\
\hline & $(0.004)$ & $(0.004)$ & $(0.004)$ & $(0.004)$ & $(0.004)$ & $(0.004)$ \\
\hline \multirow[t]{2}{*}{ under_educ } & $0.043^{* *}$ & $0.033^{* *}$ & $0.078^{* *}$ & $0.066^{* *}$ & $0.026^{* *}$ & 0.016 \\
\hline & $(0.008)$ & $(0.013)$ & $(0.008)$ & $(0.013)$ & $(0.008)$ & $(0.013)$ \\
\hline \multirow[t]{2}{*}{ over_educ } & $-0.066^{* *}$ & $-0.042^{* *}$ & $-0.103^{* *}$ & $-0.082^{* *}$ & $-0.037^{* *}$ & -0.005 \\
\hline & $(0.012)$ & $(0.021)$ & $(0.012)$ & $(0.021)$ & $(0.012)$ & $(0.021)$ \\
\hline \multirow[t]{2}{*}{ late_under } & & 0.015 & & 0.018 & & 0.014 \\
\hline & & $(0.015)$ & & $(0.015)$ & & $(0.015)$ \\
\hline \multirow[t]{2}{*}{ late_over } & & -0.034 & & -0.030 & & $-0.047^{*}$ \\
\hline & & $(0.025)$ & & $(0.025)$ & & $(0.025)$ \\
\hline $\mathrm{r} 2$ & 0.578 & 0.578 & 0.574 & 0.574 & 0.581 & 0.581 \\
\hline $\mathrm{N}$ & 39,521 & 39,521 & 39,521 & 39,521 & 39,521 & 39,521 \\
\hline
\end{tabular}

Note: This table reports the results from 6 different Mincer regressions. The depend variables for all of them is log hourly earnings. The first two columns consider the numeracy score as a measure of ability while column 3 and 4 consider the literacy score and column 5 and 6 the average of the three dimensions. Standard errors are reported in parenthesis. PIAAC scores are normalized to have mean zero and standard deviation of unity for the whole sample. The variable gender takes the value 1 if the individual is female, and 0 otherwise. The variable late_emp takes the value 0 if the individual is an early employee (25-34 years old) and 1 otherwise. The variables late_under and late_over represent interactions between late_emp and education under- and overmatch. All regressions control for country specific characteristics. A * $/ * *$ next to the coefficient indicates significance at the $10 / 5 \%$ level.

Table 26: Mincer Regressions. Cut-offs: 20th and 80th percentile

\subsubsection{Education and Job Mismatch: Correlations}




\begin{tabular}{lccc}
\hline & Ed-Job (general) & Ed-Job $($ undermatch) & Ed-Job (overmatch) \\
\hline Germany & $0.330^{*}$ & $0.386^{*}$ & $0.179^{*}$ \\
Italy & $0.420^{*}$ & $0.460^{*}$ & $0.394^{*}$ \\
Japan & $0.256^{*}$ & $0.330^{*}$ & $0.346^{*}$ \\
United States & $0.311^{*}$ & $0.412^{*}$ & $0.197^{*}$ \\
Austria & $0.270^{*}$ & $0.280^{*}$ & $0.4549^{*}$ \\
Belgium & $0.244^{*}$ & $0.261^{*}$ & $0.308^{*}$ \\
Canada & $0.307^{*}$ & $0.396^{*}$ & $0.302^{*}$ \\
Czech Republic & $0.281^{*}$ & $0.306^{*}$ & $0.405^{*}$ \\
Denmark & $0.466^{*}$ & $0.337^{*}$ & $0.662^{*}$ \\
England & $0.372^{*}$ & $0.441^{*}$ & $0.324^{*}$ \\
Spain & $0.393^{*}$ & $0.451^{*}$ & $0.093^{*}$ \\
Estonia & $0.292^{*}$ & $0.314^{*}$ & $0.357^{*}$ \\
Finland & $0.282^{*}$ & $0.274^{*}$ & $0.399^{*}$ \\
France & $0.186^{*}$ & $0.217^{*}$ & $0.181^{*}$ \\
Ireland & $0.154^{*}$ & $0.194^{*}$ & $0.170^{*}$ \\
Korea & $0.191^{*}$ & $0.249^{*}$ & $0.206^{*}$ \\
Netherlands & $0.091^{*}$ & $0.146^{*}$ & $0.175^{*}$ \\
Norway & $0.408^{*}$ & $0.355^{*}$ & $0.495^{*}$ \\
Poland & $0.363^{*}$ & $0.387^{*}$ & $0.403^{*}$ \\
Slovak Republic & $0.460^{*}$ & $0.482^{*}$ & $0.467^{*}$ \\
Sweden & $0.404^{*}$ & $0.385^{*}$ & $0.497^{*}$ \\
Pooled & $0.339^{*}$ & $0.339^{*}$ & $0.345^{*}$ \\
\hline
\end{tabular}

Note: This table reports correlations between different estimates of education and job mismatch. The first column reports the correlation between being mismatched in education and in the job. The second column reports correlations between being undermatched in education and undermatched in the job. The third column shows the correlation between being overmatched in education and overmatched in the job. The star indicates significance at the $1 \%$ level.

Table 27: Correlations between education and job mismatch.

\subsubsection{Scores}

\begin{tabular}{lccccccc}
\hline & \multicolumn{3}{c}{ Low-Skilled } & & \multicolumn{3}{c}{ High-Skilled } \\
\cline { 2 - 5 } \cline { 6 - 8 } & Mean & Sd & N & & Mean & Sd & N \\
\hline Germany & 264.09 & 43.08 & 1655 & & 302.60 & 34.75 & 1188 \\
Italy & 249.79 & 41.26 & 1388 & & 279.02 & 36.49 & 720 \\
Japan & 293.82 & 33.58 & 1534 & & 313.08 & 30.33 & 1008 \\
United States & 249.26 & 46.22 & 1248 & & 290.91 & 39.16 & 1237 \\
Austria & 264.46 & 41.52 & 1376 & & 298.56 & 31.51 & 1258 \\
Belgium & 265.13 & 42.13 & 1280 & & 302.94 & 32.29 & 1145 \\
Canada (F) & 253.04 & 44.35 & 1343 & & 287.69 & 38.44 & 1582 \\
Czech Republic & 270.05 & 35.95 & 1522 & & 298.80 & 33.62 & 1030 \\
Denmark & 258.60 & 49.75 & 1577 & & 298.08 & 37.90 & 1713 \\
England & 261.93 & 42.78 & 1373 & & 298.04 & 35.68 & 1106 \\
Spain & 243.04 & 44.91 & 2162 & & 282.55 & 35.35 & 861 \\
Estonia & 262.24 & 36.55 & 2116 & & 293.04 & 34.86 & 1675 \\
Finland & 282.47 & 41.37 & 1350 & & 314.68 & 33.454 & 1332 \\
France & 247.62 & 46.90 & 1835 & & 289.47 & 38.06 & 1596 \\
Ireland & 259.37 & 41.65 & 1784 & & 289.06 & 35.88 & 1299 \\
Korea & 265.35 & 37.71 & 1988 & & 291.77 & 29.82 & 953 \\
Netherlands & 273.53 & 41.50 & 1094 & & 305.57 & 32.97 & 1363 \\
Norway & 267.88 & 45.23 & 1066 & & 306.18 & 33.63 & 1361 \\
Poland & 258.25 & 40.09 & 1797 & & 292.31 & 37.12 & 1092 \\
Slovak Republic & 269.46 & 35.88 & 1612 & & 292.29 & 29.59 & 922 \\
Sweden & 268.65 & 50.60 & 1026 & & 309.37 & 38.12 & 1199 \\
Pooled & 258.79 & 44.88 & 38013 & & 298.13 & 36.61 & 26277 \\
\hline
\end{tabular}

Note: This table reports the moments of the distribution of the average PIAAC score by country and type of occupation.

Table 29: PIAAC average score. Moments. 


\begin{tabular}{lccccccc}
\hline & \multicolumn{3}{c}{ No College } & & \multicolumn{3}{c}{ College } \\
\cline { 2 - 5 } \cline { 7 - 8 } & Mean & Sd & N & & Mean & Sd & N \\
\hline Germany & 262.05 & 48.55 & 1939 & & 306.73 & 40.05 & 1117 \\
Italy & 249.45 & 46.03 & 2039 & & 280.91 & 40.62 & 460 \\
Japan & 279.62 & 37.56 & 1220 & & 308.71 & 33.79 & 1705 \\
United States & 231.80 & 51.39 & 1492 & & 289.25 & 42.37 & 1204 \\
Austria & 273.30 & 45.28 & 2106 & & 311.13 & 37.50 & 716 \\
Belgium & 264.98 & 45.94 & 1527 & & 312.80 & 34.98 & 1128 \\
Canada (F) & 243.45 & 48.31 & 1488 & & 285.30 & 40.86 & 1691 \\
Czech Republic & 269.44 & 39.07 & 2025 & & 309.79 & 33.56 & 741 \\
Denmark & 260.78 & 53.24 & 1776 & & 299.99 & 47.15 & 1730 \\
England & 244.19 & 51.76 & 1566 & & 289.04 & 43.71 & 1277 \\
Spain & 230.16 & 48.75 & 2206 & & 278.53 & 36.30 & 1228 \\
Estonia & 259.97 & 41.34 & 2339 & & 292.38 & 37.24 & 1730 \\
Finland & 275.47 & 46.71 & 1350 & & 312.78 & 39.36 & 1482 \\
France & 238.64 & 51.04 & 2341 & & 297.83 & 39.48 & 1400 \\
Ireland & 240.75 & 48.62 & 2010 & & 286.52 & 40.95 & 1580 \\
Korean & 248.13 & 39.70 & 1699 & & 287.07 & 31.68261 & 1784 \\
Netherlands & 248.13 & 39.70 & 1699 & & 312.24 & 33.80 & 977 \\
Norway & 269.50 & 50.16 & 1466 & & 308.37 & 44.90 & 1394 \\
Poland & 249.25 & 44.65 & 2113 & & 289.64 & 38.38 & 1251 \\
Slovak Republic & 265.89 & 45.53 & 2307 & & 305.42 & 33.49 & 639 \\
Sweden & 268.57 & 56.70 & 1333 & & 309.35 & 50.53 & 1043 \\
Pooled & 256.13 & 49.21 & 38013 & & 297.99 & 41.06 & 26277 \\
\hline
\end{tabular}

Note: This table reports the moments of the distribution of the numeracy score by country and educational level.

Table 28: PIAAC numeracy score. Moments.

\subsubsection{All Countries, All Moments}




\begin{tabular}{|c|c|c|c|c|c|c|c|c|c|c|c|c|c|c|c|c|c|c|c|}
\hline & \multicolumn{6}{|c|}{ Ed. } & \multicolumn{9}{|c|}{ Labor } & \multicolumn{4}{|c|}{ Training } \\
\hline & ed & un & ov & $\alpha_{0}$ & $\alpha_{1}$ & test & ed & late & ed un & ed ov & uu & uo & ou & oo & ue & oe & unsk & sk & fit \\
\hline & \multicolumn{19}{|c|}{ Data } \\
\hline Ger. & 0.366 & 0.092 & 0.061 & -0.883 & 1.274 & 0.149 & 0.237 & 0.173 & -0.001 & -0.034 & 0.377 & 0.000 & 0.000 & 0.250 & 0.101 & 0.038 & 0.386 & 0.643 & na \\
\hline It. & 0.184 & 0.157 & 0.065 & -1.972 & 1.015 & 0.092 & 0.276 & 0.226 & 0.018 & -0.053 & 0.446 & 0.000 & 0.000 & 0.571 & 0.165 & 0.086 & 0.195 & 0.364 & na \\
\hline Jap. & 0.583 & 0.071 & 0.116 & 0.137 & 0.915 & 0.137 & 0.120 & 0.270 & -0.070 & -0.005 & 0.609 & 0.000 & 0.000 & 0.255 & 0.134 & 0.085 & 0.380 & 0.685 & na \\
\hline US & 0.447 & 0.065 & 0.040 & -0.465 & 1.437 & 0.159 & 0.243 & 0.179 & 0.099 & -0.022 & 0.472 & 0.000 & 0.000 & 0.364 & 0.091 & 0.075 & 0.436 & 0.682 & na \\
\hline Aus & 0.254 & 0.132 & 0.043 & -1.613 & 1.123 & $0.119^{*}$ & $0.201^{*}$ & $0.152^{*}$ & 0.053 & 0.061 & 0.244 & 0.000 & 0.000 & 0.750 & 0.107 & 0.055 & 0.371 & 0.638 & na \\
\hline Bel. & 0.425 & 0.080 & 0.0381 & -0.502 & 1.492 & $0.085^{*}$ & $0.168^{*}$ & $0.185^{*}$ & 0.039 & -0.049 & 0.250 & 0.000 & 0.000 & 0.500 & 0.075 & 0.040 & 0.317 & 0.639 & na \\
\hline Can. & 0.532 & 0.079 & 0.082 & 0.045 & 1.013 & $0.130^{*}$ & $0.198^{*}$ & $0.154^{*}$ & 0.016 & 0.036 & 0.315 & 0.000 & 0.000 & 0.435 & 0.076 & 0.084 & 0.297 & 0.602 & na \\
\hline CzR. & 0.268 & 0.111 & 0.032 & -1.804 & 1.725 & $0.077^{*}$ & $0.247^{*}$ & 0.027 & 0.007 & $0.390^{*}$ & 0.287 & 0.000 & 0.000 & 0.727 & 0.110 & 0.071 & 0.401 & 0.559 & na \\
\hline Den. & 0.493 & 0.092 & 0.095 & -0.363 & 0.984 & $0.084^{*}$ & $0.150^{*}$ & $0.132^{*}$ & 0.016 & -0.032 & 0.390 & 0.000 & 0.000 & 0.537 & 0.098 & 0.074 & 0.465 & 0.730 & na \\
\hline Eng. & 0.449 & 0.094 & 0.070 & -0.343 & 0.902 & $0.142^{*}$ & $0.236^{*}$ & $0.181^{*}$ & 0.009 & $-0.138^{*}$ & 0.500 & 0.00 & 0.000 & 0.250 & 0.119 & 0.053 & 0.449 & 0.673 & na \\
\hline Est. & 0.425 & 0.095 & 0.085 & 0.361 & 0.903 & $0.119^{*}$ & $0.210^{*}$ & -0.026 & 0.042 & -0.021 & 0.263 & 0.000 & 0.000 & 0.454 & 0.081 & 0.056 & 0.383 & 0.613 & na \\
\hline Fin. & 0.523 & 0.093 & 0.080 & -0.033 & 0.918 & $0.089^{*}$ & $0.181^{*}$ & $0.167^{*}$ & -0.043 & $-0.087^{*}$ & 0.275 & 0.000 & 0.000 & 0.440 & 0.101 & 0.065 & 0.484 & 0.710 & na \\
\hline Fra. & 0.374 & 0.066 & 0.036 & -1.002 & 1.747 & $0.102 *$ & $0.182^{*}$ & $0.182^{*}$ & -0.016 & 0.059 & 0.256 & 0.000 & 0.000 & 0.273 & 0.078 & 0.047 & 0.290 & 0.511 & na \\
\hline Ire. & 0.440 & 0.074 & 0.058 & -0.552 & 1.289 & $0.118^{*}$ & $0.202^{*}$ & $0.247^{*}$ & 0.079 & 0.042 & 0.308 & 0.000 & 0.000 & 0.214 & 0.118 & 0.075 & 0.371 & 0.619 & na \\
\hline Kor. & 0.512 & 0.076 & 0.056 & -0.145 & 1.293 & $0.125^{*}$ & $0.300^{*}$ & $0.197^{*}$ & $-0.150^{*}$ & 0.001 & 0.450 & 0.000 & 0.000 & 0.242 & 0.148 & 0.089 & 0.491 & 0.605 & na \\
\hline Net. & 0.369 & 0.101 & 0.047 & -0.725 & 1.212 & $0.100^{*}$ & $0.219^{*}$ & $0.224^{*}$ & -0.020 & -0.093 & 0.140 & 0.000 & 0.000 & 0.429 & 0.088 & 0.089 & 0.471 & 0.756 & na \\
\hline Nor. & 0.487 & 0.084 & 0.089 & -0.266 & 1.016 & $0.079^{*}$ & $0.137^{*}$ & $0.131^{*}$ & 0.039 & -0.027 & 0.379 & 0.000 & 0.000 & 0.488 & 0.078 & 0.091 & 0.480 & 0.681 & na \\
\hline Pol. & 0.372 & 0.097 & 0.061 & -0.833 & 1.233 & $0.112^{*}$ & $0.354^{*}$ & $0.096^{*}$ & -0.008 & 0.154 & 0.457 & 0.000 & 0.000 & 0.360 & 0.123 & 0.059 & 0.276 & 0.544 & na \\
\hline Slo. & 0.217 & 0.131 & 0.033 & -1.542 & 1.193 & $0.116^{*}$ & $0.302^{*}$ & 0.013 & $-0.080^{*}$ & -0.028 & 0.482 & 0.00 & 0.00 & 0.714 & 0.151 & 0.047 & 0.205 & 0.484 & na \\
\hline Sp. & 0.358 & 0.085 & 0.035 & -0.900 & 1.382 & $0.089^{*}$ & $0.374^{*}$ & $0.163^{*}$ & $0.142^{*}$ & -0.161 & 0.576 & 0.000 & 0.000 & 0.083 & 0.130 & 0.027 & 0.342 & 0.625 & na \\
\hline Swe. & 0.439 & 0.084 & 0.086 & -0.672 & 1.152 & $0.086^{*}$ & $0.072^{*}$ & $0.117^{*}$ & -0.042 & 0.030 & 0.381 & 0.000 & 0.000 & 0.536 & 0.098 & 0.084 & 0.478 & 0.721 & na \\
\hline
\end{tabular}

Table 30: Moments

\subsection{Additional Robustness Exercises}

\subsubsection{Training: Formal}

The analysis of training focuses on non-formal training in order to have a clear distinction between formal education and training. The model was re-estimated to match the rates of formal rather than non-formal training. Those training rates are shown in Table 10 and used as the last two moments in the estimation. Note that these rates of formal training are much lower in all countries but do retain the pattern that workers in skilled jobs are more likely to be trained.

The moments are reported in the bottom panel of Tables 14. The model fit for this case is not as good as the baseline. The decline in fit is coming from two sources: (i) the coefficients on mismatch in the Mincer regression and (ii) the training rates. The latter are either inconsistent with the pattern of larger training rates for skilled workers (Germany, Japan) or, as in the US, have very large training rates.

For this estimation the direct cost of training is added along with the opportunity cost, reported in Table 15. The formal cost of formal training is relative to the cost of US tuition. The cost is very large for most countries other than the US, consistent with the high training rates in the US. The estimated time cost is also considerable. As with the baseline, the estimated model has almost no noise in the test score.

\subsubsection{Alternative Logistic Regressions}

Here we present results for more general versions of (1) in which the only regressor was the test score. The estimation, reported by country, includes age, gender, a measure of parental education immigration status and an indicator of whether the individual has a partner.

The estimated coefficients on the normalized test score remain positive for all countries, being largest in Germany and the US. Gender is also positive in all regressions, reflecting the higher education rate of women throughout these countries. Also, there is a positive influence of parent's education on the educational choice.

These additional regressions serve two roles. First, they provide additional insights into the determinants of the education choice. While gender is not in the model, sub-section 5.5 explores the impact of parents 


\begin{tabular}{lccc}
\hline & Model 1 & Model 2 & Model 3 \\
\hline college & & & \\
normalized numeracy score & $1.2551^{* * *}$ & $1.3481^{* * *}$ & $1.3448^{* * *}$ \\
& $(0.0830)$ & $(0.0855)$ & $(0.0858)$ \\
age & $0.0304^{* * *}$ & $0.0323^{* * *}$ & $0.0298^{* * *}$ \\
& $(0.0070)$ & $(0.0071)$ & $(0.0072)$ \\
gender & $0.3129^{* * *}$ & $0.3332^{* * *}$ & $0.3344^{* * *}$ \\
& $(0.1160)$ & $(0.1170)$ & $(0.1171)$ \\
At least one parent with tertiary education & $1.2141^{* * *}$ & $1.1981^{* * *}$ & $1.2024^{* * *}$ \\
& $(0.1213)$ & $(0.1213)$ & $(0.1216)$ \\
immig & & $0.6887^{* * *}$ & $0.6813^{* * *}$ \\
& & $(0.1781)$ & $(0.1778)$ \\
partner & & & $0.2882^{*}$ \\
& & & $(0.1692)$ \\
Constant & $-2.6191^{* * *}$ & $-2.8109^{* * *}$ & $-2.9610^{* * *}$ \\
& $(0.3090)$ & $(0.3190)$ & $(0.3327)$ \\
\hline Observations & 1970 & 1970 & 1970 \\
Pseudo $R^{2}$ & 0.2297 & 0.2360 & 0.2372 \\
\hline \hline Standar
\end{tabular}

Standard errors in parentheses. $* * * p<0.01, * * p<0.05, * p<0.1$

Table 31: Germany: Alternative Logistic Regressions

education through tastes. Second, alternative measures of mismatch can be created from these estimates, as seen in sub-section 9.2.3.

\subsubsection{Estimation using Alternative Measures of MisMatch}

An alternative definition of mismatch evaluates an agent relative to others with the same education rather than compared to the entire population. An agent is undermatched if: (i) the individual does not obtain a college degree and (ii) the predicted probability of going to college exceeds the 80th percentile of the predicted probability of going to college among college going individuals. The same point applies to the labor mismatch calculations: an individual in an unskilled job is viewed as undermatched relative to those with that same job assignment. This alternative measure has an important property: if there is perfect sorting by ability into education and jobs, then there will be zero mismatch.

This alternative method of mismatch was used to characterize educational and labor market outcomes and the model was re-estimated. The results are shown in Tables 37 and 38 .

Looking first at the data moments, the mismatch rates for both education and jobs with this alternative definition are lower for all countries. Still the patterns noted earlier remain: the education undermatch rate is larger than the overmatch in Italy, Germany and the US while overmatch dominates in Japan. One striking difference is that none of the individuals overmatched in education in Germany are overmatched in their early job assignment. This is not the case in other countries.

The fit of the models is better for Germany and Italy but not as good for Japan and the US. The match with the mismatch rates is not as good as the baseline and the model still struggles to match the education coefficient in the Mincer regression. The flows from education to job mismatch are close to the data as are the training rates. The model continues to overstate the job mismatch rates, particularly the overmatch rate.

Removing the taste shocks and re-estimating the model leads to a large deterioration of the fit. So, as in 


\begin{tabular}{lccc}
\hline & Model 1 & Model 2 & Model 3 \\
\hline college & & & \\
normalized numeracy score & $0.8700^{* * *}$ & $0.8448^{* * *}$ & $0.8435^{* * *}$ \\
& $(0.0851)$ & $(0.0857)$ & $(0.0854)$ \\
age & $-0.0338^{* * *}$ & $-0.0347^{* * *}$ & $-0.0296^{* * *}$ \\
& $(0.0096)$ & $(0.0096)$ & $(0.0094)$ \\
gender & $0.8474^{* * *}$ & $0.8604^{* * *}$ & $0.8636^{* * *}$ \\
& $(0.1519)$ & $(0.1516)$ & $(0.1519)$ \\
At least one parent with tertiary education & $2.3586^{* * *}$ & $2.4600^{* * *}$ & $2.4639^{* * *}$ \\
& $(0.2711)$ & $(0.2764)$ & $(0.2784)$ \\
immig & & $-0.8242^{* * *}$ & $-0.7842^{* * *}$ \\
& & $(0.3031)$ & $(0.2999)$ \\
partner & & & -0.2211 \\
& & & $(0.1653)$ \\
Constant & & & \\
& $-1.0944^{* * *}$ & $-1.0081^{* *}$ & $-1.0641^{* * *}$ \\
& $(0.3991)$ & $(0.4029)$ & $(0.3908)$ \\
\hline Observations & 1678 & 1678 & 1678 \\
Pseudo $R^{2}$ & 0.1936 & 0.1984 & 0.1996 \\
\hline \hline Standar
\end{tabular}

Standard errors in parentheses. $* * * p<0.01, * * p<0.05, * p<0.1$

Table 32: Italy: Alternative Logistic Regressions

the baseline, the mismatch is largely a consequence of taste shocks. The experiment with random borrowing constraints did not improve the fit for any country and is not shown.

\subsubsection{Re-evaluating Job MisMatch}

As noted earlier, the job mismatch is calculated from (2) using the average of the three PIAAC test scores. And, like the education decision, there is the potential for reverse causation, i.e. someone placed in a skilled job might acquire the knowledge to score high.

These concerns were present and examined by Hanushek, Schwerdt, Wiederhold, and Woessmann (2015), where the main focus was the estimation of the return to skill. Their main empirical model used the numeracy score as a measure of skill, rather than a composite score. ${ }^{52}$ Further, Section 5 of Hanushek, Schwerdt, Wiederhold, and Woessmann (2015) uses an IV approach to control for endogenous variations in the numeracy score, leaving their main findings intact.

Following Hanushek, Schwerdt, Wiederhold, and Woessmann (2015), the model is re-estimated using the numeracy score as the measure of ability in (2) and thus in the calculation of job mismatch. The data panel in Table 14. Compared to the baseline measures, the fraction of undermatch (overmatch) in education to undermatch (overmatch) in early employment, "uu" and "oo" respectively, is much larger in the revised data since the measures of ability underlying the education and job mismatch moments are the same. But the job mismatch rates in early employment themselves are about the same, with the exception of the high level of job overmatch in Germany.

The model fit reported in Table 39 is better for Germany compared to the baseline as well as the model estimated with noisy ability. This improved fit seems to come mainly from the ability of the estimated model to match the higher "uu" and "oo" flows The fit is worse for the other countries.

\footnotetext{
${ }^{52}$ As discussed in section 4.4 of Hanushek, Schwerdt, Wiederhold, and Woessmann (2015), the literacy and numeracy scores are very highly correlated, but the problem solving score is less correlated.
} 


\begin{tabular}{|c|c|c|c|}
\hline & Model 1 & Model 2 & Model 3 \\
\hline \multicolumn{4}{|l|}{ college } \\
\hline normalized numeracy score & $\begin{array}{c}0.8093^{* * * *} \\
(0.0594)\end{array}$ & $\begin{array}{c}0.8084^{* * * *} \\
(0.0595)\end{array}$ & $\begin{array}{c}0.8066^{* * *} \\
(0.0595)\end{array}$ \\
\hline age & $\begin{array}{l}-0.0006 \\
(0.0064)\end{array}$ & $\begin{array}{l}-0.0007 \\
(0.0064)\end{array}$ & $\begin{array}{l}-0.0014 \\
(0.0069)\end{array}$ \\
\hline gender & $\begin{array}{c}0.2495^{* *} \\
(0.1024)\end{array}$ & $\begin{array}{c}0.2488^{* *} \\
(0.1024)\end{array}$ & $\begin{array}{c}0.2493^{* *} \\
(0.1025)\end{array}$ \\
\hline At least one parent with tertiary education & $\begin{array}{c}1.2120^{* * * *} \\
(0.1170)\end{array}$ & $\begin{array}{c}1.2115^{* * *} \\
(0.1170)\end{array}$ & $\begin{array}{c}1.2109^{* * * *} \\
(0.1170)\end{array}$ \\
\hline immig & & $\begin{array}{c}0.0000 \\
(.)\end{array}$ & $\begin{array}{c}0.0000 \\
(.)\end{array}$ \\
\hline partner & & & $\begin{array}{c}0.0354 \\
(0.1225)\end{array}$ \\
\hline Constant & $\begin{array}{l}-0.2770 \\
(0.2715)\end{array}$ & $\begin{array}{l}-0.2743 \\
(0.2717)\end{array}$ & $\begin{array}{l}-0.2724 \\
(0.2719)\end{array}$ \\
\hline Observations & 2183 & 2182 & 2182 \\
\hline Pseudo $R^{2}$ & 0.1489 & 0.1484 & 0.1485 \\
\hline
\end{tabular}

Standard errors in parentheses. $* * * p<0.01, * * p<0.05, * p<0.1$

Table 33: Japan: Alternative Logistic Regressions

The baseline parameter estimates are reported in the top panel of Table 40 and the estimates using the revised data moments are reported in the bottom panel. One interesting difference relative to the baseline is that the noise in the education test is estimated to be lower for all countries except the US, where it is nearly zero anyways. Relatedly the job test noise in Germany is much lower and in Italy it is much higher For Germany, this is what allows the model to produce the higher "uu" and "oo" flows. For Italy these flows are much higher as well in the estimated model but this does not lead to an improvement in the fit.

\subsection{NLSY: Calculating US Job Flows}

Cohort and sample selection: PIAAC data was collected mainly in 2011. Thus, early workers in our sample -individuals aged aged 25-34 in 2011- were born between 1977 and 1986. Individuals in the NLSY97 data were born between 1980 and 1984 while individuals in the NLSY79 data were born between 1957 and 1964. Therefore, our US sample of early employees in PIAAC is closer to the NLSY97 cohort.

In order to identify the job assignment probabilities in late employment for individuals allocated to skilled jobs in early that do not train, we need information about their job allocation in late employment. Data for the NLSY97 cohort is available from round 1 (1997-98) through round 18 (2017-18). Respondents were 32 to 38 at the time of their round 18 interviews. We restrict our sample to individuals that were already in late employment by that time. ${ }^{53}$

College. The NLSY97 data report the highest degree completed by the respondents at each interview date. Consistent with our PIAAC education variable, we define two education levels according to the highest degree reported in 2011: (ii) below college and (ii) college and beyond.

Occupation. In every round of the survey, NLSY97 respondents answer questions about every occupa-

\footnotetext{
${ }^{53}$ As with PIAAC, we excluded respondents that reported to be self-employed in 2011. In addition, the NLSY97 data includes oversamples of Hispanics and non-Hispanic black which we dropped for this analysis. Our final sample is composed of 2,789 individuals.
} 


\begin{tabular}{lccc}
\hline & Model 1 & Model 2 & Model 3 \\
\hline college & & & \\
normalized numeracy score & $1.3365^{* * *}$ & $1.3973^{* * *}$ & $1.3809^{* * *}$ \\
& $(0.0840)$ & $(0.0856)$ & $(0.0866)$ \\
age & -0.0007 & -0.0003 & -0.0016 \\
& $(0.0073)$ & $(0.0074)$ & $(0.0074)$ \\
gender & $0.7237^{* * *}$ & $0.7421^{* * *}$ & $0.7524^{* * *}$ \\
& $(0.1235)$ & $(0.1239)$ & $(0.1238)$ \\
At least one parent with tertiary education & $0.8286^{* * *}$ & $0.8323^{* * *}$ & $0.8390^{* * *}$ \\
& $(0.1255)$ & $(0.1270)$ & $(0.1268)$ \\
immig & & $0.6826^{* * *}$ & $0.6759^{* * *}$ \\
& & $(0.1742)$ & $(0.1737)$ \\
partner & & & 0.2096 \\
& & & $(0.1538)$ \\
Constant & $-1.0516^{* * *}$ & $-1.1827^{* * *}$ & $-1.3044^{* * *}$ \\
& $(0.3099)$ & $(0.3148)$ & $(0.3273)$ \\
\hline Observations & 1819 & 1819 & 1819 \\
Pseudo $R^{2}$ & 0.2516 & 0.2584 & 0.2593 \\
\hline \hline Standard
\end{tabular}

Standard errors in parentheses. $* * * p<0.01, * * p<0.05, * p<0.1$

Table 34: USA: Alternative Logistic Regressions

tion they had since the last interview. We use the information on their most recent occupation at the time of the round 15 interview in 2011-2012, in order to define their early job type. Similarly, use information on their most recent occupation at the time of the round 18 interview in 2017-2018, in order to define their late job type.

Respondents' verbatim descriptors of their occupations are coded using a three-digit Census code frame. In order to have a closer comparison with occupations reported in PIAAC, we mapped the 2002 Census codes reported in the NLSY97 to (two-digit) ISCO88 codes. We then matched those codes to the ISCO skill levels to define our occupation variable. Same as with PIAAC, we define two types of jobs: (i) unskilled (first to third ISCO skill levels) and (ii) skilled jobs (fourth ISCO skill level).

Training. Information on training programs in which respondents participated since the last interview is also collected in every round of the survey. These data refers to training experiences of respondents outside of their regular schooling. Our training measure from PIAAC refers to any non-formal training received within the 12 months prior to the interview date. Thus, we said an individual in our NLSY97 sub-sample trained in early employment if he reported any training experience within one year before the round 15 interview in 2011-2011.

\subsection{Inferring Late Flows}

Table 41 provides the inferred probability that an individual who trains is assigned a late skilled job, by education. The inference requires the imposition of a steady state assumption to link the early and late assignments in Table 8 .

The procedure amounted to generating a single equation with a single unknown, the probability an individual with training was assigned a skilled job. The inputs into this were the training decisions along with the estimated probabilities that an individual without training would be remain in a skilled job. 


\begin{tabular}{|c|c|c|c|c|c|c|c|c|c|c|c|c|c|c|c|c|c|}
\hline \multicolumn{4}{|c|}{ Education } & \multicolumn{5}{|c|}{ Mincer Reg. } & \multicolumn{4}{|c|}{ Ed $\rightarrow$ Early Job } & \multirow{2}{*}{$\begin{array}{c}\text { Emp. } \\
\text { ue }\end{array}$} & \multirow{2}{*}{$\begin{array}{c}\text { Mismatch } \\
\text { oe }\end{array}$} & \multicolumn{2}{|c|}{ Training } & \multirow[b]{2}{*}{ fit } \\
\hline ed & un & ov & $\alpha_{1}$ & test & ed & late & ed un & ed ov & uu & uo & ou & oo & & & unsk & sk & \\
\hline \multicolumn{18}{|c|}{ Data } \\
\hline 0.366 & 0.022 & 0.021 & 1.345 & 0.150 & 0.225 & 0.171 & -0.009 & -0.055 & 0.377 & 0.000 & 0.000 & 0.250 & 0.101 & 0.038 & 0.386 & 0.643 & na \\
\hline 0.184 & 0.031 & 0.034 & 0.844 & 0.119 & 0.262 & 0.234 & -0.017 & 0.018 & 0.446 & 0.000 & 0.000 & 0.571 & 0.165 & 0.086 & 0.195 & 0.364 & na \\
\hline 0.583 & 0.036 & 0.050 & 0.807 & 0.135 & 0.122 & 0.270 & -0.076 & 0.013 & 0.609 & 0.000 & 0.000 & 0.255 & 0.134 & 0.085 & 0.380 & 0.685 & na \\
\hline 0.447 & 0.017 & 0.015 & 1.381 & 0.147 & 0.256 & 0.165 & 0.102 & -0.009 & 0.472 & 0.000 & 0.000 & 0.364 & 0.091 & 0.075 & 0.436 & 0.682 & na \\
\hline \multicolumn{18}{|c|}{ Baseline } \\
\hline 0.354 & 0.084 & 0.073 & 1.352 & 0.096 & 0.172 & 0.166 & -0.076 & 0.002 & 0.403 & 0.003 & 0.007 & 0.222 & 0.134 & 0.152 & 0.387 & 0.650 & 0.036 \\
\hline 0.249 & 0.129 & 0.098 & 0.870 & 0.114 & 0.120 & 0.206 & -0.074 & -0.021 & 0.585 & 0.000 & 0.000 & 0.301 & 0.165 & 0.165 & 0.234 & 0.351 & 0.144 \\
\hline 0.477 & 0.093 & 0.142 & 0.827 & 0.066 & 0.215 & 0.310 & -0.086 & 0.000 & 0.613 & 0.000 & 0.000 & 0.223 & 0.169 & 0.157 & 0.355 & 0.784 & 0.057 \\
\hline 0.410 & 0.076 & 0.070 & 1.393 & 0.074 & 0.276 & 0.216 & -0.034 & -0.021 & 0.491 & 0.000 & 0.000 & 0.328 & 0.139 & 0.157 & 0.446 & 0.696 & 0.046 \\
\hline \multicolumn{18}{|c|}{ No Taste Shock } \\
\hline 0.329 & 0.084 & 0.054 & 1.347 & 0.034 & 0.236 & 0.196 & -0.056 & 0.006 & 0.127 & 0.049 & 0.047 & 0.125 & 0.169 & 0.162 & 0.350 & 0.689 & 0.133 \\
\hline 0.195 & 0.146 & 0.069 & 0.870 & 0.016 & 0.279 & 0.312 & -0.025 & -0.016 & 0.155 & 0.036 & 0.072 & 0.103 & 0.187 & 0.171 & 0.085 & 0.496 & 0.381 \\
\hline 0.505 & 0.087 & 0.111 & 0.835 & 0.022 & 0.278 & 0.349 & -0.037 & 0.011 & 0.000 & 0.042 & 0.065 & 0.000 & 0.150 & 0.080 & 0.381 & 0.802 & 0.514 \\
\hline 0.000 & 0.200 & 0.040 & 1.422 & 0.005 & 0.557 & 0.085 & 0.002 & 0.095 & 0.218 & 0.038 & 0.000 & 0.000 & 0.199 & 0.198 & 0.419 & 0.001 & 1.063 \\
\hline
\end{tabular}

Note: This table reports data and simulated moments for the estimated models based upon moments for education choice and mismatch computed from a logistic regression with controls. See Table 13 for a full list of variables.

Table 35: Moments

\begin{tabular}{|c|c|c|c|c|c|c|c|c|c|c|c|}
\hline$\phi$ & $\bar{\varepsilon}$ & $\sigma_{e}$ & $h(1)$ & $\omega_{2}$ & $\sigma_{j}$ & $\zeta(0)$ & $\zeta(1)$ & $p^{t}$ & $\bar{e}^{t}$ & $\delta_{c s s}$ & $\delta_{n s u}$ \\
\hline \multicolumn{12}{|c|}{$\overline{\text { Baseline }}$} \\
\hline 6.803 & 2.412 & 0.080 & 1.270 & 1.000 & 0.467 & 1.033 & 0.937 & 1.982 & 0.223 & 0.166 & 0.991 \\
\hline 5.143 & 5.234 & 0.014 & 1.220 & 1.198 & 0.566 & 0.828 & 0.752 & 1.756 & 0.132 & 0.000 & 0.371 \\
\hline 9.396 & 5.986 & 0.052 & 1.335 & 1.000 & 0.000 & 0.746 & 1.178 & 1.369 & 0.233 & 0.929 & 0.977 \\
\hline 10.475 & 2.435 & 0.002 & 1.133 & 1.007 & 0.232 & 0.975 & 1.367 & 0.046 & 0.065 & 0.795 & 0.027 \\
\hline \multicolumn{12}{|c|}{ No Taste Shock } \\
\hline 9.587 & 0.015 & 0.156 & 1.106 & 1.007 & 1.389 & 1.047 & 1.185 & 1.908 & 0.175 & 0.458 & 0.982 \\
\hline 8.437 & 0.084 & 0.351 & 1.297 & 1.317 & 2.971 & 0.806 & 0.845 & 0.926 & 0.169 & 0.017 & 0.210 \\
\hline 13.701 & 0.002 & 0.135 & 1.330 & 1.006 & 0.014 & 0.917 & 1.261 & 1.849 & 0.208 & 0.984 & 0.961 \\
\hline 14.684 & 0.004 & 0.491 & 0.909 & 1.038 & 0.049 & 0.974 & 1.424 & 0.129 & 0.048 & 0.571 & 0.048 \\
\hline
\end{tabular}

Note: This table reports parameter estimates based upon moments for education choice and mismatch computed from a logistic regression with controls.

Table 36: Parameter Estimates

It is important to keep in mind that this decomposition of the return to training only matters for the post-estimation analysis. The estimation itself only identifies the compound effects of the human capital accumulated in training and the late job assignment.

\section{Appendix: Theory Model}

This section presents the details of the theory that is used in the estimation.

\subsection{Employment Phases}

This section summarizes the outcomes and decisions in the employment phases. The key (and only) decision explored here is training, undertaken in the early work period. This highlights a potential path to a skilled job through human capital accumulation, particularly for those who were undermatched in education. Of course, the strength of this will depend on the selection into training and its effects on human capital. 


\begin{tabular}{|c|c|c|c|c|c|c|c|c|c|c|c|c|c|c|c|c|c|c|c|}
\hline & \multicolumn{5}{|c|}{ Education } & \multicolumn{5}{|c|}{ Mincer Reg. } & \multicolumn{4}{|c|}{ Ed $\rightarrow$ Early Job } & \multirow{2}{*}{$\begin{array}{c}\text { Emp. } \\
\text { ue }\end{array}$} & \multirow{2}{*}{$\begin{array}{c}\text { Mismatch } \\
\text { oe }\end{array}$} & \multicolumn{2}{|c|}{ Training } & \multirow[b]{2}{*}{ fit } \\
\hline & ed & un-mat & over-mat & $\alpha_{0}$ & $\alpha_{1}$ & test & ed & late & ed un & ed ov & uu & uo & ou & oo & & & unsk & sk & \\
\hline \multicolumn{20}{|c|}{ Data } \\
\hline Ger. & 0.365 & 0.029 & 0.027 & -0.883 & 1.274 & 0.177 & 0.248 & 0.188 & -0.068 & -0.004 & 0.400 & 0.000 & 0.000 & 0.000 & 0.046 & 0.027 & 0.386 & 0.643 & na \\
\hline It. & 184 & 0.068 & 0.046 & -1.972 & 1.015 & 0.097 & 0.270 & 0.226 & 0.009 & -0.040 & 0.410 & 0.000 & 0.000 & 0.429 & 0.062 & 0.068 & 0.195 & 0.364 & na \\
\hline Jap. & 0.583 & 0.034 & 0.058 & 0.137 & 0.915 & 0.135 & 0.127 & 0.269 & -0.079 & -0.030 & 0.571 & 0.000 & 0.000 & 0.286 & 0.065 & 0.065 & 0.380 & 0.685 & na \\
\hline US. & 0.447 & 0.024 & 0.014 & -0.465 & 1.437 & 0.203 & 0.295 & 0.238 & -0.058 & 0.209 & 0.615 & 0.000 & 0.000 & 0.500 & 0.035 & 0.042 & 0.436 & 0.682 & na \\
\hline \multicolumn{20}{|c|}{ Baseline } \\
\hline Ger. & 0.319 & 0.012 & 0.050 & -0.868 & 1.283 & 0.088 & 0.225 & 0.184 & -0.069 & -0.006 & 0.391 & 0.001 & 0.000 & 0.003 & 0.055 & 0.089 & 0.387 & 0.643 & 0.015 \\
\hline It. & 0.154 & 0.024 & 0.040 & -1.9132 & 1.021 & 0.102 & 0.124 & 0.211 & -0.037 & -0.049 & 0.460 & 0.000 & 0.013 & 0.218 & 0.136 & 0.165 & 0.224 & 0.309 & 0.096 \\
\hline Jap. & 0.514 & 0.022 & 0.105 & 0.122 & 0.928 & 0.067 & 0.245 & 0.318 & -0.106 & 0.003 & 0.578 & 0.000 & 0.000 & 0.210 & 0.109 & 0.139 & 0.389 & 0.808 & 0.059 \\
\hline US. & 0.382 & 0.015 & 0.037 & -0.441 & 1.409 & 0.072 & 0.279 & 0.191 & -0.040 & -0.025 & 0.780 & 0.000 & 0.000 & 0.509 & 0.077 & 0.111 & 0.429 & 0.670 & 0.080 \\
\hline US. (nlsy) & 0.378 & 0.016 & 0.035 & -0.465 & 1.403 & 0.069 & 0.279 & 0.187 & -0.042 & -0.026 & 0.776 & 0.000 & 0.000 & 0.498 & 0.078 & 0.111 & 0.439 & 0.705 & 0.080 \\
\hline \multicolumn{20}{|c|}{ No Taste Shock } \\
\hline Ger. & 0.330 & 0.013 & 0.038 & -0.871 & 1.279 & 0.041 & 0.297 & 0.177 & -0.087 & 0.004 & 0.000 & 0.028 & 0.012 & 0.000 & 0.040 & 0.087 & 0.374 & 0.639 & 0.188 \\
\hline It. & 0.164 & 0.026 & 0.041 & -1.953 & 1.064 & 0.013 & 0.343 & 0.135 & -0.027 & -0.027 & 0.130 & 0.034 & 0.055 & 0.094 & 0.147 & 0.155 & 0.165 & 0.444 & 0.244 \\
\hline Jap. & 0.523 & 0.030 & 0.063 & 0.126 & 0.923 & 0.019 & 0.285 & 0.338 & -0.037 & 0.010 & 0.000 & 0.041 & 0.012 & 0.000 & 0.096 & 0.061 & 0.398 & 0.813 & 0.478 \\
\hline US. & 0.411 & 0.008 & 0.035 & -0.411 & 1.468 & 0.050 & 0.382 & 0.198 & -0.096 & 0.022 & 0.000 & 0.039 & 0.012 & 0.0375 & 0.053 & 0.089 & 0.430 & 0.696 & 0.664 \\
\hline US. (nlsy) & 0.407 & 0.008 & 0.036 & -0.432 & 1.447 & 0.052 & 0.353 & 0.223 & -0.101 & 0.021 & 0.000 & 0.033 & 0.004 & 0.000 & 0.052 & 0.076 & 0.186 & 0.692 & 0.752 \\
\hline \multicolumn{20}{|c|}{ alt logistic reg april 19} \\
\hline & 0.091 & 0.148 & 0.011 & -2.939 & 1.385 & 0.064 & 0.205 & 0.231 & -0.018 & -0.037 & 0.412 & 0.005 & 0.000 & 0.163 & 0.169 & 0.168 & 0.473 & 0.532 & 0.156 \\
\hline & 0.263 & 0.127 & 0.102 & -1.089 & 0.861 & 0.115 & 0.125 & 0.167 & -0.073 & -0.024 & 0.624 & 0.000 & 0.000 & 0.314 & 0.164 & 0.164 & 0.239 & 0.368 & 0.155 \\
\hline & 0.434 & 0.099 & 0.135 & -0.250 & 0.825 & 0.062 & 0.196 & 0.295 & -0.082 & -0.002 & 0.616 & 0.000 & 0.000 & 0.219 & 0.170 & 0.155 & 0.316 & 0.752 & 0.062 \\
\hline & 0.252 & 0.104 & 0.008 & -1.248 & 1.398 & 0.068 & 0.259 & 0.154 & -0.028 & -0.024 & 0.482 & 0.000 & 0.000 & 0.365 & 0.151 & 0.153 & 0.442 & 0.524 & 0.107 \\
\hline
\end{tabular}

This table reports data and simulated moments for the estimated models with alternative mismatch measures.

Table 37: Moments: Alternative MisMatch

\subsubsection{Late Work}

In the late work period, the worker is assigned to either a skilled or unskilled job. Let $\delta_{2}^{j}(e, \theta, \operatorname{tr})$ be the probability that a type $(e, \theta)$ agent is assigned a high skilled job in late work conditional on training $(t r)$. Here $j \in\{s, u\}$ denotes the job assignment for early employment. This function is taken as given in determining the training choice. These probabilities depend not only on the worker type and the training decision but also on the type of job in early work. This is a general specification and we return below to its implementation in the quantitative analysis.

As for compensation, workers are paid their marginal product. ${ }^{54}$ Compensation depends solely on their human capital, which reflects their innate ability, education and training. By assumption, this is independent of their early work job assignment. ${ }^{55}$

Specifically, the productivity of a worker in a skilled job is given by $H(e, \theta, t r)=h(e) \theta \zeta(e)^{t r}$ where $h(e)$ captures the effects of education, $\theta$ is innate ability, $\operatorname{tr} \in\{0,1\}$ indicates if the worker has successfully trained while $\zeta(e)$ parameterizes the effect of training on worker human capital. The specification allows the effects of training to depend on the level of education, $e$. Here both $e$ and $t r$ are dichotomous reflecting the discrete choices over college and training. Compensation per period in late work for workers in a skilled job is $\omega_{2} H(e, \theta, t r)$ where $\omega_{2}$ is the base wage for late employment.

If a worker is assigned to an unskilled job, then $H(e, \theta, t r) \equiv 1$ regardless of education, ability or training. With this specification, the returns to education and training are dependent on job assignment. In this case, the late worker employed in an unskilled job is paid $\omega_{2}$ each period.

Compensation over the entire late work period is summarized by $Y_{2}^{j}(e, \theta, t r)$ where $j \in\{s, u\}$ denotes if the worker is in a skilled or unskilled job. This is the sum of the wages earned in each period, discounted back to the start of the early employment period. ${ }^{56}$ Here $j$ refers to the type of job in late employment

\footnotetext{
${ }^{54}$ In contrast to Garibaldi, Gomes, and Sopraseuth (2020) model of labor market mismatch, there is no effect from co-workers to the productivity of a given worker.

${ }^{55}$ Alternatively, assume that ability is not directly observed but rather is signaled by a job test of the worker, described below. In this case, it is as if ex ante the worker is paid expected compensation in the event the firm observes an unbiased signal of true ability.

${ }^{56}$ To be clear, $Y_{2}^{s}(e, \theta, t r)=\omega_{2} H(e, \theta, t r) \tilde{R}^{T^{l}} / R^{T^{e}}$ and $Y_{2}^{u}=\omega_{2} \tilde{R}^{T^{l}} / R^{T^{e}}$. Here and below, $\tilde{R}^{x}=\left(1+R+R^{2}+\ldots+\right.$
} 


\begin{tabular}{|c|c|c|c|c|c|c|c|c|c|c|c|c|}
\hline & $\phi$ & $\bar{\varepsilon}$ & $\sigma_{e}$ & $h(1)$ & $\omega_{2}$ & $\sigma_{j}$ & $\zeta(0)$ & $\zeta(1)$ & $\bar{e}^{t}$ & $\delta_{c s s}$ & $\delta_{n s u}$ & $n b p$ \\
\hline & \multicolumn{12}{|c|}{ Baseline } \\
\hline Ger. & 5.725 & 2.386 & 0.182 & 1.248 & 1.002 & 0.059 & 1.027 & 0.940 & 0.231 & 0.046 & 0.619 & na \\
\hline It. & 5.113 & 4.808 & 0.019 & 1.128 & 1.205 & 2.022 & 0.800 & 0.761 & 0.074 & 0.001 & 0.245 & na \\
\hline Jap. & 8.912 & 5.450 & 0.061 & 1.355 & 1.000 & 0.0000 & 0.702 & 1.163 & 0.208 & 1.000 & 0.988 & na \\
\hline US. & 10.556 & 2.426 & 0.002 & 1.134 & 1.002 & 0.049 & 0.969 & 1.352 & 0.059 & 0.836 & 0.032 & na \\
\hline \multirow[t]{2}{*}{ US.(nlsy) } & 10.758 & 2.497 & 0.003 & 1.131 & 1.001 & 0.050 & 0.974 & 1.351 & 0.060 & 0.432 & 0.576 & na \\
\hline & \multicolumn{12}{|c|}{ No Taste Shock } \\
\hline Ger. & 7.028 & na & 0.237 & 1.267 & 1.030 & 0.132 & 1.038 & 0.951 & 0.199 & 0.382 & 0.748 & na \\
\hline It. & 7.924 & na & 0.331 & 1.319 & 1.111 & 2.597 & 0.909 & 0.815 & 0.128 & 0.050 & 0.852 & na \\
\hline Jap. & 15.746 & na & 0.103 & 1.223 & 1.000 & 0.006 & 0.717 & 1.376 & 0.153 & 0.867 & 0.984 & na \\
\hline US. & 8.065 & na & 0.159 & 1.129 & 1.014 & 0.531 & 0.956 & 1.351 & 0.030 & 0.829 & 0.039 & na \\
\hline \multirow[t]{6}{*}{ US. (nlsy) } & 7.624 & na & 0.173 & 1.136 & 1.012 & 0.256 & 0.949 & 1.350 & 0.122 & 0.432 & 0.576 & na \\
\hline & \multicolumn{12}{|c|}{ april 19 alternative logistic reg } \\
\hline & 6.789 & 2.307 & 0.100 & 1.175 & 1.000 & 0.576 & 1.064 & 0.950 & 0.245 & 0.150 & 0.999 & na \\
\hline & 5.181 & 5.403 & 0.000 & 1.228 & 1.156 & 0.461 & 0.828 & 0.755 & 0.121 & 0.008 & 0.365 & na \\
\hline & 9.628 & 5.843 & 0.052 & 1.319 & 1.018 & 0.005 & 0.685 & 1.162 & 0.241 & 0.937 & 0.983 & na \\
\hline & 10.723 & 2.438 & 0.004 & 1.122 & 1.003 & 0.289 & 0.984 & 1.334 & 0.070 & 0.760 & 0.016 & na \\
\hline
\end{tabular}

Table 38: Parameter Estimates: Alternative MisMatch

\begin{tabular}{|c|c|c|c|c|c|c|c|c|c|c|c|c|c|c|c|c|c|c|c|}
\hline & \multicolumn{5}{|c|}{ Education } & \multicolumn{5}{|c|}{ Mincer Reg. } & \multicolumn{4}{|c|}{ Ed $\rightarrow$ Early Job } & \multirow{2}{*}{$\begin{array}{c}\text { Emp. } \\
\text { ue }\end{array}$} & \multirow{2}{*}{$\begin{array}{c}\text { Mismatch } \\
\text { oe }\end{array}$} & \multicolumn{2}{|c|}{ Training } & \multirow[b]{2}{*}{ fit } \\
\hline & ed & un-mat & over-mat & $\alpha_{0}$ & $\alpha_{1}$ & test & ed & late & ed un & ed ov & uu & uo & ou & oo & & & unsk & sk & \\
\hline \multicolumn{20}{|c|}{ Data: Using Numerical Score for Job MisMatch } \\
\hline & 0.366 & 0.092 & 0.061 & -0.883 & 1.274 & 0.149 & 0.237 & 0.173 & -0.001 & -0.034 & 0.541 & 0.000 & 0.000 & 0.250 & 0.110 & 0.065 & 0.386 & 0.643 & na \\
\hline & 0.184 & 0.157 & 0.065 & -1.972 & 1.015 & 0.092 & 0.276 & 0.226 & 0.018 & -0.053 & 0.511 & 0.000 & 0.000 & 0.714 & 0.162 & 0.074 & 0.195 & 0.364 & na \\
\hline & 0.583 & 0.071 & 0.116 & 0.137 & 0.915 & 0.137 & 0.120 & 0.270 & -0.070 & -0.005 & 0.870 & 0.000 & 0.000 & 0.277 & 0.142 & 0.077 & 0.380 & 0.685 & na \\
\hline & 0.447 & 0.065 & 0.040 & -0.465 & 1.437 & 0.159 & 0.243 & 0.179 & 0.099 & -0.022 & 0.528 & 0.000 & 0.000 & 0.545 & 0.091 & 0.078 & 0.436 & 0.682 & na \\
\hline & \multicolumn{19}{|c|}{ Baseline } \\
\hline Ger. & 0.313 & 0.095 & 0.069 & -0.871 & 1.280 & 0.097 & 0.176 & 0.173 & -0.067 & 0.001 & 0.393 & 0.004 & 0.008 & 0.200 & 0.138 & 0.150 & 0.408 & 0.645 & 0.032 \\
\hline It. & 0.150 & 0.141 & 0.040 & -1.940 & 1.024 & 0.118 & 0.120 & 0.167 & -0.039 & -0.047 & 0.549 & 0.000 & 0.000 & 0.303 & 0.171 & 0.161 & 0.267 & 0.284 & 0.135 \\
\hline Jap. & 0.512 & 0.080 & 0.141 & 0.115 & 0.928 & 0.070 & 0.234 & 0.321 & -0.089 & 0.000 & 0.611 & 0.000 & 0.000 & 0.232 & 0.168 & 0.155 & 0.387 & 0.807 & 0.048 \\
\hline US. & 0.379 & 0.079 & 0.057 & -0.460 & 1.437 & 0.074 & 0.275 & 0.192 & -0.034 & -0.021 & 0.495 & 0.000 & 0.000 & 0.329 & 0.140 & 0.155 & 0.438 & 0.666 & 0.042 \\
\hline \multicolumn{20}{|c|}{ Job MM Num } \\
\hline & 0.311 & 0.097 & 0.065 & -0.869 & 1.276 & 0.098 & 0.167 & 0.170 & -0.063 & -0.004 & 0.542 & 0.001 & 0.000 & 0.231 & 0.134 & 0.139 & 0.412 & 0.638 & 0.023 \\
\hline & 0.150 & 0.140 & 0.039 & -1.940 & 1.031 & 0.121 & 0.122 & 0.206 & -0.034 & -0.051 & 0.816 & 0.000 & 0.000 & 0.660 & 0.166 & 0.149 & 0.275 & 0.290 & 0.144 \\
\hline & 0.507 & 0.087 & 0.138 & 0.103 & 0.937 & 0.066 & 0.234 & 0.313 & -0.085 & -0.015 & 0.795 & 0.000 & 0.000 & 0.350 & 0.171 & 0.159 & 0.382 & 0.804 & 0.061 \\
\hline & 0.378 & 0.079 & 0.056 & -0.463 & 1.444 & 0.074 & 0.276 & 0.191 & -0.033 & -0.022 & 0.664 & 0.000 & 0.000 & 0.472 & 0.134 & 0.142 & 0.441 & 0.665 & 0.061 \\
\hline
\end{tabular}

This table reports data and simulated moments for the estimated models with alternative mismatch measures.

Table 39: Moments: Job MisMatch

These income measures as well as the uncertainty over late job assignment can be combined to create a measure of expected income, discounted to the start of early employment, over the late period for a type $(e, \theta)$ worker given by:

$$
\bar{Y}_{2}^{k}(e, \theta, t r)=\delta_{2}^{k}(e, \theta, t r) Y_{2}^{s}(e, \theta, t r)+\left(1-\delta_{2}^{k}(e, \theta, t r)\right) Y_{2}^{u} .
$$

Here the $k \in\{s, u\}$ in $\bar{Y}_{2}^{k}(e, \theta, t r)$ and $\delta_{2}^{k}(e, \theta, \operatorname{tr})$ refers to the early job assignment.

\subsubsection{Early Work}

Workers are hired by firms at the end of period $T^{s}$. At the time a worker is hired, the firm observes each worker's education and ability.

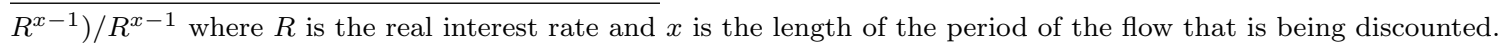




\begin{tabular}{|c|c|c|c|c|c|c|c|c|c|c|c|c|}
\hline & $\phi$ & $\bar{\varepsilon}$ & $\sigma_{e}$ & $h(1)$ & $\omega_{2}$ & $\sigma_{j}$ & $\zeta(0)$ & $\zeta(1)$ & $\bar{e}^{t}$ & $\delta_{c s s}$ & $\delta_{n s u}$ & $n b p$ \\
\hline & \multicolumn{12}{|c|}{ Baseline } \\
\hline Ger. & 5.725 & 2.386 & 0.182 & 1.248 & 1.002 & 0.059 & 1.027 & 0.940 & 0.231 & 0.046 & 0.619 & na \\
\hline It. & 5.113 & 4.808 & 0.019 & 1.128 & 1.205 & 2.022 & 0.800 & 0.761 & $0.0^{7}$ & 0.001 & 15 & na \\
\hline Jap. & 8.912 & 5.450 & 0.061 & 1.355 & 1.000 & 0.0000 & 0.702 & 1.163 & 0.208 & 1.000 & 0.988 & na \\
\hline \multirow[t]{6}{*}{ US. } & 10.556 & 2.426 & 0.002 & 1.134 & 1.002 & 0.049 & 0.969 & 1.352 & 0.059 & 0.836 & 0.032 & na \\
\hline & \multicolumn{12}{|c|}{ Job MM Num } \\
\hline & 6.581 & 2.586 & 0.077 & 1.245 & 1.001 & 0.170 & 1.031 & 0.936 & 0.215 & 0.159 & 0.999 & na \\
\hline & 4.432 & 4.875 & 0.010 & 1.125 & 1.150 & 0.008 & 0.833 & 0.771 & 0.136 & 0.000 & 0.267 & na \\
\hline & 9.829 & 5.976 & 0.016 & 1.341 & 1.005 & 0.004 & 0.680 & 1.180 & 0.201 & 0.994 & 0.978 & na \\
\hline & 10.392 & 2.386 & 0.004 & 1.135 & 1.001 & 0.076 & 0.972 & 1.352 & 0.060 & 0.776 & 0.000 & na \\
\hline
\end{tabular}

Table 40: Parameter Estimates: Job MisMatch

\begin{tabular}{lcc}
\hline country & college & no college \\
\hline Germany. & 0.849 & 0.603 \\
Italy & 1.0 & 0.672 \\
Japan & 0.578 & na \\
US & 0.798 & 0.690
\end{tabular}

Table 41: Inferring Late Flows

Based upon these two pieces of information, the worker is assigned to either a low or a high skill job. ${ }^{57}$ Regardless of the job assignment, as in the late work, the worker is assumed to be paid its marginal product, $H(e, \theta) \omega_{1}$. There is no effect of training on productivity in early work so that $H(e, \theta)=h(e) \theta$ if the worker with education $e$ and ability $\theta$ is in a skilled job. Otherwise $H(0, \theta)=1$ for all $\theta$ so that productivity and the wage for unskilled workers is $\omega_{1}$ regardless of education and ability.

Compensation in early work is summarized by $Y_{1}^{j}(e, \theta)$ where $j \in\{s, u\}$ denotes if the worker is in a skilled or unskilled job. This is the sum of wages per period over the early work period, discounted to the start of early work. Denote the probability of assignment to a skilled job in the early period by $\delta_{1}(e, \theta)$.

\subsubsection{Training}

During the early employment phase, agents have an option to receive training. The cost of training is a fraction of time, $0 \leq \bar{e}^{t} \leq 1$, that must be allocated to the acquisition of skills in place of early work. Further there is a direct payment of $p^{t}$ for formal training.

The benefit of training is the expected gain in human capital in late employment: $H(e, \theta, \operatorname{tr})=h(e) \theta \zeta(e)^{t r}$. Recall that this gain is realized iff the worker obtains a skilled job. Thus there may be uncertainty over the returns to training due to randomness in the job assignment. ${ }^{58}$

Formally, the expected income gain to training for a type $(e, \theta)$ early worker in job of skill $j \in\{s, u\}$ is given by:

\footnotetext{
${ }^{57}$ In our quantitative analysis this is restricted so that assignment in early employment is based only on the education level.

${ }^{58} \mathrm{An}$ alternative formulation would allow for a stochastic element to the training outcome as well, with (or without) randomness in the job assignment. Since agents are effectively risk neutral, this uncertainty is fully captured by $\zeta(e)$. So this should not be interpreted solely as human capital accumulation but rather the compound lottery associated with training. For ease of exposition, throughout we refer to $\zeta(\cdot)$ as parameterizing the human capital accumulation from training. Relatedly, Flinn, Gemici, and Laufer (2017) acknowledge measurement error associated with training and its outcomes.
} 


$$
\begin{aligned}
\Delta^{j}(e, \theta) & \equiv \bar{Y}_{2}^{j}(e, \theta, 1)-\bar{Y}_{2}^{j}(e, \theta, 0) \\
& =\delta_{2}^{j}(e, \theta, 1)\left(Y_{2}^{s}(e, \theta, 1)-Y_{2}^{u}\right)-\delta_{2}^{j}(e, \theta, 0)\left(Y_{2}^{s}(e, \theta, 0)-Y_{2}^{u}\right) .
\end{aligned}
$$

Here the expected income given training, discounted back to the start of the early work period, was taken from (9). From this expression there are two effects of training. The first comes from the dependence of the probability of being in a skilled job on training: $\delta_{2}^{j}(e, \theta, 1) \neq \delta_{2}^{j}(e, \theta, 0)$. The second effect comes from productivity in a skilled job: $Y_{2}^{s}(e, \theta, 1)>Y_{2}^{s}(e, \theta, 0)$. This gain is characterized by $\zeta(e)$.

A type $(e, \theta)$ agent currently in a skilled job will train iff:

$$
\omega_{1} h(e) \theta \bar{e}^{t} \tilde{R}^{T^{e}}+p^{t} \leq \Delta^{s}(e, \theta)
$$

The left side includes the opportunity cost of training, discounted to the start of the early work period, while the right side is the expected gain from training. The condition for training of an agent in an unskilled job is:

$$
\omega_{1} \bar{e}^{t} \tilde{R}^{T^{e}}+p^{t} \leq \Delta^{u}(e, \theta) .
$$

Let $\xi^{j}(e, \theta) \in\{0,1\}$ be the training choice for a type $(e, \theta)$ worker in job type $j$ in early employment. ${ }^{59}$ At the individual level this is a discrete choice with $\xi^{j}(e, \theta)=1$ indicating a choice to train. With the specification $H(e, \theta, t r)=h(e) \theta \zeta(e)^{t r}$, if $\zeta(1)>\zeta(0)$ the training choice will be increasing in both education and ability. In addition, the cost of training is increasing in both ability and education if the agent is assigned a skilled job.

To see these incentive effects more clearly, consider an agent in a skilled job early. Suppose that the agent will remain in the skilled job in the late work period regardless of the training decision. Then (11) can be written as:

$$
\omega_{1} h(e) \theta \bar{e}^{t} \tilde{R}^{T^{e}} \leq \omega_{2} h(e) \theta(\zeta(e)-1)\left(\tilde{R}^{T^{l}} / R^{T^{e}}\right) .
$$

In this case, the non-formal training choice is independent of $h(e) \theta$ since the agents retains a skilled job regardless.

But if the agent is currently in an unskilled job, assuming that the only way to obtain a late skilled job is through training, the condition for non-formal training is:

$$
\omega_{1} \bar{e}^{t} \tilde{R}^{T^{e}} \leq \omega_{2}(\theta h(e) \zeta(e)-1)\left(\tilde{R}^{T^{l}} / R^{T^{e}}\right) .
$$

In this case, the incentives to train are clearly increasing in both ability and education. This will provide a way for undermatched individuals, assigned to unskilled jobs early, to climb up to skilled jobs.

The choice, $\xi^{k}(e, \theta)$ can be used to obtain measures of discounted (to the start of the early work phase) expected income that incorporate the optimal training decision. For late income,

$$
\bar{Y}_{2}^{k}(e, \theta)=\delta_{2}^{k}\left(e, \theta, \xi^{k}(e, \theta)\right) Y_{2}^{s}\left(e, \theta, \xi^{k}(e, \theta)\right)+\left(1-\delta_{2}^{k}\left(e, \theta, \xi^{k}(e, \theta)\right)\right) Y_{2}^{u}
$$

where $k \in\{s, u\}$ denotes the early assignment. From this, and given the randomness in early work assign-

\footnotetext{
${ }^{59}$ The choice is $\{0,1\}$ given observables as there is no training specific choice shock.
} 
ment, unconditional expected late income is given by:

$$
\bar{Y}_{2}(e, \theta)=\delta_{1}(e, \theta) \bar{Y}_{2}^{s}(e, \theta)+\left(1-\delta_{1}(e, \theta)\right) \bar{Y}_{2}^{u}(e, \theta) .
$$

Using the optimal training decision to incorporate training costs, the expected income from early work is given by:

$$
\bar{Y}_{1}(e, \theta)=\delta_{1}(e, \theta)\left[Y_{1}^{s}(e, \theta)-\left[\omega_{1} h(e) \theta \bar{e}^{t} \tilde{R}^{T^{e}}+p^{t}\right] \xi^{s}(e, \theta)\right]+\left(1-\delta_{1}(e, \theta)\right)\left[Y_{1}^{u}-\left[\bar{e}^{t} \omega_{1} \tilde{R}^{T^{e}}+p^{t}\right] \xi^{u}(e, \theta)\right] .
$$

\subsection{College Choice}

Given these labor market flows and the dependence of compensation on ability, education and training, each agent makes an education choice. Here that choice is restricted to no college or college: $e \in\{0, \bar{e}\}$ where $0 \leq \bar{e} \leq 1$ is the fraction of time in school.

There are three direct influences that impact the education choice: ability, taste and borrowing constraints. As ability and education are, by assumption, complements in productivity in skilled jobs, individuals, all else the same, will sort into education based on ability. That is, all agents above a critical ability will choose college.

But there are other factors at play. Agents may differ in their valuation of college, either the experience itself, or the prestige of a degree, etc. This effect is captured by "tastes". In addition, there is an opportunity cost of going to college and tuition must be paid. If agents are unable to borrow against their future income, so that borrowing constraints matter, then the education choice will be impacted.

It is useful to relate the education choice directly to mismatch. In this model, mismatch will arise either from the presence of taste shocks or binding borrowing constraints. In both cases undermatch may occur, high ability individuals may not choose the college option, either because they do not directly value the experience or because of the cost due to limited borrowing possibilities. Further, overmatch can arise from taste shocks that induce a relatively low individual to choose the college path.

Finally, another possibility is that no education mismatch occurs despite its measurement in the data. This would reflect noisy test scores. While individuals sort efficiently based on ability, the test results are noisy enough to produce the levels of mismatch found in the data. As discussed below, this result is not trivial since there is discipline in the estimation on the informativeness of the test score in wage regressions.

Importantly, the assignment of agents to jobs in the early work phase will have an independent impact on the education choice. For example, if either low education agents can be assigned high skilled jobs or high education agents are assigned to low skilled job, then the return to education falls relative to no education. While this impacts the education rate, it does not create education mismatch.

More formally, knowing ability and labor market prospects, an individual at the start of the education phase chooses an education level. ${ }^{60}$ Under the no college option, the individual goes to work immediately and earns $\omega_{1}$ in an unskilled job. As long as $\delta_{1}(0, \theta)>0$ this individual will have an opportunity to work in a skilled job after the education phase and even train in that period.

If the agent chooses college, then a fraction of time, denoted $\bar{e}$, is spent at school. Earnings during the school phase are then $\omega_{1} *(1-\bar{e})$. In addition, there is a direct tuition cost denoted $p$. The gain to

\footnotetext{
${ }^{60} \mathrm{An}$ extension below relaxes the assumption that the individual knows $\theta$.
} 
education, of course, comes in the early and later work phase where high ability agents are compensated for their education as long as they are in skilled jobs.

Let $Y(e, \theta)$ be the discounted value of expected lifetime income for an agent with education $e$ and ability $\theta$ :

$$
Y(e, \theta)=Y_{0}(e)+\frac{\bar{Y}_{1}(e, \theta)+\bar{Y}_{2}(e, \theta)}{R^{T^{s}}}
$$

with both $\bar{Y}_{2}(e, \theta)$ defined in (16) and $\bar{Y}_{1}(e, \theta)$ defined in (17) including the costs and benefits of training for a type $(e, \theta)$ individual. The first term is income, net of tuition, during the education phase:

$$
Y_{0}(e)=\frac{\omega_{0}(1-e)-p e}{\tilde{R}^{T^{s}}}
$$

with $e \in\{0, \bar{e}\} .{ }^{61}$

If capital markets are perfect so that there are no borrowing constraints, agents are able to completely insure themselves over income fluctuations coming from transitions between skilled and unskilled jobs, post education. ${ }^{62}$ Thus their consumption each period is proportional to the sum of the discounted present value of their expected income, $Y(e, \theta)$, as given in (20)

$$
c(e, \theta)=\frac{Y(e, \theta)}{\tilde{R}^{T}} .
$$

If household utility over consumption is given by $u(c)$, then lifetime utility for an agent of ability $\theta$ choosing education $e$ is given by:

$$
V(e, \theta)=u(c(e, \theta)) \tilde{\beta}^{T}+\varepsilon(e)
$$

Here $\varepsilon(e)$ is a "taste shock" associated with each choice of education, $e \in\{0, \bar{e}\} .{ }^{63}$ As specified, the taste shock is directly associated with the education choice. It is possible to include additional taste shocks in the model, say for training and for high skilled jobs. The difficulty though is in distinguishing these taste variations. Thus a more generous interpretation of $\varepsilon(e)$ to include other sources of variation is certainty consistent with the analysis.

\subsection{Efficiency}

The idea that mismatch is inefficient is certainly present in the ongoing policy discussions. This short section describes efficient allocations for our environment. Sub-section 6.1 provides estimates of output loss due to mismatch.

Assuming that risk sharing can be achieved through type specific transfers, the key to efficiency is a mapping from agent type $(\theta, \varepsilon)$ to education, job assignment outcomes and training outcomes. ${ }^{64}$ For this economy, ability influences productivity only for agents who are assigned skilled jobs. Also, assume that the number of skilled (unskilled) jobs is totally elastic rather than predetermined so there are no congestion effects.

\footnotetext{
${ }^{61}$ As above, $\tilde{R}^{x}=\left(1+R+R^{2}+\ldots+R^{x-1}\right) / R^{x}-1$ where $R$ is the real interest rate and $x$ is the length of the period of the flow that is being discounted.

${ }^{62}$ Borrowing constraints during the employment phase are considered in section 5 . Our main interest is in the interaction of education and job mismatch and the incompleteness of markets post-education, while potentially influencing the education rate, is not key.

${ }^{63} \operatorname{In}(21) \tilde{\beta}^{T}=1+\beta+\beta^{2}+\ldots \beta^{T-1}$.

${ }^{64}$ As we shall see, the estimation does not uncover any role for borrowing constraints so that assuming all agents are risk neutral is consistent with the results.
} 
In this case, an efficient outcome has the following characteristics:

1. there exists a function $\theta^{*}(\varepsilon(e))$ such that $e=\bar{e}$ iff $\theta>\theta^{*}(\varepsilon(e))$. The function $\theta^{*}(\varepsilon(e))$ comes from an indifference condition with respect to the education decision given that training and job assignments are efficient, as detailed next. If there are no taste shocks, then there is a single $\theta^{*}$.

2. all agents with $e=\bar{e}$ get skilled jobs. Otherwise, their education is useless.

3. agents with $e=0$ get unskilled jobs for $\theta<\theta^{* *}$ where $H\left(0, \theta^{* *}\right)=1$ and those with $e=0$ get skilled jobs for $\theta \geq \theta^{* *}$.

4. given the training technology, the efficient solution is the same as the individual choice expressed in (11) and (12).

5. all agents who train are assigned skilled jobs. 